LBL-36212

UCF 2010

RAC-1

\title{
The Cascade of Reservoirs of the "Mayak" Plant: Case History and the First Version of a Computer Simulator
}

\author{
M.V. Mironenko, M.Yu. Spasennykh, V.B. Polyakov, S. Ivanitskii, \\ A.V. Garanin, A.G. Volosov, and I.L. Khodakovsky, \\ Vernadsky Institute of Geochemistry and Analytical Chemistry of the \\ Russian Academy of Sciences, Moscow, Russia
}

\begin{abstract}
A.B. Smirnov, G.Yu. Mokrov, Y.G. Glagolenko, and Eu.G. Drozhko Production Association "Mayak," Ministry of Atomic Energy, Chelyabinsk-65, Russia
\end{abstract}

July 1994

Lawrence Berkeley Laboratory

University of California

Berkeley, California 94720

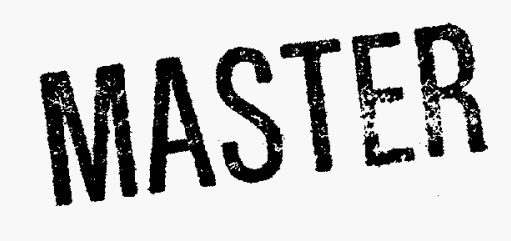

This work was supported by the U.S. Department of Energy, Office of Environmental Management, Office of Technology Development, and the Office of Energy Research, Office of Basic Energy Sciences, under Contract No. DE-AC03-76SF00098. 


\section{DISCLAIMER}

This report was prepared as an account of work sponsored by an agency of the United States Government. Neither the United States Government nor any agency thereof, nor any of their employees, make any warranty, express or implied, or assumes any legal liability or responsibility for the accuracy, completeness, or usefulness of any information, apparatus, product, or process disclosed, or represents that its use would not infringe privately owned rights. Reference herein to any specific commercial product, process, or service by trade name, trademark, manufacturer, or otherwise does not necessarily constitute or imply its endorsement, recommendation, or favoring by the United States Government or any agency thereof. The views and opinions of authors expressed herein do not necessarily state or reflect those of the United States Government or any agency thereof. 


\section{DISCLAIMER}

Portions of this document may be illegible in electronic image products. Images are produced from the best available original document. 


\begin{abstract}
The improvement of the ecological conditions at waste storing reservoirs is an important task of the restoration activity at Production Association (PA) "Mayak" (South Urals). The radionuclides, mostly ${ }^{90} \mathrm{Sr},{ }^{137} \mathrm{Cs}$, and chemical pollutants deposited in the reservoir water and in the bottom sediment are very dangerous sources for the contamination of Techa River below the reservoirs and the contamination of groundwater in the surrounding formations. The spreading of radioactive contaminants has both hydrogeological and the chemical features.

The thermodynamic approach used to account for physical-chemical interactions between water and the bed rocks based on Gibbs free energy minimization of multicomponent system ( $\mathrm{H}-\mathrm{O}-\mathrm{Ca}-\mathrm{Mg}-\mathrm{K}-\mathrm{Na}-\mathrm{S}-\mathrm{Cl}-\mathrm{C}-\mathrm{Sr}$ ) permitted to calculate the corresponding ionic and complex species existing in the solutions, and to characterize the processes of precipitation and dissolution.

The model takes into account the input and output surface and underground water fluxes, mass exchange of the reservoir with the atmosphere, radioactive decay and watersediment interaction including processes of the ${ }^{90} \mathrm{Sr}$ and ${ }^{137} \mathrm{Cs}$ sorption on the grains of the sediment and the radionuclide diffusion in the pore water. This model was used in the retrospective and prognosis calculations of radiation and hydrochemical regime of these reservoirs.
\end{abstract}


Sect ion

Table of Contents

Abstract $\ldots \ldots \ldots \ldots \ldots \ldots \ldots \ldots \ldots \ldots \ldots \ldots \ldots \ldots \ldots \ldots$ iii

Table of Contents $\ldots \ldots \ldots \ldots \ldots \ldots \ldots \ldots \ldots \ldots \ldots \ldots$ iv

List of Figures $\ldots \ldots \ldots \ldots \ldots \ldots \ldots \ldots \ldots \ldots \ldots \ldots \ldots \ldots$

List of Tables $\ldots \ldots \ldots \ldots \ldots \ldots \ldots \ldots \ldots \ldots \ldots \ldots \ldots \ldots \ldots$ vii

1. Introduction

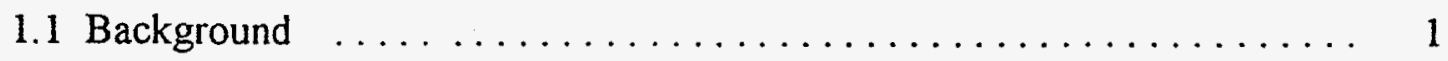

1.2 Scope of work, basic goals, and objectives $\ldots \ldots \ldots \ldots \ldots \ldots$

2. Site description

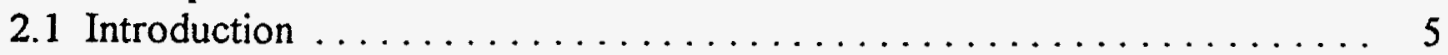

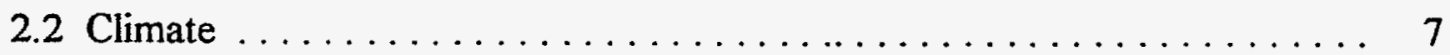

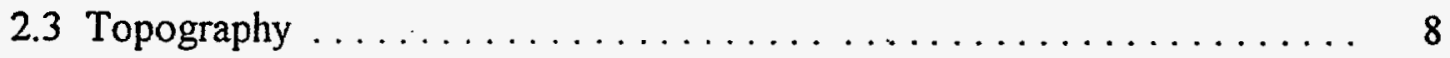

2.4 Geology .......................... 8

3. The history of contamination and building of the reservoirs $\ldots \ldots \ldots \ldots$. 9

4. Background of the field testing and databases

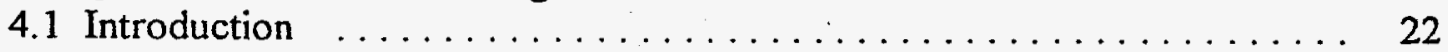

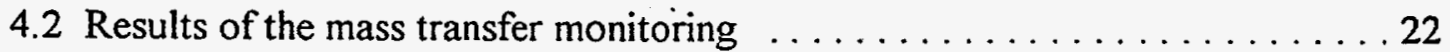

4.3 Chemical composition monitoring of discharges and reservoir waters . . . 25

4.4 Radionuclide contents and mineralogical composition of the sediments ... 26

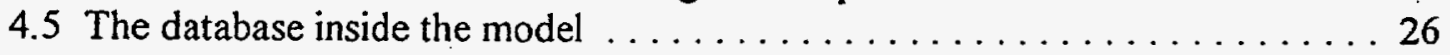

5. The first version of the computer map $\ldots \ldots \ldots \ldots \ldots \ldots \ldots \ldots$

6. Constraints for computer models

6.1 Space and time boundaries . . . . . . . . . . . . . . . . 34

6.2 Processes to be taken into account $\ldots \ldots \ldots \ldots \ldots \ldots \ldots \ldots$

7. The first version of the computer model

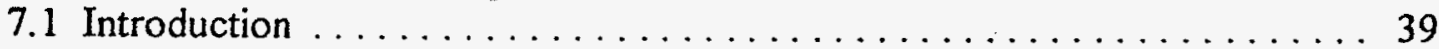

7.2 Mass balance . . . . . . . . . . . . . . . . . . . . . . 39

7.3 Chemical and physical processes taken into account for the first version of the

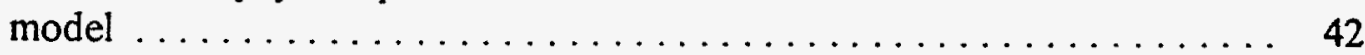

7.3.1 The thermodynamic model of chemical transformations ... . . . . . 42

7.3.2 Vertical diffusion of radionuclides in pore water of the soils, coupling

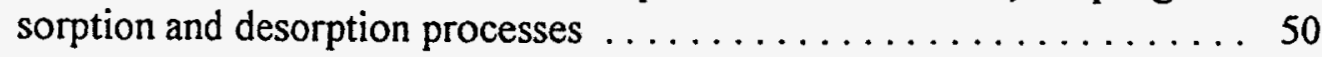

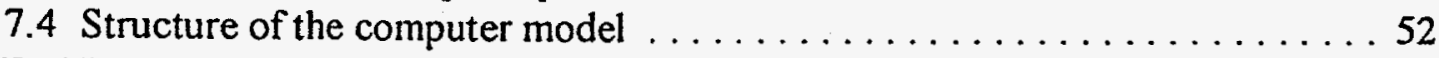

8. Verification of the model and its application to the simulation of the reservoirs cascade

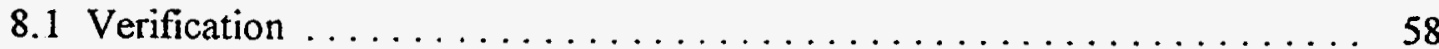

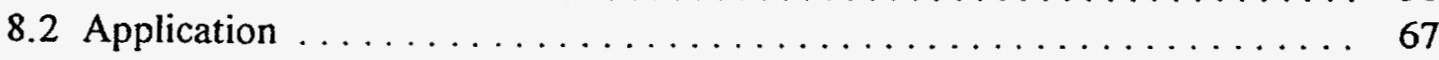


CONTENTS (continued)

Page

9. Conclusions and the directions for further model development and necessary experimental data $\ldots \ldots \ldots \ldots \ldots \ldots \ldots$

Acknowledgments $\ldots \ldots \ldots \ldots \ldots \ldots \ldots \ldots \ldots \ldots \ldots \ldots \ldots \ldots \ldots \ldots$

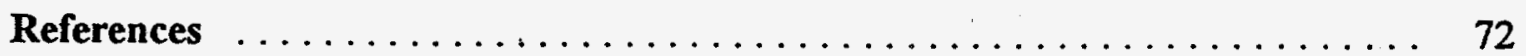

Appendixes

APPENDIX 1 Help for program "Computer map of the reservoir \#11 . . . . . . 76

APPENDIX 2 An example of a record in the input data base $\ldots \ldots \ldots \ldots \ldots 7$

APPENDIX 3 Input data used for prognoses computation of conditions of the reservoirs during $1992-2000$ 


\section{List of Figures}

Figures

$\underline{\text { Page }}$

2.1 The sheme of bodies at the "Mayak" site $\ldots \ldots \ldots \ldots \ldots \ldots$

3.1. Discharge of radioactivity to the Techa River, 1949-1956 . . . . . 11

3.2. The sheme of "Mayak" contaminated reservoirs. . . . . . . . . . . 13

3.3. Mass inflow of $\mathrm{H}_{2} \mathrm{SO}_{4}, \mathrm{CO}_{2}$ content and $\mathrm{pH}$ of reservoir \#10 for the period from 1972 to $1988 . \ldots \ldots \ldots \ldots \ldots \ldots \ldots \ldots \ldots \ldots \ldots \ldots \ldots \ldots$

3.4. Characteristics and radioactivity discharges from reservoir $\# 11$. .... 19

5.1a. The construction of the topographic map of the Reservoir N11 . . . . 31

5.1b. The Development of the Reservoir from 1972 to $1992 \ldots \ldots \ldots \ldots$

5.1c. The development of the Reservoir at $1972 \ldots \ldots \ldots \ldots \ldots \ldots$

5.1d. The development of the Reservoir from 1972 to $1986 \ldots \ldots \ldots \ldots$

5.1e. The development of the Reservoir from 1972 to $1992 \ldots \ldots \ldots \ldots$

5.1f. The selection of the area for scaling. $\ldots \ldots \ldots \ldots \ldots \ldots \ldots \ldots$

5.1g. The scaling of the area. $\ldots \ldots \ldots \ldots \ldots \ldots \ldots \ldots \ldots \ldots$

5.1h. The calculation of the resources of ${ }^{137} \mathrm{Cs}$ in selected area. . . . . . 33

6.1. Distribution of ${ }^{137} \mathrm{Cs}$ between water solutions and the sediments for the reservoirs of the Mayak site $\ldots \ldots \ldots \ldots \ldots \ldots \ldots \ldots \ldots \ldots \ldots \ldots$

6.2. Distribution of ${ }^{90} \mathrm{Sr}$ between water solutions and the sediments for the reservoirs of the Mayak site $\ldots \ldots \ldots \ldots \ldots \ldots \ldots \ldots$

7.1. The principal scheme of processes which should be taken into account for computer simulation. . . . . . . . . . . . . . 40

7.2 The principal block-scheme of user interface $\ldots \ldots \ldots \ldots \ldots$

8.1 Comparison of measured and predicted $\mathrm{pH}$-values of reservoir $\# 10$ as a function of time. $\ldots \ldots \ldots \ldots \ldots \ldots \ldots \ldots \ldots \ldots \ldots \ldots \ldots$

8.2 The calculated ${ }^{90} \mathrm{Sr}$ distribution in the sediments in the inundated region of reservoir \#10 beyond the flood plain

8.3 The calculated ${ }^{137} \mathrm{Cs}$ distribution in the sediments in the inundated region of reservoir $\# 10$ beyond the flood plain $\ldots \ldots \ldots \ldots \ldots$

8.4. Average content of the ${ }^{90} \mathrm{Sr}$ and the ${ }^{137} \mathrm{Cs}$ in the sediments as a function

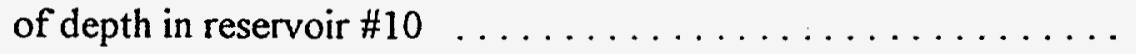

8.5 Concentration of $\mathrm{SO}_{4}{ }^{2-}$ in aqueous phase of the reservoirs \#10 and \#11 as a function of time (results of the computer simulation) 
List of Tables

Tables

Page

3.1 Composition of liquid radioactive wastes discharged to the Techa River, 1949-1952

3.2 Physical characteristics of the reservoirs of the cascade $\ldots \ldots \ldots \ldots 14$

3.3 Chemical and radiochemical compositions of the water of the reservoirs - 15

3.4 Contamination characteristics of the reservoirs, January, $1992 \ldots \ldots . . .20$

3.5 Average annual ${ }^{90} \mathrm{Sr}$ and ${ }^{137} \mathrm{Cs}$ concentration in the Techa River at the Muslyumovo settlement. . . . . . . . . . . . . . . . 21

4.1 Water balance of reservoirs \#10 for the period of 1978-1983 . . . . . 23

4.2 Water balance of reservoirs \#1 1 for the period of 1978-1983 . . . . . . 24

7.1 Minerals and aqueous species taken into account for hydrochemical conditions computation and their Gibbs free energies

7.2 Results of computer modeling equilibrium composition of reservoir \#11

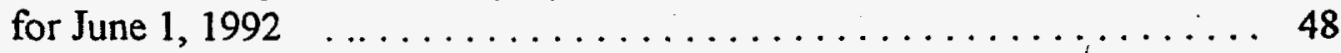

8.1 The distribution ratios, and effective diffusion coefficients $\ldots \ldots \ldots \ldots .61$

8.2 The calculated ${ }^{90} \mathrm{Sr}$ concentration distribution in the sediments of flooded

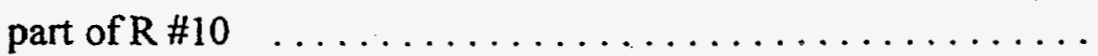

8.3 The calculated Cs-137 concentration distribution in the sediments of flooded part of R 10 


\section{Section 1}

\section{INTRODUCTION}

\subsection{Background}

The problem of radioactive contamination of the biosphere seems to be particularly serious for the countries of the "Nuclear Club", being the most serious for the sizable territories of Russia, Belorussia, Ukraine, and Kazakhstan which resulted from the Kyshtym and the Chernobyl disasters, and nuclear weapon testing, as well as using imperfect technologies for the treatment of the nuclear materials. It should be emphasized that only lately with the termination of "the cold war" and because of the remarkable political changes all around the world it becomes possible to raise a little the "secrecy curtain" which hid many deceptions concerning the dramatic facts of great and uncontrolled radioactive contamination of soils, the surface and underground waters in the areas of activity of nuclear weapon plants (Laverov and Khodakovsky, 1994).

Among the large key-objects and areas of Russia (for which the conditions of radiation safety call up threats for the decisionmakers and the public) two are located in the Chelyabinsk region (South Ural):

- East-Ural radioactive trace resulting from "Kyshtym" (1957) radiation disaster;

- Radiochemical plant and military industry complex for the production of the nuclear weapon components (Chelyabinsk-65) with depositories of the radioactive wastes.

Authorities of the former USSR really did not follow the recommendations of the International Organizations on solving ecological problems of nuclear power production and industry mainly due to political and economical reasons masked by the intensified regime of secrecy. Only during the last two years have significant efforts been made by Russia to develop the State Program of rehabilitation of contaminated territories, and 
localization of radioactive wastes. The programs are aimed at realization of the solutions based on the world experience in the field of radioecology.

The best way for their transfer and assimilation is a broad participation of the scientists and engineers from Russia in the international scientific projects focused on supporting the solution of the complex problems of rehabilitation of the most contaminated regions. At the same time specialists engaged in such projects will have access to the information on radionuclide behavior in environments, which gives a unique opportunity of verification of the models describing the radionuclide distribution in the geosphere, hydrosphere, and biosphere in the case of radioactive waste disposal, and of severe radiation accidents.

The Russian-American Center for Contaminant Transport Studies was establish in spring 1993 at Lawrence Berkeley Laboratory (LBL), Berkeley, California, with the financial support of U.S. Department of Energy (Office of Environmental Restoration and Waste Management - Office of Technology Development and Office of Energy Research Office of Basic Energy Sciences) and in discussions with the Russian Academy of Sciences, Mayak Production Association, Ministry of Atomic Energy of the Russian Federation, and in coordination with Sandia National Laboratory, Pacific Northwest Laboratory, and Argonne National Laboratory.

The objectives of the Center are: (I) to conduct cooperative studies on several case histories at different locations in the Chelyabinsk region in Russia, based on past and ongoing field investigations of contaminant transport; (2) to discuss the modeling approaches, data needs, and experience in interpretation of field testing relevant to environmental evaluation and restoration; (3) to propose and discuss ideas for future cooperation between Russian and American scientists.

The experience and data base concerning radioactive contaminant transport in the Chelyabinsk region in Russia are extensive both in spatial and temporal scales. They 
represent unique information that can be profitably studied jointly by U.S. and Russian researches, with mutual benefits to both countries.

The improvement of the ecological conditions at waste storing reservoirs \#10 and \#11 is an important task of the restoration activity at Production Association (PA) "Mayak". ${ }^{90} \mathrm{Sr},{ }^{137} \mathrm{Cs}$, and chemical pollutants deposited in the reservoir water and in the bottom sediment are very dangerous sources for the contamination of Techa River below the reservoirs and the contamination of groundwater in the surrounding formations. To develop the capability of predicting waste behavior and to assess the effectiveness of remedial actions, it is essential to have a computer simulator to study physical and chemical processes taking place in the cascade of reservoirs. Under PA "Mayak" support, a team of scientists from Vernadsky Institute of Geochemistry and Analytical Chemistry and PA "Mayak", with Igor L. Khodakovsky as the principal investigator, was formed in 1992 to develop the computer simulator "CASCADE" (Mironenko et al., 1992). The first version of the computer model was completed in early 1993. This version still needs improvements to include additional program modules and to use additional field and experimental data.

This report is prepared as a part of the activity of the Russian-American Center for Contaminant Transport Studies, and under DOE/MINATOM US-Russian Joint Coordination Committee on Environmental Restoration and Waste Management. The materials of this report were reported partly by Dr. M.V.Mironenko on the first workshop of the Russian-American Center for Contaminant Transport Studies on July 9, 1993.

The report is divided into nine sections: (1) an introduction covering the background of the problem, goals, and objectives, (2) a short description of the "Chelyabinsk-65 nuclear site, (3) the history of contamination and building of the reservoirs of liquid radioactive wastes, (4) the background of the field testing, (5) the main requirements for the development of a software computer map, and a short description of the first version 
for reservoir \# 11. (6) a discussion regarding what must be modeled in relation to chemical evolution of the reservoirs due to natural and radio-contaminant inflows, (7) the description of the first version of the computer model of the physical and chemical processes, and results of studying the evolution of the main characteristics of low-level waste reservoirs, (8) the results of verification of the model and its application for the prediction of the reservoirs cascade conditions in the future, (9) the directions of further developing of the model and necessary experimental data.

\subsection{Scope of work, basic goals, and objectives}

For finding the economically and politically relevant ways of the remediation of the contaminated territories and radioactive waste disposal, it is very important to prepare the relevant recommendations for the decisionmakers. Obviously, the argumentation for such

recommendations should be supported by numerical estimates with a high level of certainty. These estimates should be obtained by development of an computer system to accumulate information on the main physical and chemical characteristics, radiation sources and contamination of environmental objects. This system should also be able to provide the mathematical modeling of the radionuclide migration in the reservoirs.

The basic goal of the work is generalization and analysis of the information about the main physical and chemical characteristics, and radiation sources of low-level radioactive wastes reservoirs at the "Mayak" site.

Thus, the objectives of this report are to give a brief description of the available information concerning the site, the history of contamination, and analytical data, the critical processes that need to be taken into account, and the structure and the main modules of the developed model, the current status of the development of the computer model, and a list of additional field and experimental data necessary for the further development of the model. 
Section 2

\section{SITE DESCRIPTION}

\subsection{Introduction}

The Production Association (PA) "Mayak" (The Chelyabinsk-65 complex) is located near the small town of Kyshtym, (about $70 \mathrm{~km}$ north-west of the Chelyabinsk city, South Ural) and covers an area on the order of $200 \mathrm{sq}$. km. (Fig. 2.1). In addition to the production plants, Mayak contains a town (Chelyabinsk-65) with a population of 80.000 people. This location was chosen, among other reasons, for its supply of water, because there are many lakes in this territory. It is the first enterprise in the former USSR on plutonium production for military aims and reprocessing of fissible materials.

Construction of the plants began in November 1945 and the first reactor (building A"Annushka") was put into operation in June 19, 1948. The first radiochemical complex (in building 101 of plant \# 25 (B), and in building 9 of plant \# 20) started operating to extract plutonium for military purposes in February 1949 (Polukhin, 1993) and was taken out of operation in 1961. At present, most of the reactors are decommissioned, but heavy water reactors are still operating.

The $\mathbf{4 5}$ years of activity have resulted in local accumulation of large quantities of wastes from radiochemical technology, and radioactive contamination of parts of the territory of Chelyabinsk, Kurgan and Sverdlovsk regions by long-lived radionuclides, mainly ${ }^{90} \mathrm{Sr}$. Radioactive contamination of the Urals region are partly due to liquid radwaste discharge into the small Techa River which belong to the hydrographical basin of the $\mathrm{Ob}^{\prime}$ River in 1949-1956, accidental discharge into the atmosphere resulting from the detonation of a radwaste tank on 29th September 1957, and radioactive substance resuspension from dried-up shores of Lake Karachay in the dry spring of 1967. 


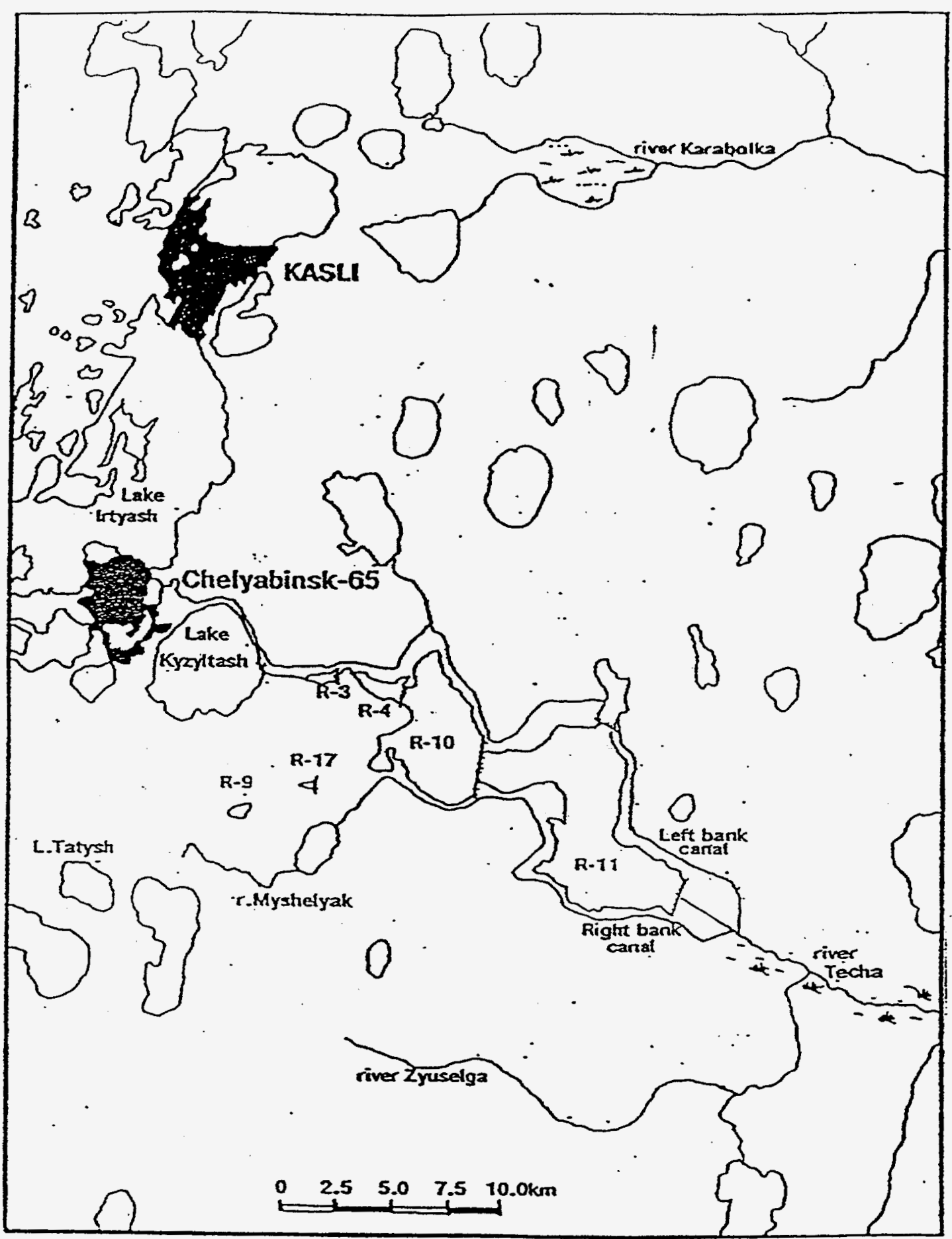

Figure 2.1. The sheme of bodies at the "Mayak" site. (taken from Drozhko, et al., 1993) 
The radioactivity discharged directly to the environment has been distributed by (Chukanov et al., 1991; Bol'shakov et al., 1991; Nazarov et al., 1991). The practical impossibility to fully isolate the radionuclides and to prevent their migration from the surface reservoirs are confirmed by the from the surface reservoirs are confirmed by the formation of contaminated underground water lenses under Lake Karachay, and the filtration of contaminated water from terminal storage-reservoirs of low-level wastes into the below sited Techa River flood plain, too.

\subsection{Climate}

The climate of the region is continental with large daily and annual variations of air temperatures. Winters are long and cold, summers are warm. The cold period of the year is from October to May. The coldest months are January and February with an average temperature of $-13.3^{\circ} \mathrm{C}$ (minimum $-43.3^{\circ} \mathrm{C}$ had been observed in 1956). The warmest month is July, with an average temperature of $19^{\circ} \mathrm{C}$. The average annual precipitation is $450 \mathrm{~mm} /$ year with a maximum rainfall in the summer season $(155 \mathrm{~mm})$.

Analysis of the plots for annual precipitation for a period of 45 years (Avramenko et al., 1993) reveals a pattern in the appearance of high and low-watered years. Low-watered years were: 1951, 1958, 1965-66, 1974-76, 1985; high-watered years: 1955, 1968-71, $1978,1983-84,1987$. The intervals between two neighboring wateriness maximums (or minimums) last 6-13 years, from minimum to maximum - 3-4 years; from maximum to minimum $-4-6$ years.

The driest months are December and January $(16 \mathrm{~mm})$. Snow fall start on the 10th of November in average and melt usually begins at the last decade of March and continues for about 20 days. The snow pack is about $25-30 \mathrm{~cm}$ thick. The prevailing wind direction is from west and south-west. The strongest winds take place in October and November (average $5 \mathrm{~m} / \mathrm{sec}$, maximum $20 \mathrm{~m} / \mathrm{sec}$ ). 


\subsection{Topography}

The site is located on a generally flat terrain which consists of numerous lakes, marshes and flood plains of several rivers. The catchment basin of the system is part of a wide basin of connected lakes, which are located from north to south along mountain ranges. The west side of the catchment basin has mountains with absolute altitudes of 300 $500 \mathrm{~m}$ up to $700 \mathrm{~m}$, and the east side is located on hills piedmont plain (absolute altitudes are 200-300 meters). Topography is dissected with wide depressions occupied by lakes and marshes. Ground water is reported (Petukhov 1991) to be located at a depth of 0.9 to $4.0 \mathrm{~m}$ below the surface (Bradley 1992).

Figure 2.1 shows the flood plain where a cascade of reservoirs has been built for waste storage. The flood plain of the Techa-river in the area of the cascade of reservoirs was not a particulary deep valley prior flooding. Its width was about $400-600 \mathrm{~m}$. The north-east (left) side was low and marched and the south-west (right) side is higher with the bank 2-3 $\mathrm{m}$ above the water level.

\subsection{Geology}

The geological section of the PA "Mayak" area contains mostly Lower-Silurian diabase and andesite porphyrites and tuffs. The west side also has carbonate rocks. All these rocks are covered with quaternary sediments of clay soils mixed with gravel, rock debris and sands. Porphyrites are fractured and weathered, carbonates contain karst caverns and cavities to a depth of about 500 meters, according to geophysical data. The basement rocks are exposed only in the top of the ridges and hills. 


\section{Section 3}

\section{THE HISTORY OF CONTAMINATION AND BUILDING OF THE RESERVOIRS}

For understanding the entrance rate of technogenic contaminants in natural systems and their chemical and radiochemical composition, it is very important to understand the historical and current data on the chemical technology of the Pu production and waste management. As a consequence of a variety of irradiated material compositions reprocessed, as well as changes in reprocessing technology, a variety of radioactive wastes with considerably different chemical and radiochemical compositions have been accumulated at the plant.

The first reprocessing method used at the radiochemical plant for uranium and plutonium purification from fission products and their separation was developed at the Khlopin Radium Institute in St. Petersburg. It was based on dissolution of irradiated aluminum blocks containing $\mathrm{UO}_{2}$ in nitric acid solutions with following precipitation of slightly soluble sodium uranyl acetate, $\mathrm{NaUO}_{2}\left(\mathrm{CH}_{3} \mathrm{COO}\right)_{3}$. Plutonium, in the VI valence state as sodium plutonil acetate, coprecipitates isomorfically with sodium uranyl acetate, or remains in solution if it is reduced to plutonium (IV) or plutonium (III). In the first case, uranium and plutonium purification from fission products was achieved, and in the second case ---their separation from each other.

At the initial period of the radiochemical plants operation (December 1948 to 1951) all radioactive wastes from the radiochemical plant were discharged directly into the Techa River, $6 \mathrm{~km}$ below its source (Proceedings, 1991; Cochran et al. 1993). The acetatenitrate solutions with amorphous aluminum hydroxide made up the bulk of high level radioactive wastes, which had sodium nitrate concentrations exceeding $100 \mathrm{~g} / \mathrm{L}$ and 
sodium acetate concentrations of 60 to $80 \mathrm{~g} / \mathrm{L}$ (Bradley, 1992). The isotopic distribution of the discharged liquid waste is given in Table 3.1 (Kossenko et al. 1990).

Table 3.1

\section{Composition of Liquid Radioactive Wastes}

\section{Discharged to the Techa River, 1949-1952}

\begin{tabular}{lr}
\hline Rare earth elements & $26.8 \%$ \\
${ }^{103} \mathrm{Ru},{ }^{06} \mathrm{Ru}$ & $25.9 \%$ \\
${ }^{95} \mathrm{Zr},+{ }^{95} \mathrm{Nb}$ & $13.6 \%$ \\
${ }^{137} \mathrm{Cs}$ & $12.2 \%$ \\
${ }^{90} \mathrm{Sr}$ & $11.6 \%$ \\
${ }^{89} \mathrm{Sr}$ & $8.8 \%$ \\
\hline
\end{tabular}

About 76 million $\mathrm{m}^{3}$ of wastes containing 2.75 million $\mathrm{Ci}$ of radionuclides were discharged directly into the Techa River. About $95 \%$ of this amount of radionuclides [averring 4300 curies/day (Ci/d)] was discharged from March 1950 to November 1951 (Figure 3.1), and was deposited within the first 35 kilometers downstream. On estimation of Cochran et al. (1993), the total ${ }^{90} \mathrm{Sr}$ and ${ }^{137} \mathrm{Cs}$ discharged through 1951 , about $300,000 \mathrm{Ci}$ each, implies that $100 \mathrm{~kg}$ of plutonium were recovered during that period.

Most part of these radionuclides has been accumulated in the upper reaches of the river; however, the Iset', Tobol, and Ob' Rivers, which successively drain into each other, were also contaminated. The average concentrations of ${ }^{90} \mathrm{Sr}$ and ${ }^{137} \mathrm{Cs}$ in the Techa River on 1951 year at the Muslimovo settlement $78 \mathrm{~km}$ downstream was $40,000 \mathrm{pCi} / \mathrm{L}$ and $510,000 \mathrm{pCi} / \mathrm{L}$ correspondingly.

The concentration of radionuclides in the Iset was about a factor of 10 lower than in the Techa, and about 100 to 1000 times lower in the Tobol (Kossenko et al., 1992). 


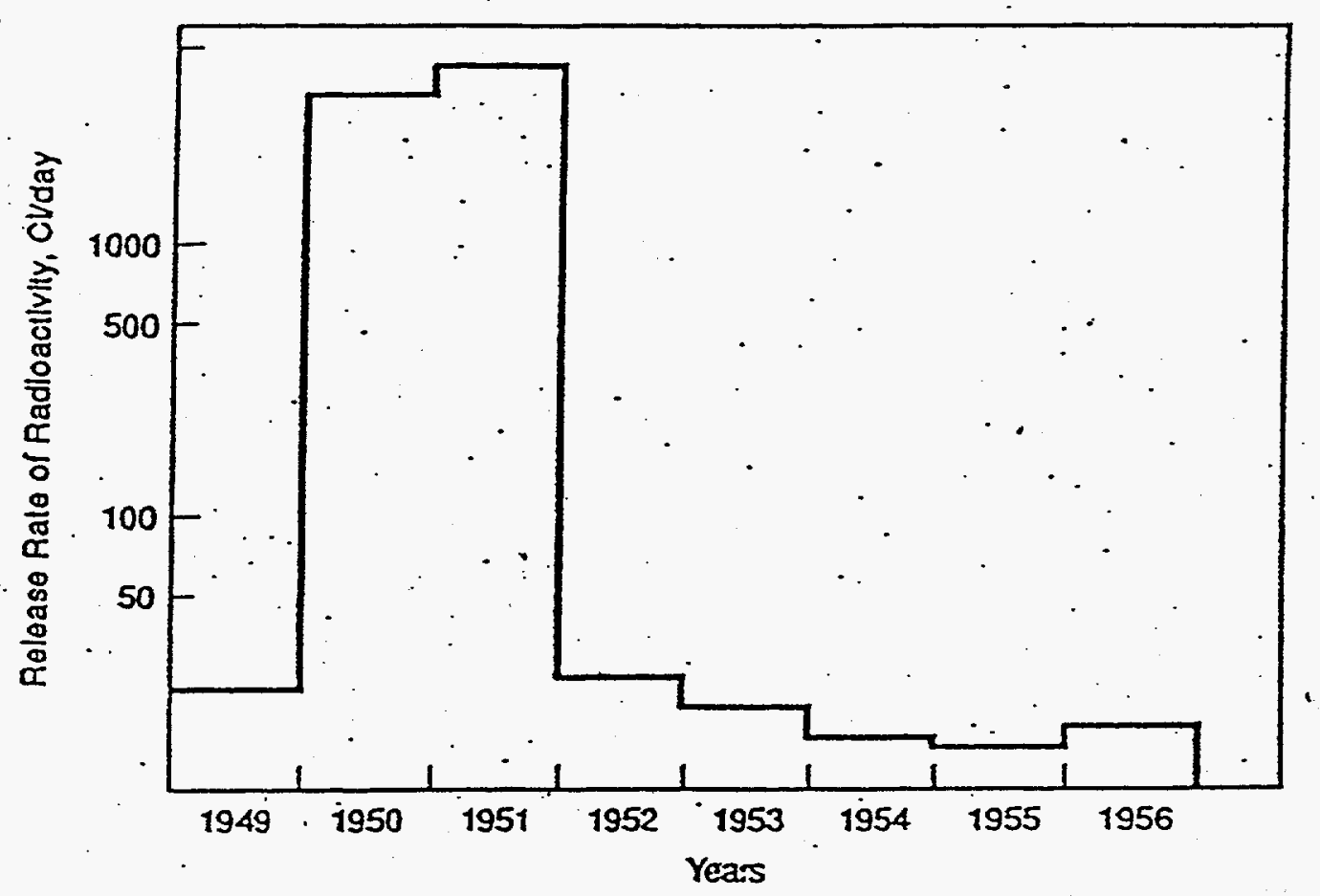

Figure 3.1. Discharge of radioactivity to the Techa River, 1949-1956 (Kossenko et al., 1990, taken from Bradley 1992) 
A radiation survey, taken in the summer of 1951, recognized extensive exposure contamination of the floodplain and bed of the Techa River and excessive exposure to the inhabitants of the region. The greatest exposure was at the village of Metlino, $7 \mathrm{~km}$ downstream from the release point. There, the gamma dose on the river bank was 5 roentgen/hour $(\mathrm{R} / \mathrm{h})$ in spots, and $3.5 \mathrm{R} / \mathrm{h}$ at household patches near the river in the village.

New solutions were adopted since November 1951. The contamination of the Techa River was reduced (to $25-10 \mathrm{Ci} / \mathrm{d}$ ) by using new "precipitation-crystallization sorption" technology, and instead of discharging the radioactive waste into the Techa River, the middel level wastes (MLW) were diverted into Lake Karachay (reservoir \# 9) ---at the time, a natural 45-ha (110-acre), 2-3 m deep lake with no surface outlet (Proceedings, 1991; Avramenko et al., 1993, Cochran et al. 1993).

Also, in order to isolate the most contaminated upper reaches of the Techa River the Techa's cascade of artificial reservoirs was founded by ground dams constructed in the period of 1951 to 1964 (Figure 2.1). This cascade was also used for the current collecting and surface storage of low-level waste (LLW) from the PA "Mayak" reprocessing plant (Drozhko et al., 1993).

The Lake Kyzyltash (Reservoir \# 2) is a natural reservoir, which is used as a heat sink for industrial reactors and the main source of the service water for the radiochemical technology. Plant \# 22, which prepared water for the first reactor, started operating in May 1948 (Polukhin, 1993). The water surface level is $225.4 \mathrm{~m}$. An ion-exchange technology is the main measure for keeping the water quality of the industrial reservoir. An ion-exchange technology is used for the treatment of trap water, too. 


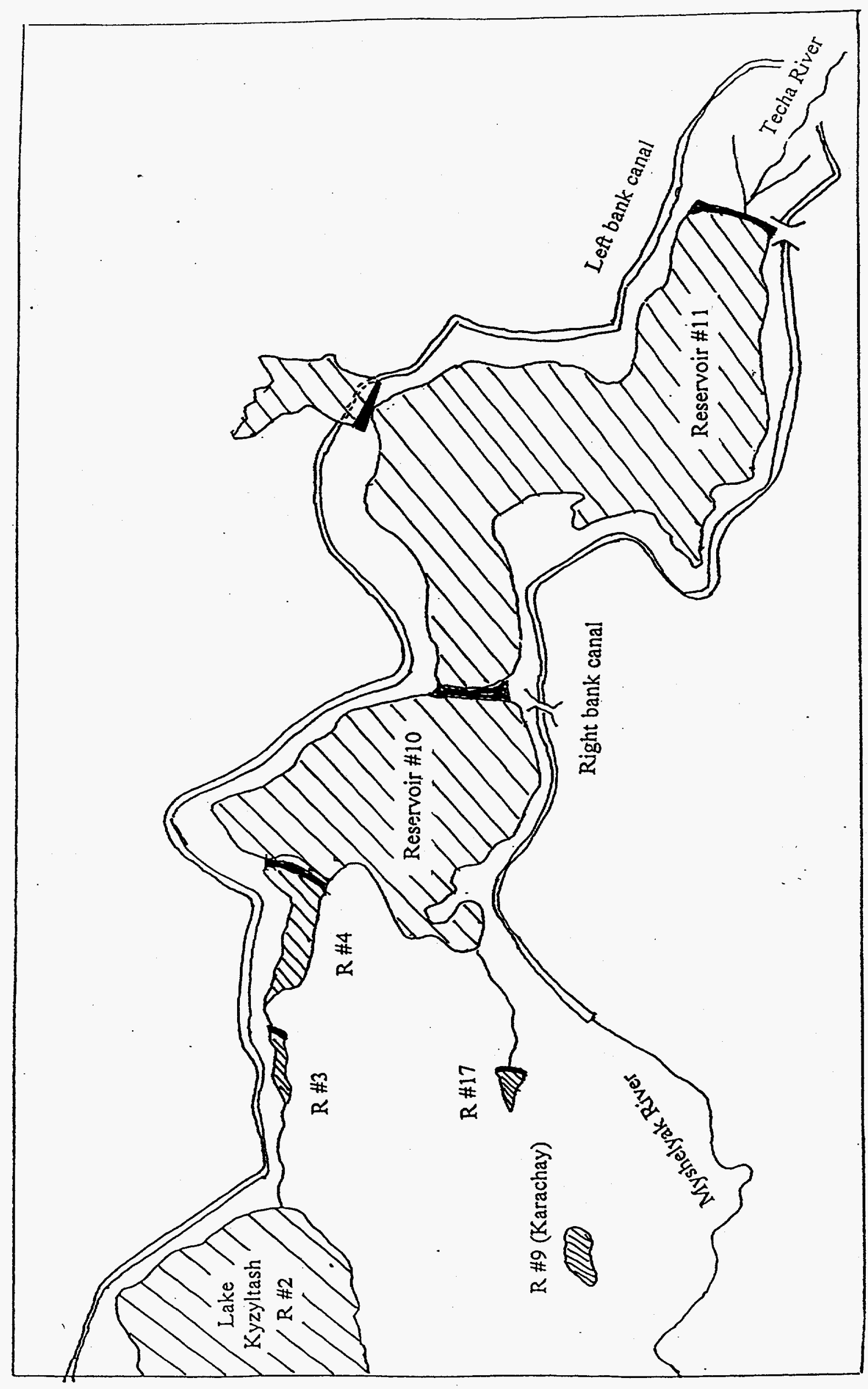


At the period from 1951 to 1954 , more than 100 million $\mathrm{m}^{3}$ water were discharged from Lake Kyzyltash for the dilution of accumulated radionuclides.

As a results of this operation, radioactive contamination was distributed up to the 50 $\mathrm{km}$ downstream. In spring Techa overflows, and the banks of the river with a total area of $80 \mathrm{~km}^{2}$ have also been contaminated.

Table 3.2 Physical Characteristics of the reservoirs of the cascade.

\begin{tabular}{|c|c|c|c|c|c|c|c|c|c|}
\hline \multirow[t]{2}{*}{ Parameter } & \multirow[t]{2}{*}{ Unit } & \multicolumn{8}{|c|}{ Reservoir Number } \\
\hline & & 2 & 3 & 4 & 6 & $9^{*}$ & 10 & 11 & 17 \\
\hline Length & $\mathrm{km}$ & 4.9 & & & & & 6.9 & 11.0 & \\
\hline Maximum Width & $\mathrm{km}$ & 4.9 & & & & & 4.6 & 5.3 & \\
\hline Water Level & $\mathrm{m}$ & 225.42 & 23.05 & 20.2 & & & 219.5 & & \\
\hline Surface Area & sq. $\mathrm{km}$ & 18.6 & 0.78 & 1.6 & 3.6 & 0.25 & 18.6 & 47.5 & 0.17 \\
\hline Volume & $10^{6} \mathrm{~m}^{3}$ & 74.6 & 0.85 & 4.2 & 17.5 & 0.40 & 80.0 & 220.0 & 0.30 \\
\hline Average depth & $\mathrm{m}$ & & & & & & 4.3 & 5.7 & \\
\hline Maximum depth & $\mathrm{m}$ & & & & & & 9.5 & 13.0 & \\
\hline
\end{tabular}

* Reservoir \# 2, often named as Lake Kyzyltash.

** Reservoir \# 9, most often referred to as Lake Karachai. The data listed are for 1991. 
Table 3.3 Chemical and Radiochemical Compositions of the Water of the Reservoirs Species Unit Reservoirs

\begin{tabular}{|c|c|c|c|c|c|c|c|}
\hline & & $\mathrm{R} \# 2$ & $\mathrm{R} \# 2$ & $\mathrm{R} \# 3$ & R.\#4 & $\mathrm{R} \# 10$ & $\mathrm{R} \# 11$ \\
\hline $\mathrm{pH}$ & & - & 9.1 & 8.6 & 2.3 & 4.8 & 8.4 \\
\hline $\mathrm{Ca}^{2+}$ & $\mathrm{mg} / 1$ & 36. & - & 80.2 & 280.6 & 268.5 & 139.4 \\
\hline $\mathrm{Mg}^{2+}$ & $\mathrm{mg} / \mathrm{l}$ & 11 & - & 50.1 & 107. & 96.4 & 65.7 \\
\hline $\mathrm{Na}^{+}$ & $\mathrm{mg} / 1$ & 6. & - & - & - & - & - \\
\hline $\mathrm{Cl}^{-}$ & $m g / l$ & 6. & 75.6 & 96.6 & 125.1 & 120.9 & 70.2 \\
\hline $\mathrm{SO}_{4}^{2-}$ & $\mathrm{mg} / \mathrm{l}$ & 5. & 134 & 281. & 2048 & 1472. & 548. \\
\hline $\mathrm{HCO}_{3}^{-}$ & $\mathrm{mg} / 1$ & 164 & - & - & - & - & - \\
\hline $\mathrm{NO}_{3}^{-}$ & $\mathrm{mg} / \mathrm{l}$ & - & 0.25 & 300. & 3.5 & 0.7 & 0.15 \\
\hline $\mathrm{O}_{2}$ & $\mathrm{mg} / \mathrm{l}$ & - & 12.9 & 16 & 21.2 & 10. & 11.9 \\
\hline $\mathrm{Fe}$ & $\mathrm{mg} / 1$ & - & 0.17 & 0.1 & 4.5 & 0.68 & 0.11 \\
\hline $\operatorname{Sr}($ total $)$ & $\mathrm{mg} / \mathrm{l}$ & - & - & - & 6.5 & 2.4 & - \\
\hline${ }^{90} \mathrm{Sr}$ & $\mathrm{Ci} / \mathrm{l}$ & - & - & $1.22 \cdot 10^{-6}$ & $3.4 \cdot 10^{-7}$ & $6.9 \cdot 10^{-7}$ & - \\
\hline${ }^{137} \mathrm{Cs}$ & $\mathrm{Ci} / 1$ & - & - & $2 \cdot 10^{-7}$ & $6 \cdot 10^{-8}$ & $5.6 \cdot 10^{-9}$ & - \\
\hline${ }^{134} \mathrm{Cs}$ & $\mathrm{Ci} / \mathrm{l}$ & - & - & $1.16 \cdot 10^{-8}$ & $1.5 \cdot 10^{-5} ? ?$ & $8.4 \cdot 10^{-10}$ & - \\
\hline${ }^{3} \mathrm{H}$ & $\mathrm{Ci} / 1$ & - & - & $1.13 \cdot 10^{-6}$ & $1 \cdot 10^{-6}$ & $3.2 \cdot 10^{-7}$ & - \\
\hline${ }^{106} \mathrm{Ru}$ & $\mathrm{Ci} / 1$ & - & - & $1.19 \cdot 10^{-8}$ & $3.5 \cdot 10^{-9}$ & $2 \cdot 10^{-9}$ & \\
\hline${ }^{60} \mathrm{Co}$ & $\mathrm{Ci} / 1$ & - & - & $1.04 \cdot 10^{-7}$ & $2 \cdot 10^{-8}$ & $2.6 \cdot 10^{-9}$ & - \\
\hline${ }^{141} \mathrm{Ce}$ & $\mathrm{Ci} / 1$ & - & - & $3.7 \cdot 10^{-9}$ & - & - & - \\
\hline${ }^{144} \mathrm{Ce}$ & $\mathrm{Ci} / 1$ & - & - & $1.4 \cdot 10^{-8}$ & - & $4 \cdot 10^{-9}$ & - \\
\hline${ }^{125} \mathrm{Sb}$ & $\mathrm{Ci} / 1$ & - & - & - & $2.2 \cdot 10^{-9}$ & $1.6 \cdot 10^{-9}$ & - \\
\hline
\end{tabular}

Source: for chemical composition - Smirnov, 1994 for radiochemical composition - Avramenko et al., 1993 
Reservoir \#3 was created in the valley of the Techa River after dam \#3 was built in 1951. The pulps and highly-mineralized solutions (acid and alkaline) intakes into $R \# 3$ after regeneration of the ion exchangers.

Reservoir \#4 was created on the placement of the former Metlinski pond. Dam \#4 was an existing dam, but was raised in 1956. After waste reprocessory, recovered water containing sulfuric acid and ${ }^{90} \mathrm{Sr}$ and ${ }^{137} \mathrm{Cs}$ was discharged into reservoir \#4.

The dumping consists of $17,200 \mathrm{~m}^{3} /$ day of liquid wastes, sewage flows from industrial sites, and flow from reservoir \#3, passing through the spillway in dam \#3. Its hydrochemical and hydrological conditions also depend on the outflow from reservoir \#3.

The reservoirs R-3 and R-4 have small capacity, which conforms with the annual intake of $L L W$ to the Techa's cascade. Finally, all contaminated water from the reservoirsettlers entries into $\mathrm{R}-10$.

Reservoir \#10 was created in the valley of the Techa River after dam \#10 was built in October 1956. There were no direct discharges from industrial installations into this reservoir, so its hydrochemical and radionuclide regime mainly depended on masses and chemical compositions of the outflows from $\mathrm{R} \# 4$. The basement formations underlying the bottom sediments of $\mathrm{R} \# 10$ are composed of both volcanic and carbonate rocks. The rock type is important for the hydrochemical conditions of the reservoirs, especially with acid discharges into the reservoir. To minimize the contamination of the Techa River due to waste water leaking through dam \#10, a pumping station was built in 1960 . It pumped leaking water back into $\mathrm{R} \# 10$.

Reservoir \#10 has been used for the last 20 years for storage of highly mineralized solutions which were formed after regeneration of the ion-exchangers of the water from $\mathrm{R} \# 2$. These solutions contained the radionuclides and abundant sulphuric acid. 
About 3000 tons of sulphuric acid were drained every year into the reservoir \#10 with industrial wastes during the first 10 years of operation. However, monitoring data during this period show hat reservoir water was alkaline with constant average $\mathrm{pH}$ values of 7.5 and bicarbonate concentration of $1.5 \mathrm{mmol} / \mathrm{l}$ until 1977 .

Formation of sulphuric acid wastes increased by $50 \%$ at the end of the 1970 's. Due to this increase, as shown in Fig.3.3, the pH of the water decreased from 7.5 to 4.5 ; $\mathrm{pH}$ transformation took 4 months (October 1980 to January 1981). It is interesting that water was acid (pH 4.3-5.2) till the end of 1991 (Fig.3.2) even though some steps to reduce the acid drain into reservoir were taken in the period following Jan.1981. Associated with the change of $\mathrm{pH}$ from 7.5 to 4.5 , the ${ }^{90} \mathrm{Sr}$ content in the aqueous phase increased because of the strontium desorption.

In 1991-1992 after decommissioning the production reactors at PA"Mayak", the discharge of sulfuric acid with sewage after water-purification was practically reduced to zero. This predetermined the later increase of water $\mathrm{pH}$ in the $\mathrm{R}-10$ up to ordinary values (7.0-8.0). The dynamic of water $\mathrm{pH}$-factor for $\mathrm{R}-10$ was predicted in the late 1991 by our balance-thermodynamic model (Mironenko et al., 1991).

The reservoir $\# 11$ is the lowest and biggest in the cascade. Because of fast filling of R\#10, dam \#11 was built in 1963. Excess water drains from R \#10 to R \#11 via the canal by passing dam \#10. At present time, the water level in the lowest reservoir \#11 is close to the maximum acceptable (Fig. 3.4). As a result of the high water level, the leakage of radioactive contaminated water increases through the impounding dam which separates the reservoir from the open hydrographic network downstream (Drozhko et al. 1993).

The cascade of the reservoirs is bounded by Right-side and Left-side by-pass canals on the banks. These canals devert flood water around the reservoirs and discharge into Techa River below Dam \#11. 


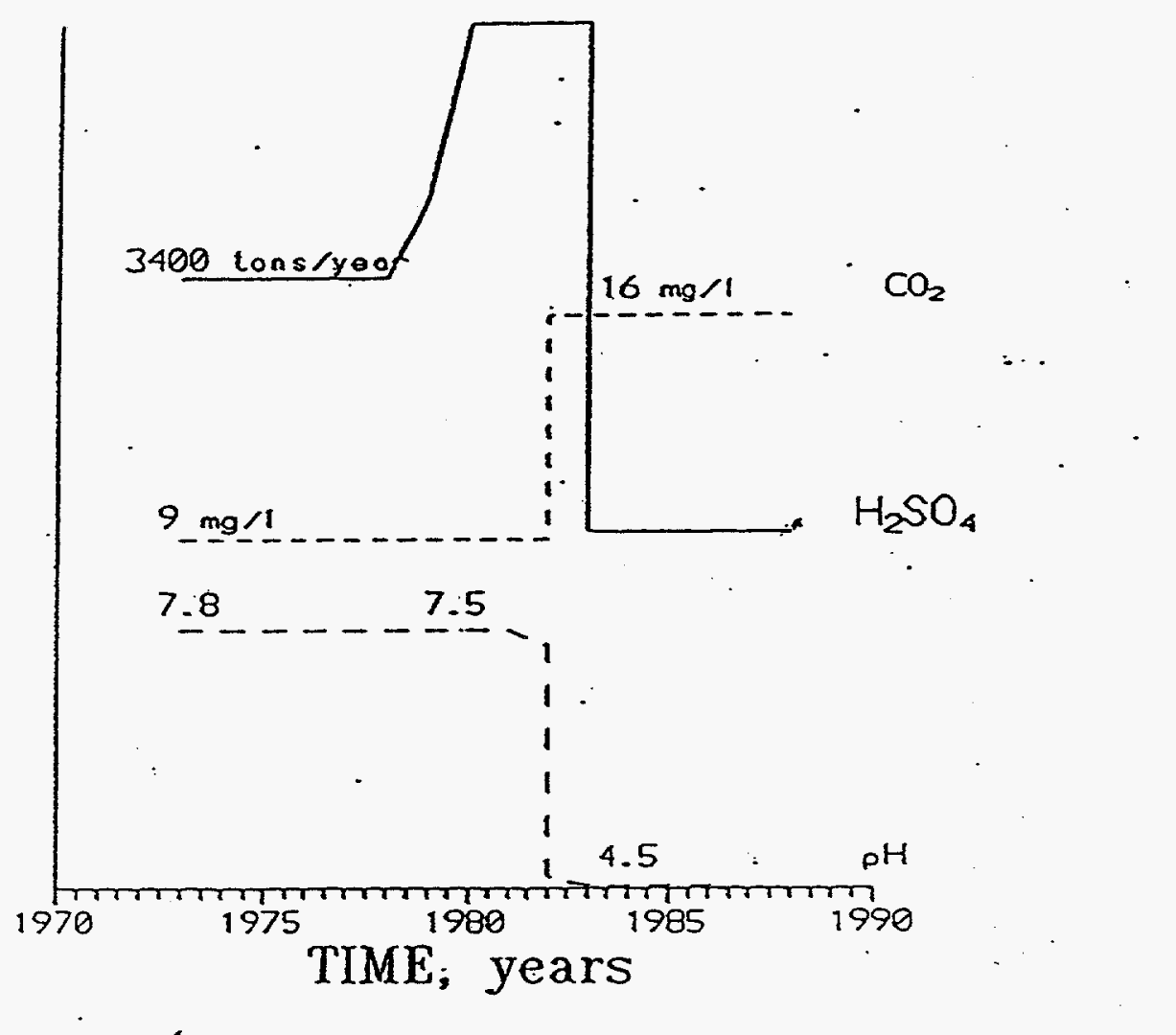

Figure 3.3. Mass inflow of $\mathrm{H}_{2} \mathrm{SO}_{4}, \mathrm{CO}_{2}$ content and $\mathrm{pH}$ of reservoir $\# 10$ for the period from 1972 to 1988. 
Filtrale Acilvily, $\mathrm{Ci} \times 10^{-\mathrm{S}}$ /lite:

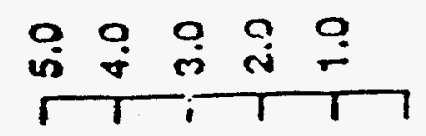

Radioactlvily Discharge, Cl/yr

(80\% overtiow, $20 \%$ liltrate)

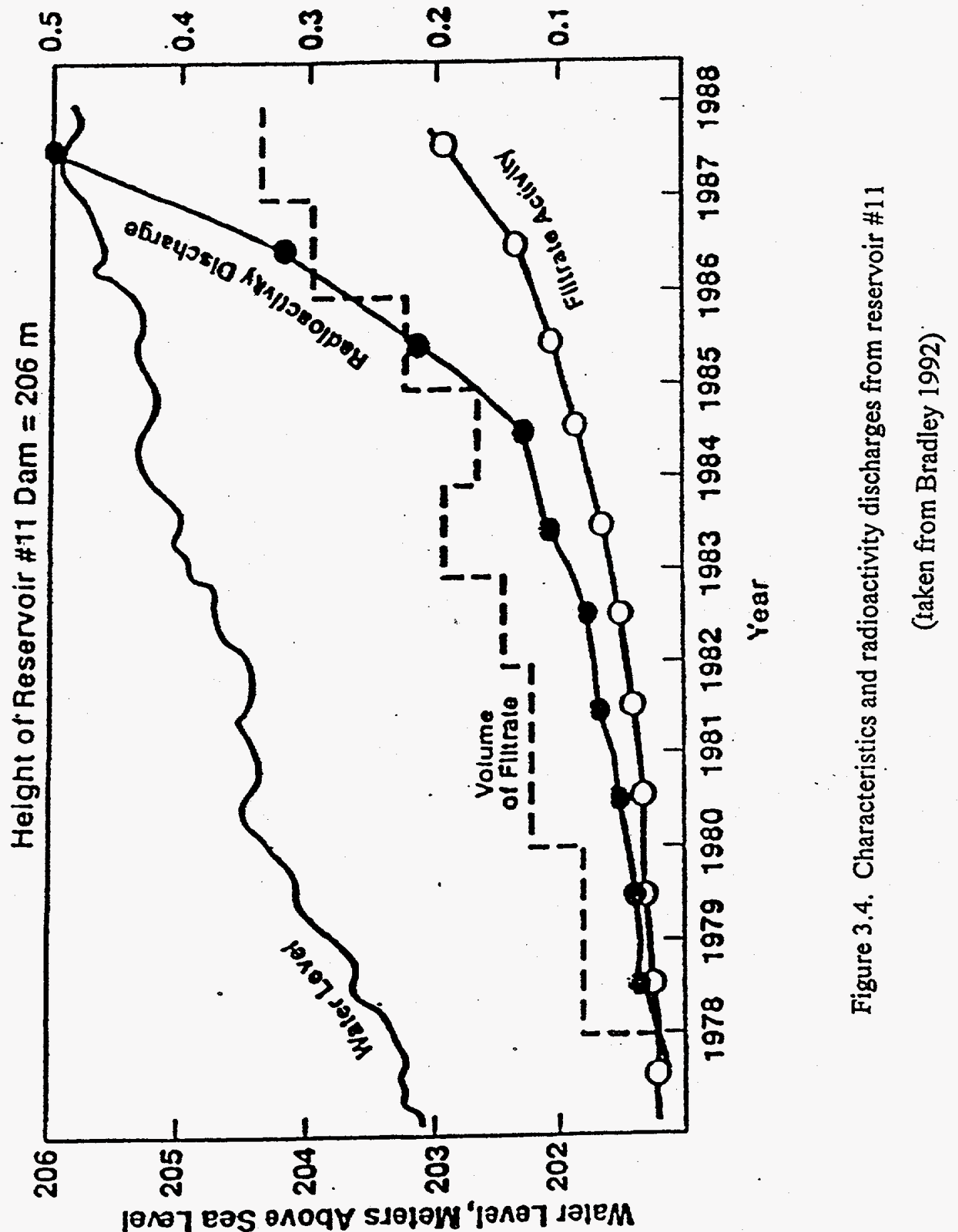

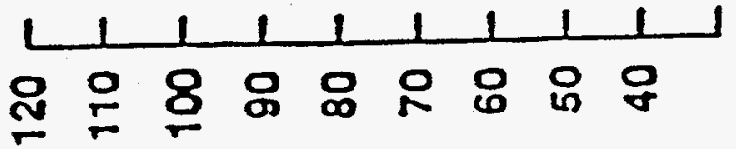

$$
\begin{aligned}
& \left.{ }_{\varepsilon} \text { OL } x_{\varepsilon}{ }^{m}\right) \text { aleding } 10 \text { ounnon }
\end{aligned}
$$


The canal on the north side of the reservoirs was built in 1962, and the canal on the south side was built in 1972. At the present time the volume of impounded radioactive water in the two lowest and largest reservoirs is 80 and 220 million $\mathrm{m}^{3}$, respectively (Table 3.2).

Different parts of the submerged surface of the reservoirs (river channel, flood plain, flooded margins), have various distributions of radionuclides in the bottom sediments, depending on soil compositions and the previous history of contamination of the Techa River.

Table 3.4 Contamination Characteristics of the Reservoirs, January, 1992.

\begin{tabular}{lccccccc}
\hline \multicolumn{8}{c}{ Reservoirs } \\
R\#2 & R\#3 & R.\#4 & R\#6 & R\#9 & R\#10 & R\#11 & R\#17 \\
\hline
\end{tabular}

\section{Concentrations in Solution $(\mathrm{Ci} /)$ :}

${ }^{90} \mathrm{Sr} \quad 1.1 \cdot 10^{-8} \quad 1.2 \cdot 10^{-6} \quad 3.4 \cdot 10^{-7} \quad 3.7 \cdot 10^{-10} \quad 1.7 \cdot 10^{-3} \quad 6.9 \cdot 10^{-7} \quad 5.1 \cdot 10^{-8} \quad 7.0 \cdot 10^{-4}$ $\begin{array}{llllllll}{ }^{137} \mathrm{Cs} \quad 4.5 \cdot 10^{-9} & 2 \cdot 10^{-7} & 6 \cdot 10^{-8} & 2.0 \cdot 10^{-11} & 1.2 \cdot 10^{-2} & 5.6 \cdot 10^{-9} & 2.0 \cdot 10^{-11} & 4.0 \cdot 10^{-6}\end{array}$ Radionuclides concentrations in bottom sediments and soils $(\mathrm{Ci} / \mathrm{kg})$ :
${ }^{90} \mathrm{~S}$
$1.3 \cdot 10^{-6}$
$1.4 \cdot 10^{-4}$
$4.0 \cdot 10^{-6} \quad 3.0 \cdot 10^{-7}$
$0.3 \quad 3.5 \cdot 10^{-6}$
$1.3 \cdot 10^{-6}$
$1.2 \cdot 10^{-1}$
${ }^{137}$ Cs $3.0 \cdot 10^{-}$
$1 \cdot 10^{-3} \quad 6.0 \cdot 10^{-5}$
1.4
$1.5 \cdot 10^{-4}$
$1.3 \cdot 10^{-7} \quad 3.3 \cdot 10^{-2}$

Total Contamination (Ci):

In Solution:
$2.0 \cdot 10^{3}$
$2.6 \cdot 10^{3}$
$1.7 \cdot 10^{3}$
2.0
$8.4 \cdot 10^{6}$
$5.0 \cdot 10^{4}$
$2.4 \cdot 10^{4}$
$4.5 \cdot 10^{4}$

In Bottom:
$1.8 \cdot 10^{4}$
$1.53 \cdot 10^{4}$
$4.2 \cdot 10^{3}$
$3.0 \cdot 10^{2}$
$1.1 \cdot 10^{8} \quad 6.0 \cdot 10^{3}$
$1.5 \cdot 10^{4}$
$2.0 \cdot 10^{6}$

Grand Total:
$2.0 \cdot 10^{4}$
$1.8 \cdot 10^{4}$
$6.0 \cdot 10^{3}$
$3.0 \cdot 10^{2}$
$1.2 \cdot 10^{8}$
$1.1 \cdot 10^{5}$
$3.9 \cdot 10^{4} \quad 2.0 \cdot 10^{6}$ 
At present, 400 million tons of contaminated water with more than 180000 Curie of long-living radionuclides ${ }^{90} \mathrm{Sr}$ and ${ }^{137} \mathrm{Cs}$ are accumulated in the Techa's cascade including the following reservoirs: R-2 (Lake Kyzyltash), R-3, R-4, R-10, and R-11 (Nikipelov et al, 1990; Proceedings, 1991). Most of the discharged ${ }^{137} \mathrm{Cs}$ and approximately $60 \%$ of ${ }^{90} \mathrm{Sr}$ was absorbed by organic matter, clay and mica minerals of the bottom sediments.(Table 3.3).

It was hypothesized that "about 70 percent of the activity dumped in 1950-1951 had migrated into the bottom deposits of the Kohsharov and Metlinsk ponds in the upper reaches of the Techa River, and about 10 percent into bottom deposits of the lower section of the river down to $78 \mathrm{~km}$ from the discharge spot. In subsequent years the radioactively contaminated bottom deposits have become a powerful source of secondary contamination of the river water" (Proceedings, 1991). The average annual concentrations of ${ }^{90} \mathrm{Sr}$ and ${ }^{137} \mathrm{Cs}$ in the Techa River at the Muslimovo settlement $78 \mathrm{~km}$ downstream from the reservoirs is shown in Table 3.5.

Table 3.5 Average annual ${ }^{90} \mathrm{Sr}$ and ${ }^{137} \mathrm{Cs}$ concentration in the Techa River at the Muslyumovo settlement.

\begin{tabular}{lrr}
$\begin{array}{l}\text { Observation } \\
\text { year }\end{array}$ & $\begin{array}{c}{ }^{90} \mathrm{Sr} \text { content } \\
(\mathrm{pCi} / \mathrm{l})\end{array}$ & $\begin{array}{r}{ }^{137} \mathrm{Cs} \text { content } \\
(\mathrm{pCi} / \mathrm{l})\end{array}$ \\
\hline 1951 & 40,000 & 510,000 \\
1962 & 10,000 & 4,000 \\
1964 & 3,0000 & 250 \\
1973 & 2,000 & 40 \\
1978 & 1,500 & 36 \\
1983 & 350 & 24 \\
1988 & 420 & 40 \\
\hline
\end{tabular}


The Asanovskie marshes (or swamps), an area of $30 \mathrm{~km}^{2}$ through which the Techa flows just below the last reservoir \#11, contain some $6000 \mathrm{Ci}$ of ${ }^{90} \mathrm{Sr}$ and ${ }^{137} \mathrm{Cs}$ (Chukanov et al., 1991).

\section{Section 4}

\section{BACKGROUND OF THE FLELD TESTING AND DATABASES}

\subsection{Introduction}

Since the establishment of PA "Mayak" over 45 years ago, a great deal of information concerning the dynamics of the radioactive contamination has been accumulated. Beginning in 1991, a large-scale effort is underway, using computer processing to classify the available data (Mokrov et al. 1993)

The water environment monitoring has been carried out since the first days of the PA "Mayak" operating. For this goal the special hydrochemical laboratory and hydrological office was founded at the plant site.

Each day the main hydrochemical indexes of the reservoir \#2 are measured. The hydrochemical analyses of the other reservoirs are carried out each month. Each quarter the averages of the data are transferred to the Central plant laboratory, where annual reports about the hydrochemical, hydrological and radioecological state of the Techa's cascade are published. Reports older than 20 years are passed to the special archives. It is absolutely clear that the most complete database is containing in the operating logs.

\subsection{Results of the mass transfer monitoring}

The analytical survey of the "Mayak" PA controls the following parameters concerning the cascade of the reservoirs: 
- water tables and volumes of water bodies;

- volumes of wastes and concentrations of radionuclides into reservoirs;

- volumes of flows from one reservoir to another;

- amounts of rainfall and evaporation;

There are estimations of amounts of:

- leakage through dam body from reservoir \#10 to \#11 and

- surface runoff in the reservoirs;

- underground inflows into reservoirs \#10 and \#11;

- underground leakage out of reservoirs \#10 and \#11 in the most permeable parts of the bottom and the bank;

Table 4.1 Water balance of Reservoir \#10 for the period of 1978-1983

\begin{tabular}{|c|c|c|c|c|c|c|}
\hline Year & 1978 & 1979 & 1980 & 1981 & 1982 & 1983 \\
\hline $\begin{array}{l}\text { Discharge into Reservoir } \\
\text { from Reservoir } \# 4,10^{6} \mathrm{~m}^{3}\end{array}$ & 7,2 & 8,1 & 9,5 & 8,7 & 7,9 & 7,3 \\
\hline $\begin{array}{l}\text { Average Water } \\
\text { level, } \mathrm{m}\end{array}$ & 209,28 & 209,45 & 209,19 & 209,20 & 209,24 & 209,29 \\
\hline $\begin{array}{l}\text { Surface of } \\
\text { Reservoirs, } \mathrm{km}^{2}\end{array}$ & 18,55 & 18,9 & 18,85 & 18,4 & 18,5 & 18,55 \\
\hline Volume, $10^{6} \mathrm{~m}^{3}$ & 81,2 & 76,6 & 77,0 & 76,1 & 78,4 & 77,6 \\
\hline $\begin{array}{l}\text { Change of the } \\
\text { Volume, } 10^{6} \mathrm{~m}^{3}\end{array}$ & $+5,2$ & $-4,6$ & $+0,4$ & $-0,9$ & $+2,3$ & $-0,8$ \\
\hline $\begin{array}{l}\text { Atmospheric } \\
\text { Precipitations, mm }\end{array}$ & 515,7 & 484,4 & 447 & 403,5 & 447,6 & 565,1 \\
\hline $\begin{array}{l}\text { Volume of Atmospheric } \\
\text { precipitations, } 10^{6} \mathrm{~m}^{3}\end{array}$ & 9,6 & 9,15 & 8,2 & 7,4 & 8,3 & 10,5 \\
\hline
\end{tabular}




\begin{tabular}{lllllll}
\hline Watershed Area, $\mathrm{km}^{2}$ & 15,1 & 14,7 & 15,1 & 15,1 & 15,1 & 15,0 \\
\hline $\begin{array}{l}\text { Annual Discharge, } \\
\mathrm{L} \cdot \mathrm{sec}^{-1} \cdot \mathrm{km}^{2}\end{array}$ & 0,96 & 2,31 & 2,45 & 2,7 & 0,72 & 1,97 \\
\hline Annual Runoff, $10^{6} \mathrm{~m}^{3}$ & 0,46 & 1,07 & 1,17 & 1,29 & 0,84 & 0,98
\end{tabular}

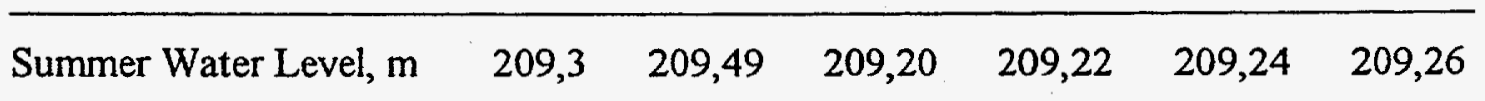

Square of Annual

Evaporation, $\mathrm{km}^{2}$

$18,6 \quad 19,0 \quad 18,4 \quad 18,4 \quad 18,5 \quad 18,5$

\begin{tabular}{lrrrrrr}
\hline Annual Evaporation, mm & 541,0 & 557,9 & 487,6 & 541,7 & 394,2 & 399,6 \\
\hline $\begin{array}{l}\text { Volume of Annual } \\
\text { Evaporation, } 10^{6} \mathrm{~m}^{3}\end{array}$ & 10,06 & 10,6 & 8,05 & 10,0 & 7,3 & 7,4 \\
\hline $\begin{array}{l}\text { Ground Water } \\
\text { Recharge/Discharge, } 10^{6} \mathrm{~m}^{3}\end{array}$ & $-2,0$ & $-12,3$ & $-10,4$ & $-8,3$ & $-6,9$ & $-12,1$ \\
\hline
\end{tabular}

Table 4.2 Water balance of Reservoir \#11 for the period of 1978-1983

\begin{tabular}{lllllll}
\hline Year & 1978 & 1979 & 1980 & 1981 & 1982 & 1983
\end{tabular}

Discharge into Reservoir

from Reservoir \#10, $10^{6} \mathrm{~m}^{3} \quad 2,0 \quad 12,3 \quad 10,4 \quad 7,8 \quad 6,9 \quad 12,5$

Average water

level, $\mathrm{m}$

$203,19 \quad 203,49 \quad 203,95 \quad 204,33 \quad 204,38 \quad 204,57$

Surface of

Reservoirs, $\mathrm{km}^{2}$

$\begin{array}{llllll}33,8 & 34,8 & 36,4 & 37,6 & 37,8 & 38,4\end{array}$

Volume, $10^{6} \mathrm{~m}^{3}$

to End of Year

$\begin{array}{llllll}124,0 & 137,5 & 154,5 & 161,5 & 163,5 & 176,5\end{array}$

Change of the

Volume, $10^{6} \mathrm{~m}^{3}$

$7,5 \quad 13,5$

17

7

2

13 
Atmospheric

Precipitations, mm

515

$15,7 \quad 434,4 \quad 447,0 \quad 408,0 \quad 447,6 \quad 565,1$

Volume of Atmospheric

Precipitations, $10^{6} \mathrm{~m}^{3}$

$\begin{array}{llllll}17,4 & 16,8 & 16,3 & 15,2 & 16,9 & 21,7\end{array}$

\begin{tabular}{lllllll}
\hline Watershed Area, $\mathrm{km}^{2}$ & 23,6 & 24,5 & 22,9 & 21,8 & 21,6 & 21,1
\end{tabular}

Annual Discharge,

$\mathrm{L} \cdot \mathrm{sec}^{-1} \cdot \mathrm{km}^{2}$

$0,96 \quad 2,81 \quad 2,45$

$2,7 \quad 0,72$

1,97

\begin{tabular}{lllllll}
\hline Annual Runoff, $10^{6} \mathrm{~m}$ & 0,78 & 1,78 & 1,77 & 1,86 & 0,49 & 1,31
\end{tabular}

\begin{tabular}{lllllll}
\hline Summer Water Level, m & 203,2 & 203,5 & 204,1 & 204,4 & 204,4 & 204,6
\end{tabular}

Square of Annual

Evaporation,. $\mathrm{km}^{2}$

$33,8 \quad 35,0 \quad 36,8$

37,8

$37,9 \quad 36,5$

\begin{tabular}{lllllll}
\hline Annual Evaporation,. $\mathrm{mm}$ & 541,0 & 557,9 & 437,6 & 541,7 & 394,2 & 399,6
\end{tabular}

Volume of Annual

Evaporation, $10^{6} \mathrm{~m}^{3}$

$18,8 \quad 19,5$

16.1

20,5

14,9

15,4

Ground Water

Recharge/Discharge, $10^{6} \mathrm{~m}^{3}$

5,6

1,6

4,6

2,1

$-7,4$

$-7,1$

Recently some hydrogeological wells were drilled around reservoirs \#10 and 11 to determine the water exchange among reservoirs and the aquifer. The data of these wells are being processed.

\subsection{Chemical composition monitoring of discharges and reservoir waters}

The analytical survey of the PA "Mayak" covers the following parameters concerning the cascade of the reservoirs:

- radionuclides: ${ }^{90} \mathrm{Sr}$ and ${ }^{137} \mathrm{Cs}$ content; 
- $\mathrm{pH}$, alkalinity, $\mathrm{CO}_{2}$ (not dissociated), $\mathrm{H}_{4} \mathrm{SiO}_{4}(\mathrm{aq})$;

- anions: $\mathrm{SO}_{4}{ }^{2-}, \mathrm{Cl}^{-}, \mathrm{NO}_{3}{ }^{-}, \mathrm{PO}_{4}{ }^{3-}$;

- cations: $\mathrm{Ca}^{2+}, \mathrm{Mg}^{2+}, \mathrm{Fe}$ (total), $\mathrm{Cr}$ (total) $, \mathrm{NH}_{4}{ }^{+}, \mathrm{Sr}^{2+}$

The content of sodium and potassium is not measured analytically, but their total contents are calculated on the base of the anions and other cations concentrations and $\mathrm{pH}$.

Recently more complete analytical determinations were made by chemists of the Laboratory of Radiochemistry of Vernadsky Institute (Novikov et al., 1992).

\subsection{Radionuclide Contents and Mineralogical Composition of the Bottom Sediments:}

In 1992 detailed sampling of bottom sediments was carried out to obtain the distribution of the radionuclides with depth of the sediments in different parts of the reservoir bottom surfaces.(A.I.Smagin, 1994).

The mineralogists of Institute of Mineralogy of Ural Branch of Russian Academy of Sciences (Miass) carried out detailed mineralogical investigations of the bottom sediments. They investigated processes of dissolution of primary minerals, deposition of new minerals, and the distributions of the radionuclides among different minerals and within individual grains. The organic matter content is also investigated.

\subsection{The database inside the "CASCADE" model}

For input and output data for the simulator "CASCADE", a special data base, have been developed. All information necessary for the computation is written as dated records. For a given date, two records are required for the simulations. The main record contains information about volummetric input and output flow rates, the current volumes of reservoirs \#10 and \#11, and the chemical composition of the flows and the reservoirs. It contains data of the current mineralogical compositions in the bottom sediments, too. Due 
to the absence of official information on the bottom sediments, rough estimates were made for these data, especially for radionuclide distributions in the former channel, flood plain and flooded part of the reservoirs as a function of depth. Appendix 1 contains input and output parameters. The second record contains detailed information concerning current ${ }^{137} \mathrm{Cs}$ and ${ }^{90} \mathrm{Sr}$ distributions in the bottom sediments, separately for the former channel, the flood plain and the flooded part of the reservoirs as a function of depth. It should be emphasized that the data are preliminary and were used as input data to our model only because they were evaluated on the background of some of analytical data.

Each record is valid until the next dated record, which usually updates changes in flows. After updating the record, all computed information concerning conditions of the reservoirs and the bottom sediments become current information of the second date.

During the computation, the model creates a new database where computed changes in the controlled conditions of the reservoirs are being written. After the computation it is possible to inspect the results both in tables and figures. 


\section{Section 5}

\section{THE FIRST VERSION OF THE COMPUTER MAP}

For generalization and efficient and flexible analysis of the ecological situation in the investigated region, it is necessary to prepare of computer maps on different scales. These maps should be associated with computer databases of the ecological description of the natural and man-made objects, which are continuously updated. It is important to have the software for computer analysis of the radionuclide distribution of the studied area. In the near future these computer maps may become official documents, using for decisions of the people social issues and taking decisions on the remediation of the territories which suffered from radiation contamination and the other ecological disasters.

The functions of the cartographic base are as follows:

- organize observed data and derived quantities for database operation.

- optimization of the retrieval of the data stored in the database by making reference to an object or the coordinate system.

- computer decision of a special geochemical tasks is universally recognized in the prospecting geochemistry : the exposure and outline of the areas of the anomalous concentration elements, the determination of the mass transport, etc.

- search and analysis of the factors regulating of contamination processes by combining maps of different contents with the results of objects studies, plotted on maps.

- visualization of the results of the system analysis for prognosis and decision making purposes.

- combination of the particular modeling results to obtain the total system behavior. 
- visualization of results from model predictions to study operational decision and designing appropriate measures.

The realization of a cartographic database can help creating specific computer maps for the objects under investigations. The geographic coordinate system gives the possibility to consolidate the object maps into a unified system. It is necessary that the program environment, in which the digital maps, are created submit following requirements:

- the software environment and equipment are to be compatible and accessible for all participant of the ecological projects.

- an integrated system of interconnected databases of diferent types and the numerical models of the systems under investigation has to be created.

- integrated software environment and system communications are to be subdivided into blocks for solving particular problems.

- integrated systems of the primary information have to be created.

The current status of the project is contain to the solution of a particular task: the creation of the cartographic base of reservoir \#11 connected with our model.

It is necessary to develop the software which gives the possibility to represent the model solution on a topographic map of the corresponding object. This part of the project consists of developing software to set up the cartographic database and to model time and space depent processes on the basis of the information contained in the database, and received through the interface from the computer models.

The first version of the software to create computer maps, and an example for reservoir \#11 were developed on an IBM PC (see Appendix 1 also).

The software, developed consists of two functional blocks. 
1. The preparation block, input cartographic information - realization of the database.

2. The graphic modeling of the objects to be studied, the simulation of the evolution of these objects in time, and the calculation of the resources.

In the first block the cartographic information is entered by means of a digitizer. The maps of arbitrary size are divided in fragments to adjust to their size of the working field of the digitizer. Then the input of the fragments is made. After that the program runs, which reassembles the fragments and makes the consolidated computer map of the object and stores it to the cartographic database. In this way we have realized the hardwareindependent input of the cartographic information.

The input information for the 2nd functional block is the cartographic database and the information obtained by solving the physical-chemical problems. The following functions are realized in this block:

- a topographic map is created by contouring the land surface on certain elevations (Fig. 5.1a.);

- volumetric model is illustrated by grading the contours with different intensities on a given color, for reservoir \#11, various intensities of blue are used (Fig. 5.1b 5.1e);

- a rectangular area of the map is selected using the mouse for enlargement. The proportions of the figure are retained (Fig. $5.1 \mathrm{f}-5.1 \mathrm{~g}$ );

- the square of the reservoir surface is calculate (in this case the area of the reservoir N11 can be calculated for.any time period);

- the value of the resources of the substance in the outlined area can be calculated by taking into account different contour intervals (Fig.5.1h.). 


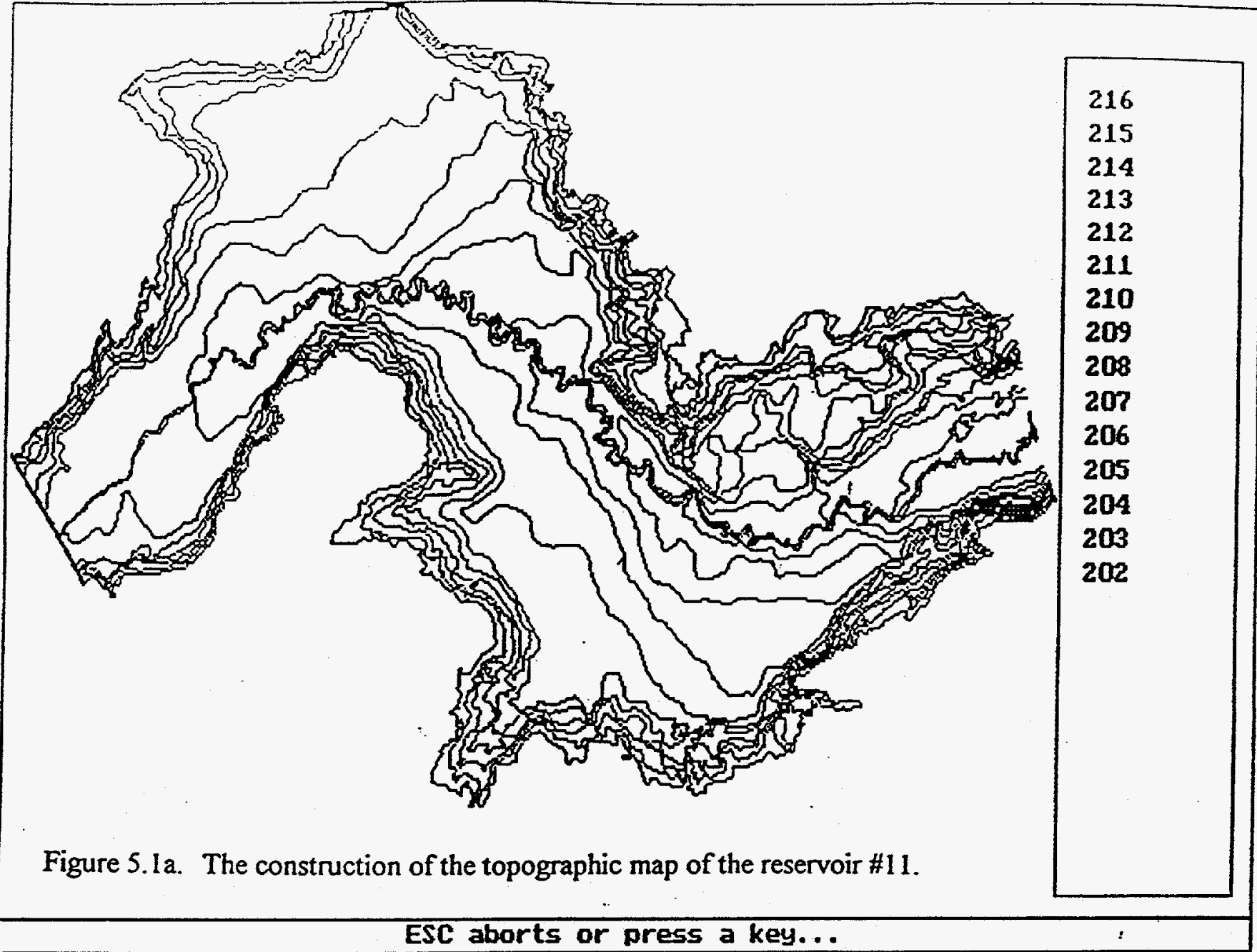

\section{DEUELOPMENT of the RESERUOIR N11}

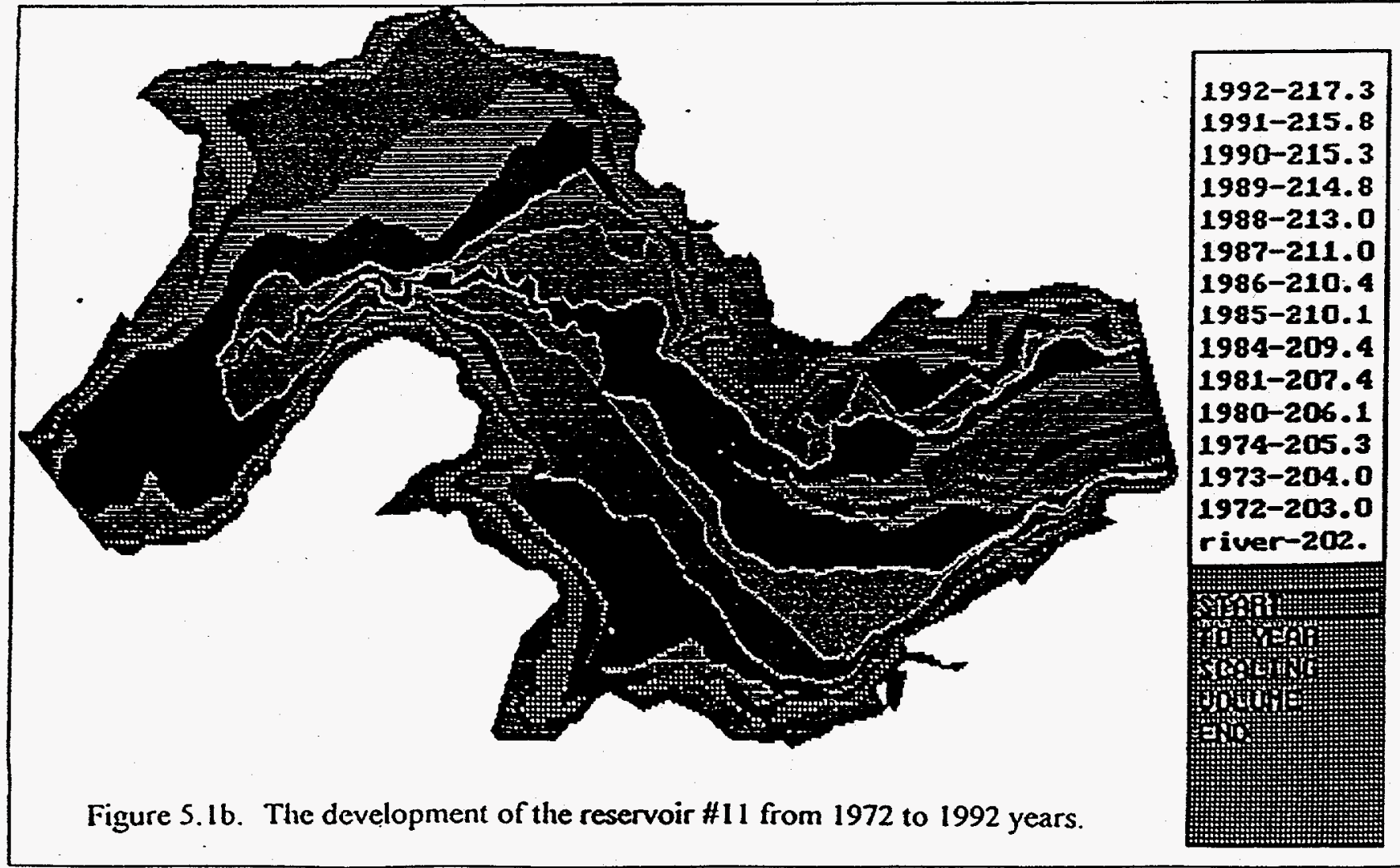



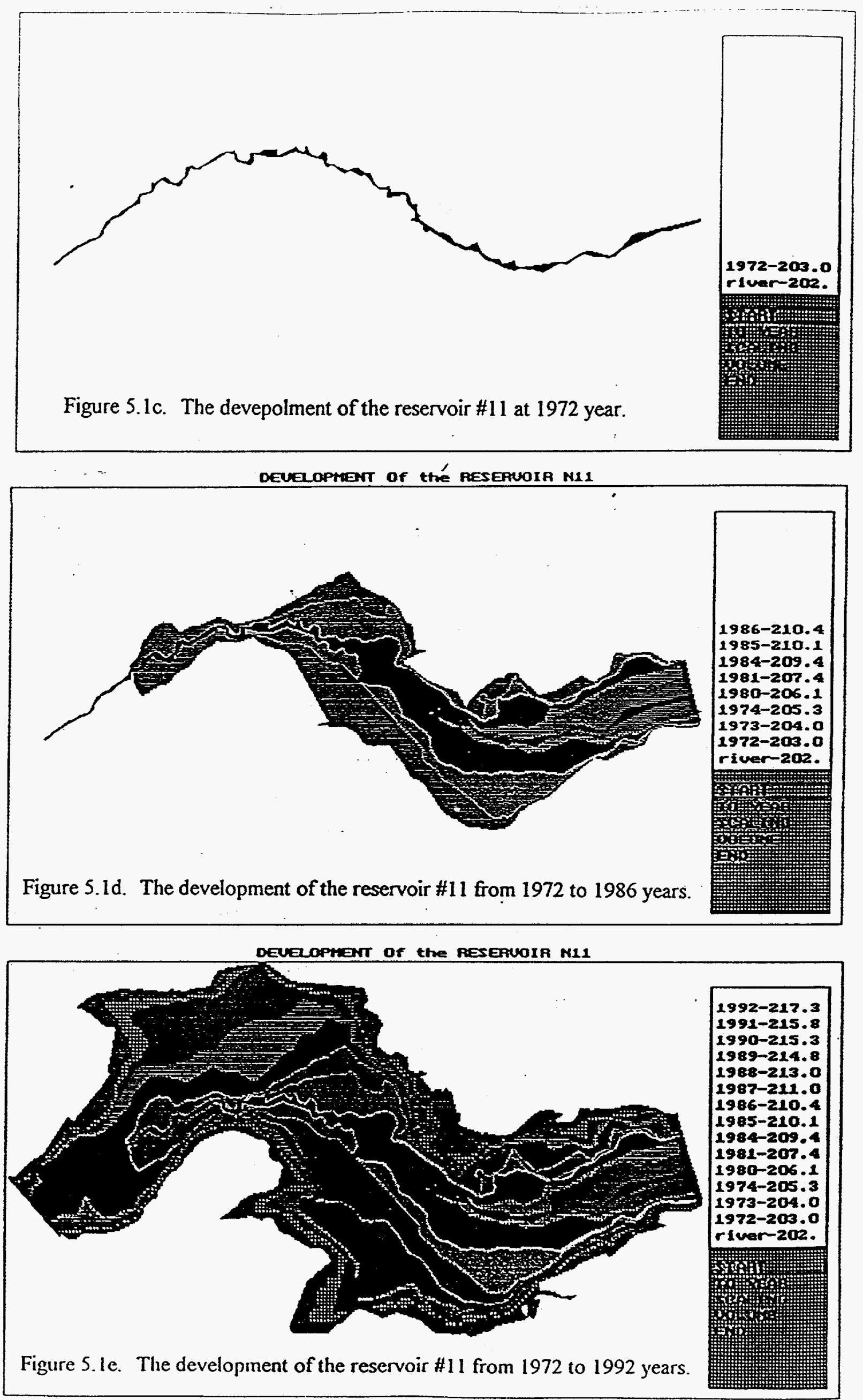

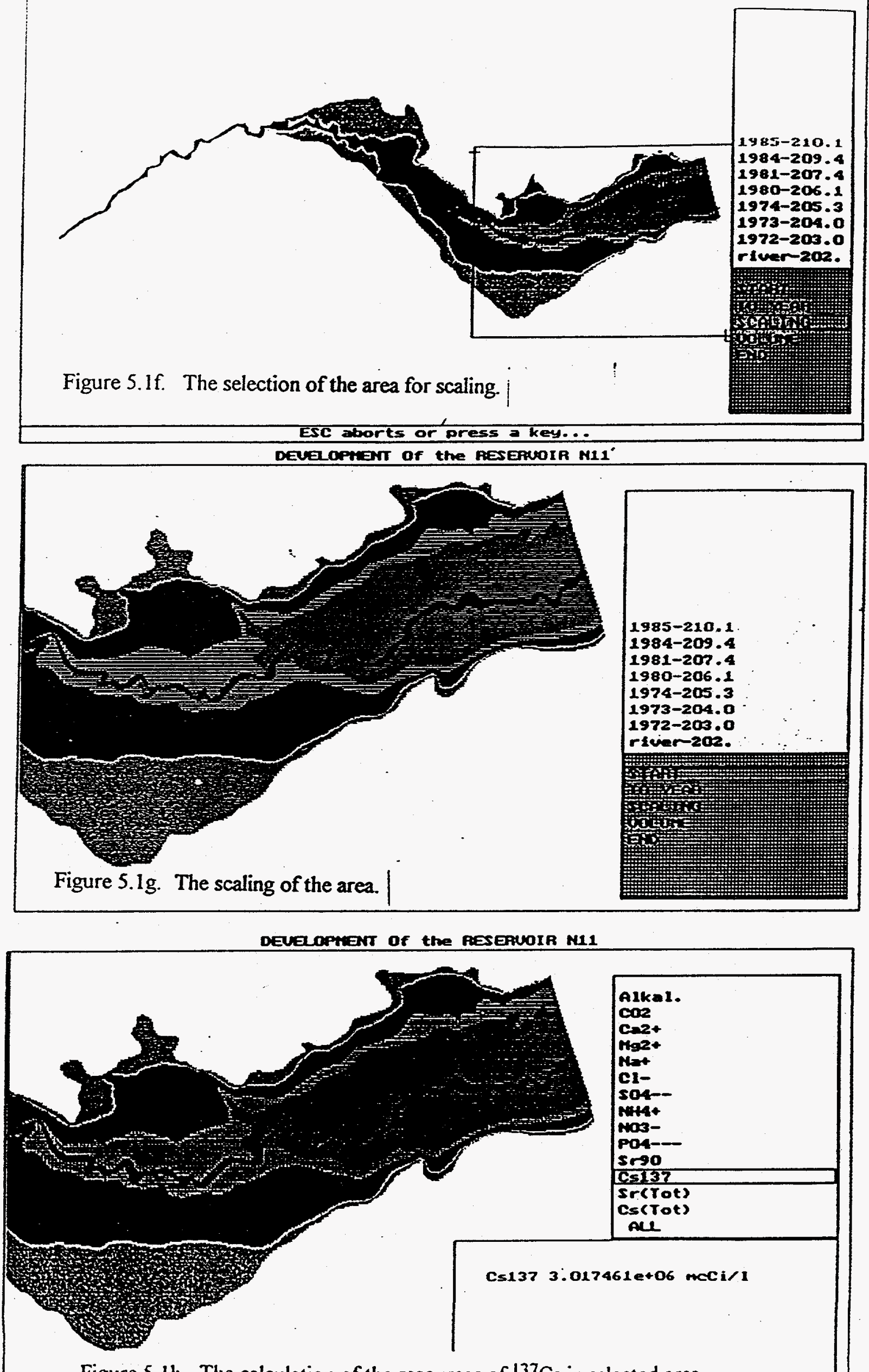

Figure 5.1h. The calculation of the resources of ${ }^{137} \mathrm{Cs}$ in selected area. 
Section 6

\section{CONSTRAINTS FOR COMPUTER MODELS}

\subsection{Space and time boundaries.}

Initially, the spatial boundary for the domain of interest should include the space occupied by water bodies of the reservoirs \#10 and \#11 and in addition about 200 meters around and about 40 meters under the bottom of the reservoirs. If the results of field testing or simulations indicate wider spreading of wastes through ground waters outside the boundary, more area should be taken into account.

For the time scale, the model is designed to give long term prediction of a waster water behavior either in natural conditions or for cases of different possible restoration activities to the middle of the twenty-first century. For restoration studies, it is convenient to choose a recent date for the starting date of the simulation. More complete information is available for recent dates. On the other hand, it would be useful to match the history of contamination in details and simulate waster water behavior from 1949 until present time. The calculated results can be compared with real conditions of the reservoirs at the present time. The aim of this comparison is to verify the validity of the model and to evaluate the effective parameters of different processes for further simulations.

\subsection{Processes to be taken into account}

The development of a possibility to model actinides and fission products behavior in environmental media is important both as fundamental and applied problem.

It was shown, using the approach developed by Nikolsky (Nikolsky et al, 1990), that mixing processes of water in the reservoirs \#10 and \#11 are fast, so aqueous solutions of the reservoirs are considered to be homogeneous. 
"Reservoir" is considered here (in terms of chemical termodynamics) as a chemical system, consisting of an aqueous phase, solid sediments, and the atmosphere. The chemical components in these systems are distributed between these three phases determined by the laws of chemical equilibrium. The changes in the chemical composition of a given system due to flows and the environmental changes or changes of temperature or pressure perturb the equilibrium and induce chemical reactions so that the system reaches a new chemical equilibrium state.

Pressure was taken to be equal to $1 \mathrm{bar}$, temperature was taken to be equal to $25^{\circ} \mathrm{C}$ $(298.15 \mathrm{~K})$ in summer and $4^{\circ} \mathrm{C}(277.15 \mathrm{~K})$ in winter.

In summer, when the surface of the reservoirs is not covered with ice, the aqueous phase components contact with the atmosphere which has a fixed partial pressure for the gaseous components. The most important component for our system is carbon dioxide, because it influences the $\mathrm{pH}$-conditions of the solutions. Carbon dioxide may be formed or may be consumed in the system due to chemical interactions between the aqueous phase and the carbonates in the basement rocks, biological functions of microorganisms, or due to the decomposition of organic matter in the sediments. As the first approximation, we assumed, that in summer (April to October) the content of dissolved free $\mathrm{CO}_{2}$ in the water of the reservoirs corresponds to the content in equilibrium with the atmosphere. The system is open with respect to carbon dioxide. If carbonic acid is produced in the system, the excess of $\mathrm{CO}_{2}$ goes into the atmosphere, and, conversely if $\mathrm{CO}_{2}$ is consumed (for example, by carbonate formation), it is "consumed" from the atmosphere. In winter the system was assumed to be closed.

The specific feature of radionuclides is their inability to form their own solid phases due to low concentrations. Their mobilization or fixation is governed by processes of sorption /desorption on minerals in soils and bottom sediments, by coprecipitation 
together with newly forming minerals, and complex formation with macro components of natural and technogenic waters mainly.

Recently a significant amount of papers concerning equilibrium and kinetics of heavy metal and radionuclide sorption on clay, oxide, hydroxide, and carbonate minerals from aqueous solutions were published (Proceedings, 1989, Zachara et al., 1991, Comans R.N. et al., 1991 etc.). Some of these papers reported models of sorption and coprecipitation and values of equilibrium constants. Others contain reliable experimental results, which could be used for evaluating thermodynamic data (Comans R.N. et al., 1991). Approaches to evaluation of thermodynamic data on sorption using experimental absorption isotherms are known. They are based on the possibility to correctly estimate the chemical potentials of components in the aqueous solution using the theory of electrolyte solutions, and applying one of the most sophisticated models of sorption (Sposito G., 1989).

In fact, as it is seen in Figures 6.1 and 6.2, the processes of sorption and desorption of radionuclides in the bottom sediments, and on suspended solids in water and biota, is a main factor which controlls the distribution of ${ }^{90} \mathrm{Sr}$ and ${ }^{137} \mathrm{Cs}$ between water and soil sediments in the reservoirs.

Thus, as a result of the physical and chemical analysis of the reservoir processes, we suppose that the current hydrochemical and radionuclide conditions of the reservoirs are mainly determined by:

- mass balance of the reservoirs (balance between input and output flows);

- radioactive decays;

- chemical reactions, taking place in the aqueous phase;

- processes of precipitation and dissolution of solids in the bottom sediments; 


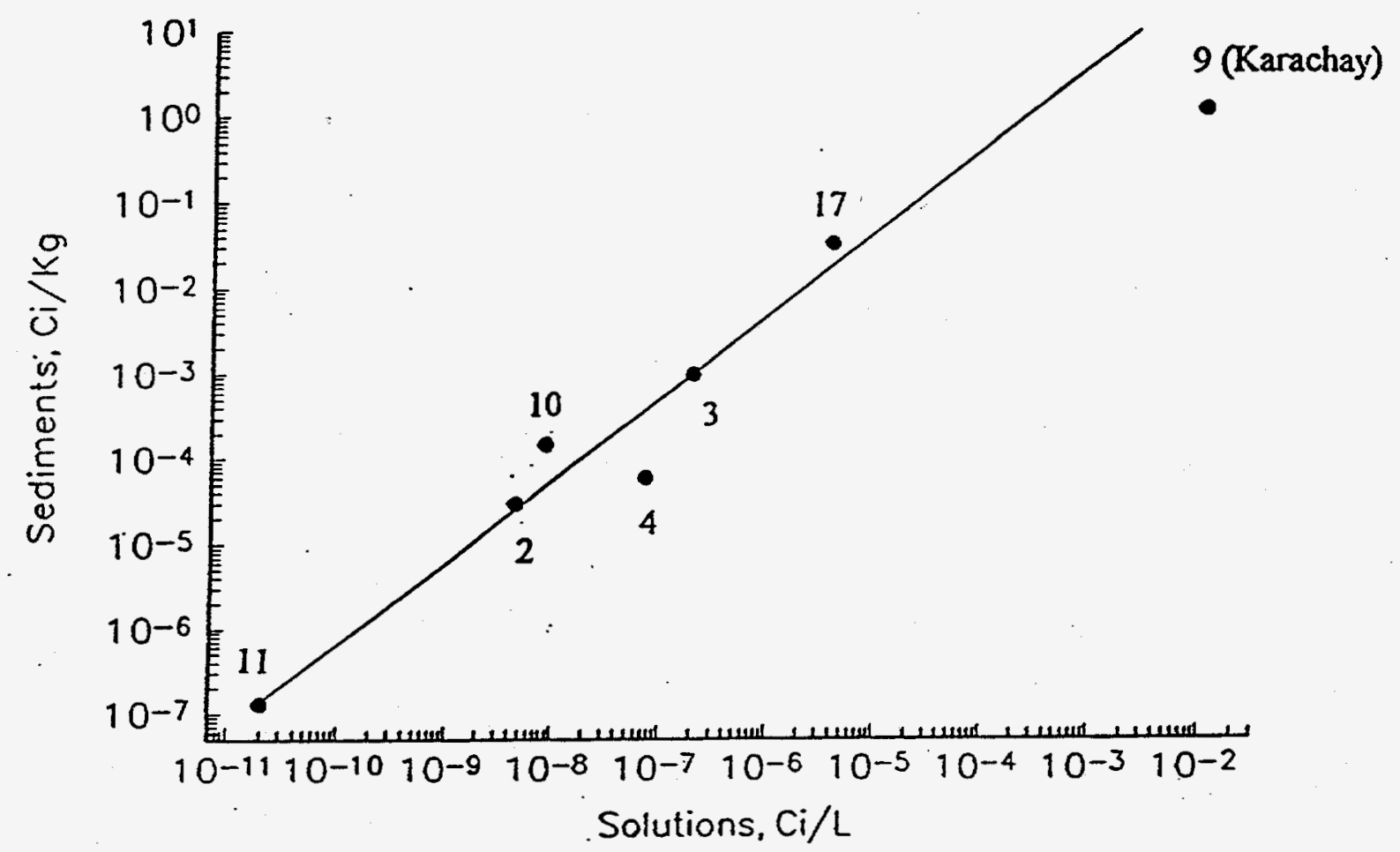

Figure 6.1. Distribution of ${ }^{137} \mathrm{Cs}$ between water solutions and the sediments for the reservoirs of the Mayak site. 


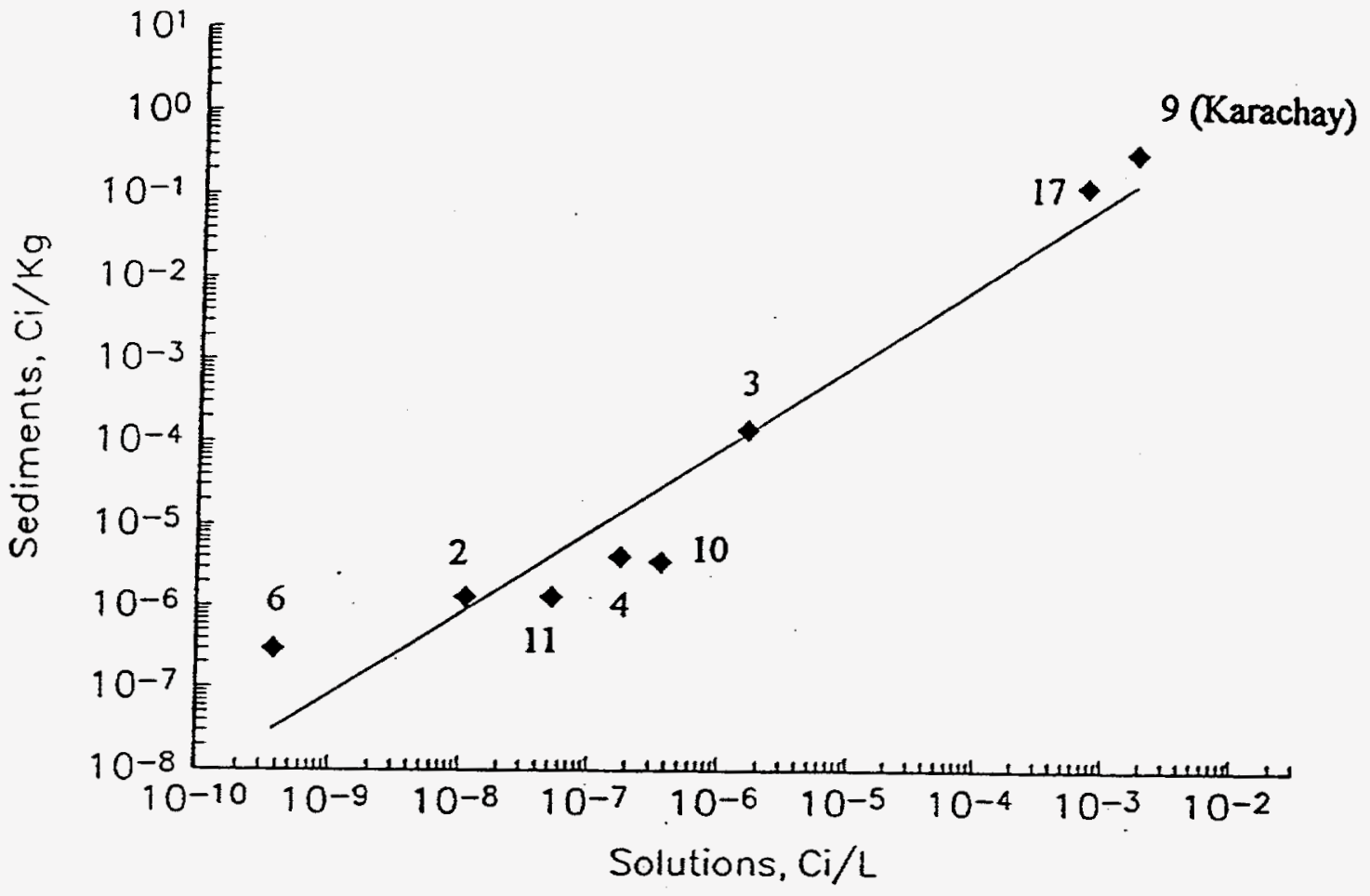

Figure 6.2. Distribution of ${ }^{90} \mathrm{Sr}$ between water solutions and the sediments for the reservoirs of the Mayak site. 
- processes of sorption and desorption of radionuclides and other components in the bottom sediments, and on suspended solids in water and biota;

- sedimentation due to biological processes and solid surface runoff

- processes of sorption during water filtration in permeable parts of the bottom and through the dams.

\section{Section 7}

\section{THE FIRST VERSION OF THE COMPUTER MODEL.}

\subsection{Introduction}

The essence of the computer model can be stated as follows: for every time step, the inflow and outflow for each reservoir is taken into account, and a balance of each component (including radionuclides) is calculated as well as the redistribution of the substances between the aqueous phase and the bottom sediments. This permits us to model the evolution of the hydrochemical and radionuclide conditions of the reservoir cascade. The principal scheme of processes which should be taken into account for computer simulation is shown in Figure 7.1.

\subsection{Mass balance.}

We take into account the following mass transfers:

- flow of waste water to the reservoir \#10 from reservoir \#4;

- flow from reservoir \#10 into reservoir \#11;

- atmospheric precipitation and evaporation; 


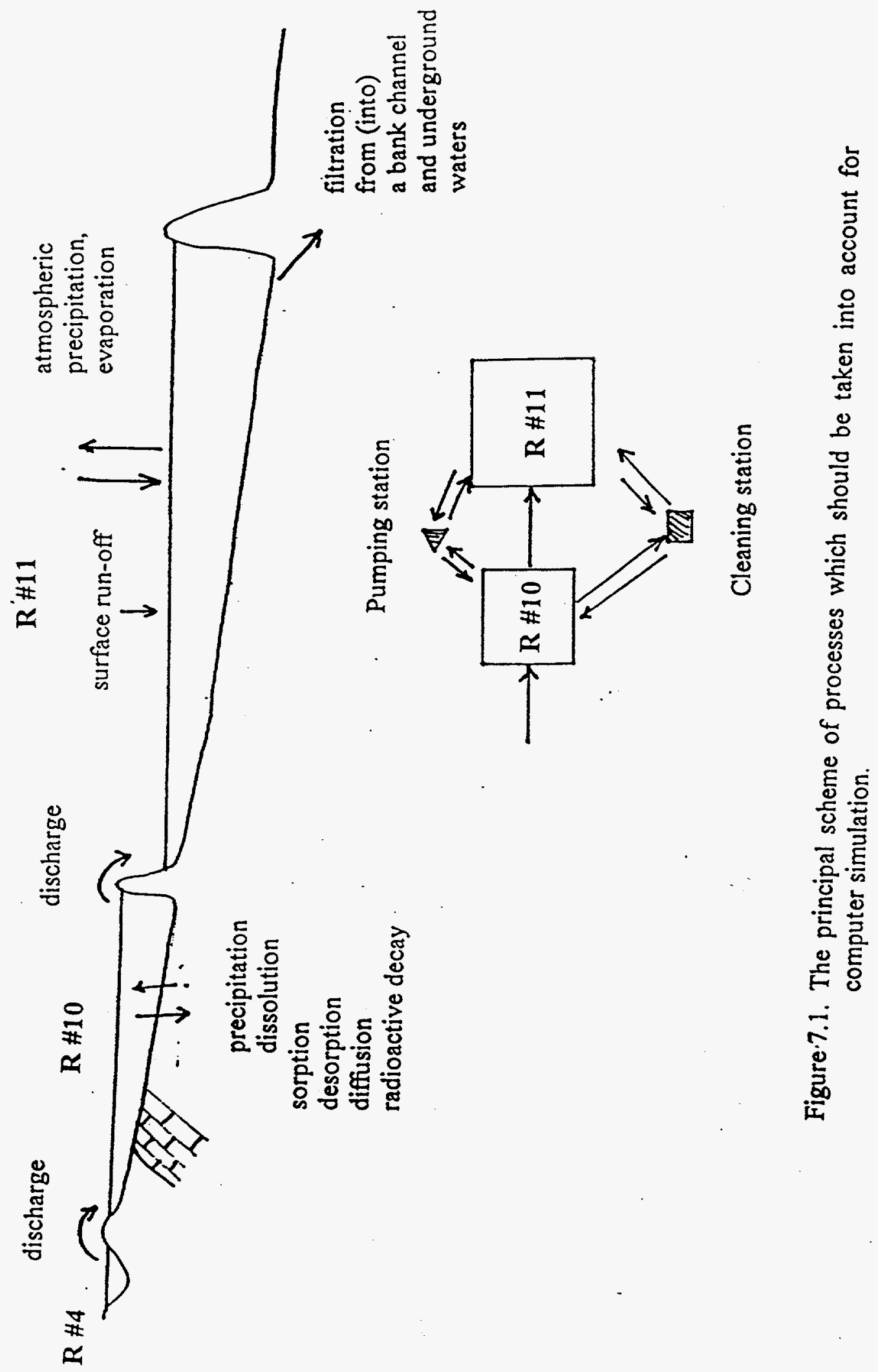


- surface runoff and underground flows into reservoirs

- operation of the treatment plant in the future, etc.

In this first version of the model, the processes of radionuclide sorption during leakage was not taken account. We assumed that radionuclides left the reservoirs according to their current concentrations in the aqueous phase. These processes will be accounted for in future versions of the code.

For calculating the mass balance for any reservoir, the model takes into account vectors of input and output flows and the vector of the current conditions in a reservoir. Certain vectors of input and output flows are included in the database. Other ones in the database contain only components which determine the total flow without concentrations of components. With the exception of evaporation, the outflows usually have current chemical composition of the reservoir. The chemical composition of the outflow from the treatment plant is specified by its working capacities. These rules are also prescribed in the database. The model calculates the chemical composition of any reservoir at any time $\mathbf{t}$ and the redistribution of components between the aqueous phase and the bottom sediments during a time step $\Delta t$ as described below. For example, the material balance for the ith chemical component in the 10th reservoir is written as:

$$
\begin{aligned}
& \nabla_{10^{\circ}} m_{110^{\prime}}^{(t \Delta t)}=\nabla_{10^{*}} m_{110^{+}}^{(t)}+\Delta t \sum_{k} \nabla_{k} \cdot m_{i k}-\Delta t \sum_{j} \nabla_{j} \cdot m_{1 j}^{(t \Delta t)}-\nabla_{1011^{*}} \cdot m_{110}^{\left(t_{\Delta} \Delta t\right)} \\
& \text { where the flow from the R10 to R11 } \nabla_{1011}=\sum_{k} \nabla_{k}-\sum_{j} \nabla_{j} \text { if the volume of the }
\end{aligned}
$$

10th reservoir is equal to maximum capacity and equal to zero if the reservoir is not filled, -because its volume is restricted by dam, $m_{i k}$ is the content of $i$ th component in $k$ th flow, $\mathrm{V}$ is a flow volume per time, and $\Delta t$ is a time step. 
The current chemical composition of the reservoir $m_{i 10}^{t \Delta t}$ is calculated using this equation and taking into account the redistribution of chemical components due to chemical an physical processes. The time step was chosen to be 1 month in this version.

7.3 Chemical and physical processes taken into account for the first version of the model:

- hydrolysis and complex forming in the aqueous phase;

- precipitation of the components from the solution;

- dissolution of the solids in the bottom sediments;

- exchange of carbon dioxide between the reservoirs and the atmosphere;

- radionuclide decay

- vertical diffusion of radionuclides in the pore water of the bottom sediments;

- sorption and desorption of ${ }^{137} \mathrm{Cs}$ and ${ }^{90} \mathrm{Sr}$ on bottom sediments separately for different parts of the submerged surface, i.e. channel, flood plain, and inundated land adjacent to the flood plain.

\subsubsection{The thermodynamic model of chemical transformations.}

For numerical modeling of the chemical interactions of wastes with the host media, thermodynamic data on rock-forming and weathering minerals, aqueous species, as well as on their interaction with hazardous components are needed. The thermodynamic data for species and minerals were taken from the computer system "DiaNIK", developed at Vernadsky Institute (Shapkin A.I. et al, 1987, and Khodakovsky I.L. et al., 1993).

"DiaNIK" is an interactive research information system of chemical thermodynamic data for minerals and mineral-forming substances. The structure of thermodynamic 
database "DiaNIK" is based on principles, which were developed by the CODATA International Group on Geothermodynamic Data to provide thermodynamic information. The accepted structure allows to performe a consistency procedure both for the individual substances or the individual chemical reactions (local consistency), and for the chemical systems, containing a set of substances and reactions (global consistency). The "DiaNIK" system core supports the work of separate blocks, which can provide different opportunities and alternatives for the user.

A substantial portion of the thermodynamic values recommended by "DiaNIK" experts, for the substances in the User Version 3.1 resulted from the analyses based on review of the literature data, making use of original algorithms of the Expert Version 3.2. All the values, which one accepted in the "DiaNIK" data base, are consistent with the CODATA key-values and IUPAC recommended values.

"DiaNIK"'s (version 3.1) user is able to:

- calculate tables on thermodynamic properties $\left(\mathrm{Cp}, \mathrm{H}^{\circ} \mathrm{T}^{-\mathrm{H}^{\circ}}{ }_{298.15}, \mathrm{~S}^{\circ}, \Delta_{\mathrm{f}} \mathrm{H}^{\circ}, \Delta_{\mathrm{f}} \mathrm{G}^{\circ}\right)$ of individual substances at $P=1$ bar in wide temperature ranges (of 2000 to 3000 $\mathrm{K}$;

- based on the Haar-Gallagher-Kell water state equation, it can calculate tables on the water and steam thermodynamic properties up to $1273 \mathrm{~K}$ and $10 \mathrm{kbar}$, and theoretical coefficients in Born and Debye-Huckel equations for aqueous systems;

- obtain thermodynamic characteristics of chemical reactions using "DiaNIK" data base for individual substances and aqueous species;

- calculate equilibrium composition of closed and open systems under isothermalisobaric conditions aimed at determination of masses (volumes) of condensed phases, fugacities of gaseous species, concentrations of aqueous solution components and $\mathrm{pH}$ of stable and metastable equilibria; 
- obtain full bibliographical description of data source using reference code, author's names or key words.

The distinguishing features of the system include commentaries accompanying the recommended thermodynamic values, completely automated procedure for the primary information preparation intended for the computing of the equilibrium composition of multicomponent systems, including aqueous species, over a wide T, P-range.

The data base contains thermodynamic information on more than 500 solids, including main rock-forming minerals, 570 aqueous, and 300 gas species for wide PT ranges. During the last two years the information about more then 150 compounds of $\mathrm{Th}, \mathrm{U}, \mathrm{Pu}$, $\mathrm{Am}, \mathrm{Np}$, including carbonate, hydroxo-, cloride aqueous complexes of them have been evaluated by and included in the "DiaNIK" database.

For the computation of the chemical equilibrium in heterogeneous multicomponent systems of the reservoirs we used the "SLGSOL" code (Mironenko et al., 1992), which is based on Gibbs free energy minimization method. The code "SLGSOL" is build into the "DiaNIK" system (Khodakovsky, et al., 1993). It takes into account the non ideal formation of aqueous, gaseous, and solid solutions, and is able to compute equilibrium both in closed and open systems. The possibility of a passing the reaction basis and computed values of chemical potentials of independent components from one task to another allows the fast calculation of chemical equilibrium, to couple this program with mass transfer routines.

Gibbs free energy minimization is used which is constrained by liner mass balance equations. A search of the extremum of the Lagrangian function was carried out on reaction basis. Starting estimates of chemical potentials values of independent components (Lagrangian multipliers) are obtained by liner approximations of the free energy function. 
An input file containing a list of possible aqueous and gas species, and solids and their free energies could be formed automatically for selected chemical composition of a system and given $\mathrm{T}$ and $\mathrm{P}$. For the computation of activity coefficients of aqueous species the Debay-Hukkel equation (Gugenkheim approximation) is used. The program code permits to both free energies of individual substances, and equilibrium constants of chemical reactions for an equilibria computation.

It is possible to take into consideration chemical interaction rates using the reaction progress variable approach (Murphy, W.M., 1986). The input information needed for this code could be automatically prepared for any PTX parameters also.

We assumed that all chemical reactions in the system are fast, with the exception of reactions of solid dissolution. The rates of solid dissolution reactions were restricted.

At the first stage, chemical equilibrium composition was computed with a 11 component system: $\mathrm{H}, \mathrm{O}, \mathrm{Ca}, \mathrm{Mg}, \mathrm{Na}, \mathrm{S}, \mathrm{C}, \mathrm{Cl}, \mathrm{Cs}, \mathrm{Sr}, \mathrm{N}, \mathrm{H}^{+}$. It took into account 54 aqueous species(including complexes), and 8 solid carbonates and sulfates. (Table 7.1)

A list of minerals and aqueous species taken into account and their free energies for $25 \mathrm{C}$ (summer periods) and $4 \mathrm{C}$ (winter periods) are shown in the table 7.1.

Table 7.1 Minerals and aqueous species taken into account for hydrochemical conditions computation and their Gibbs free energies.

Substance

$\begin{array}{lcc} & 25^{\circ} \mathrm{C} & 4^{\circ} \mathrm{C} \\ \text { Minerals } & & \\ \text { lengardtite } & -2158322 . & -2154322 . \\ \text { epsomite } & -2880604 . & -2872628 . \\ \text { anhydrite } & -1321970 . & -1319807 . \\ \text { gypsum } & -1797335 . & -1793401 . \\ \text { magnesite } & -1029504 . & -1027377 .\end{array}$




\begin{tabular}{|c|c|c|}
\hline calcite & -1128880 & -1127387 \\
\hline dolomite & -2161701 & -2159781 \\
\hline \multicolumn{3}{|c|}{ Aqueous species } \\
\hline $\mathrm{O}_{2}(\mathrm{ao})$ & 16549 & 18645 \\
\hline $\mathrm{H}_{2}(\mathrm{ao})$ & 17726 & 18803 \\
\hline $\mathrm{OH}^{-}(\mathrm{ao})$ & -157299 & -157402 \\
\hline $\mathrm{Cl}^{-}(\mathrm{ao})$ & -131287 & -129993. \\
\hline $\mathrm{HCl}(\mathrm{ao})$ & -128629 & -129132 \\
\hline $\mathrm{HS}^{-}(\mathrm{ao})$ & 11969. & 13484 \\
\hline $\mathrm{H}_{2} \mathrm{~S}(\mathrm{ao})$ & -27914 & -25422 \\
\hline $\mathrm{SO}_{4}^{2-(\mathrm{aO})}$ & -744459 & -743830 \\
\hline $\mathrm{HSO}_{4}^{-}(\mathrm{ao})$ & -755750 & -753128 \\
\hline $\mathrm{H}_{2} \mathrm{SO}_{4}(\mathrm{ao})$ & -723537 & -719550 \\
\hline $\mathrm{CO}_{2}(\mathrm{ao})$ & -385968 & -383699 \\
\hline $\mathrm{CO}_{3}{ }^{2-}(\mathrm{aO})$ & -527987 & -528787 \\
\hline $\mathrm{HCO}_{3}{ }^{-}(\mathrm{ao})$ & -586935 & -584833 \\
\hline $\mathrm{CH}_{4}(\mathrm{ao})$ & -34447 & -32831 \\
\hline $\mathrm{Mg}^{2+}(\mathrm{ao})$ & -453992 & -456865 \\
\hline $\mathrm{MgOH}^{+}(\mathrm{ao})$ & -625874 & -626827 \\
\hline $\mathrm{MgCl}^{+}(\mathrm{ao})$ & -589023 & -588913 \\
\hline $\mathrm{MgSO}_{4}(\mathrm{ao})$ & -1211158 & -1211855 \\
\hline $\mathrm{Ca}^{2+}(\mathrm{ao})$ & -552793 & -553952 \\
\hline $\mathrm{CaOH}^{+}(\mathrm{ao})$ & -716634 & -716355 \\
\hline $\mathrm{CaCl}^{+}(\mathrm{ao})$ & -685546 & -684079 \\
\hline $\mathrm{CaSO}_{4}(\mathrm{ao})$ & -1310417 & -1309494 \\
\hline $\mathrm{Sr}^{2+}(\mathrm{ao})$ & -563838 & -564459 \\
\hline $\mathrm{SrOH}^{+}(\mathrm{ao})$ & -725169 & -724489 \\
\hline $\mathrm{SrCl}^{+}(\mathrm{ao})$ & -695450 & -842984 \\
\hline $\mathrm{SrSO}_{4}(\mathrm{ao})$ & -1322832 & -1321429 \\
\hline $\mathrm{Na}^{+}(\mathrm{ao})$ & -261878 & -260675 \\
\hline
\end{tabular}




$\begin{array}{lll}\mathrm{NaOH}(\mathrm{ao}) & -414612 . & -414200 . \\ \mathrm{NaCl}(\mathrm{ao}) & -388730 . & -386583 \\ \mathrm{NaSO}_{4}^{-}(\mathrm{ao}) & -1003711 . & -1001864 . \\ \mathrm{Cs}^{+}(\mathrm{ao}) & -291660 . & -288841 \\ \mathrm{CsOH}(\mathrm{ao}) & -445982 . & -442699 . \\ \mathrm{CsCl}(\mathrm{ao}) & -421737 . & -417604 . \\ \mathrm{CsSO}_{4}^{-}(\mathrm{ao}) & -1782225 . & -1777492 \\ \mathrm{H}_{2} \mathrm{O}(\mathrm{l}) & -237174 . & -235763 . \\ \mathrm{H}^{+}(\mathrm{ao}) & 0 . & 0 .\end{array}$

There are examples of successful simulation of sorption of radionuclides, using the EQ3/6 geochemical modeling code (Viani B.E. and Bruton C.J., 1992), which operates with equilibrium constants of chemical reactions. Our model can be also easily modified to simulate the coprecipitation of ${ }^{90} \mathrm{Sr}$ with $\mathrm{Ca}^{2+}(\mathrm{ao}), \mathrm{Mg}^{2+}(\mathrm{ao})$ and $\mathrm{Sr}^{2+}(\mathrm{ao})$ (common) in terms of solid solutions of carbonates and sulfates of these metals. But this module is not included in the model in this first version.

The data base for output results contains only parameters, controlled by a monitoring survey of Mayak. They are listed in Appendix 2. On the other hand the model calculates more detailed characteristics of the reservoirs. As an example of a computed chemical model, the results of an equilibrium composition calculation of Reservoir 11 on June 1, 1992 are shown in Table 7.2. 
Table 7.2 Results of computer modeling equilibrium composition of Reservoir 11 for June 1, 1992.

\section{Conditions:}

$$
\text { Temperature }=298.15 \mathrm{~K} \text {; Pressure }=1.0 \mathrm{bar}
$$

It was taken into account: solid phases - 7; the aqueous species - 33

The system is open with respect to 1 component $\left(\mathrm{CO}_{2}\right)$ with $a_{\mathrm{CO}_{2}}=5.0 \cdot 10^{-4}$

\begin{tabular}{|c|c|c|c|c|c|}
\hline \multicolumn{6}{|c|}{ Solution } \\
\hline & Ionic s & renght $=.0017$ & $\mathrm{pH}=7.94$ & & \\
\hline species & mole & molality & activity & act.coeff. & $\mathrm{G}(\mathrm{J} / \mathrm{mol})$ \\
\hline $1 \mathrm{H}_{2} \mathrm{O}(1)$ & 55.520 & $.99969 \mathrm{D}+00$ & $.99969 D+00$ & 1.0000 & -237174 \\
\hline $2 \mathrm{H}^{+}(\mathrm{ao})$ & $.11594 \mathrm{E}-07$ & $.11589 \mathrm{D}-07$ & $.11361 \mathrm{D}-07$ & .9803 & 0. \\
\hline $3 \mathrm{OH}^{-}(\mathrm{ao})$ & $.90683 \mathrm{E}-06$ & $.90639 D-06$ & $.88858 \mathrm{D}-06$ & .9803 & -157299 \\
\hline $4 \mathrm{Cl}^{-}(\mathrm{ao})$ & $.19748 \mathrm{E}-02$ & $.19739 D-02$ & $.19351 D-02$ & .9803 & -131287 \\
\hline $5 \mathrm{HCl}(\mathrm{ao})$ & $.75257 \mathrm{E}-11$ & $.75221 \mathrm{D}-11$ & $.75226 \mathrm{D}-11$ & 1.0001 & -128629 \\
\hline $6 \mathrm{SO}_{4}{ }^{2-}(\mathrm{ao})$ & $.41235 \mathrm{E}-02$ & $.41215 \mathrm{D}-02$ & $.38062 \mathrm{D}-02$ & .9235 & -744459 \\
\hline $7 \mathrm{HSO}_{4}^{-}(\mathrm{ao})$ & $.41990 E-08$ & $.41970 \mathrm{D}-08$ & $.41145 \mathrm{D}-08$ & .9803 & -755750 \\
\hline $8 \mathrm{CO}_{2}(\mathrm{ao})$ & $.10004 E-04$ & $.99992 \mathrm{D}-05$ & $.99999 D-05$ & 1.0001 & -385968 \\
\hline $9 \mathrm{CO}_{3}^{2-(a o)}$ & $.17811 \mathrm{E}-05$ & $.17802 \mathrm{D}-05$ & $.16440 D-05$ & .9235 & -527987 \\
\hline $10 \mathrm{HCO}_{3}-(\mathrm{ao})$ & $.40650 \mathrm{E}-03$ & $.40631 \mathrm{D}-03$ & $.39832 \mathrm{D}-03$ & .9803 & -586935 \\
\hline $11 \mathrm{Mg}^{2+}(\mathrm{ao})$ & $.12320 \mathrm{E}-02$ & $.12314 \mathrm{D}-02$ & $.11383 \mathrm{D}-02$ & .9244 & -453992 \\
\hline $12 \mathrm{MgOH}^{+}(\mathrm{ao})$ & $.37072 \mathrm{E}-06$ & $.37054 \mathrm{D}-06$ & $.36326 \mathrm{D}-06$ & .9803 & -625874 \\
\hline $13 \mathrm{MgCl}^{+}(\mathrm{ao})$ & $.10182 E-04$ & $.10177 \mathrm{D}-04$ & $.99769 D-05$ & .9803 & -589023 \\
\hline $14 \mathrm{MgSO}_{4}(\mathrm{ao})$ & $.73024 \mathrm{E}-03$ & $.72989 D-03$ & $.72994 \mathrm{D}-03$ & 1.0001 & -1211158 \\
\hline $15 \mathrm{Ca}^{2+}(\mathrm{ao})$ & $.16202 \mathrm{E}-02$ & $.16194 \mathrm{D}-02$ & $.14970 \mathrm{D}-02$ & .9244 & -552793 \\
\hline $16 \mathrm{CaOH}^{+}(\mathrm{ao})$ & $.19012 \mathrm{E}-07$ & $.19003 \mathrm{D}-07$ & $.18630 \mathrm{D}-07$ & .9803 & -716634 \\
\hline $17 \mathrm{CaCl}^{+}(\mathrm{ao})$ & $.53409 \mathrm{E}-05$ & $.53383 \mathrm{D}-05$ & $.52334 \mathrm{D}-05$ & .9803 & -685546 \\
\hline $18 \mathrm{CaSO}_{4}(\mathrm{ao})$ & $.11553 \mathrm{E}-02$ & $.11547 \mathrm{D}-02$ & $.11548 \mathrm{D}-02$ & 1.0001 & -1310417 \\
\hline $19 \mathrm{Sr}^{2+}(\mathrm{ao})$ & $.10376 \mathrm{E}-04$ & $.103710-04$ & $.95873 \mathrm{D}-05$ & .9244 & -563838 \\
\hline
\end{tabular}




\begin{tabular}{|c|c|c|c|c|c|}
\hline $\mathrm{OH}^{+}(\mathrm{ao})$ & $44229 E-10$ & -10 & .43 & .9803 & -7 \\
\hline $1 \mathrm{SrCl}^{+}(\mathrm{ao})$ & $586 E-07$ & $1575 \mathrm{D}-07$ & $.21151 D-07$ & .9803 & -695450 \\
\hline $2 \mathrm{SrSO}_{4}(\mathrm{ao})$ & $.12859 E-04$ & $.12853 \mathrm{D}-04$ & $.12854 \mathrm{D}-04$ & 1.0001 & $12{ }^{\circ}$ \\
\hline$+(\mathrm{ao})$ & 2610 E-02 & $.52585 \mathrm{D}-02$ & $.51551 \mathrm{D}-02$ & .9803 & -2 \\
\hline $\mathrm{NaOH}(\mathrm{aO})$ & .72650 E-09 & $.72616 \mathrm{D}-09$ & $.72621 D-09$ & 1.0001 & \\
\hline 1 & .166 & .166 & .16 & 1.0001 & -3887 \\
\hline $26 \mathrm{NaSO}_{4}{ }^{-}(\mathrm{ao})$ & $.69411 \mathrm{E}-05$ & $.69378 D-05$ & $.68015 \mathrm{D}-05$ & .9803 & 10 \\
\hline $7 \mathrm{Cs}^{+}(\mathrm{ao})$ & $.13381 E-05$ & $.133^{\circ}$ & $.13111 \mathrm{D}-05$ & .9803 & -2 \\
\hline $\mathrm{CsOH}(\mathrm{ao})$ & $.35066 \mathrm{E}-12$ & $.35050 \mathrm{D}-12$ & $.35052 D-12$ & 1.0001 & -4459 \\
\hline $\mathrm{CsCl}(\mathrm{ao})$ & $.15578 \mathrm{E}-08$ & $.15570 \mathrm{D}-08$ & $.15571 D-08$ & 1.0001 & -42 \\
\hline $\mathrm{OCsSO}_{4}{ }^{-}(\mathrm{ao})$ & $.27895 \mathrm{E}-07$ & $.27881 \mathrm{D}-07$ & $.27333 \mathrm{D}-07$ & .9803 & -10 \\
\hline
\end{tabular}

Solid Phases (Volume $=.04091 \mathrm{~cm} 3$ )
n phase
mole
G $(\mathrm{J} / \mathrm{mol})$
vol \%
1 Dolomite (cr) .63589225E-03
-2161701 . $\quad 100.000$

\begin{tabular}{lcccc}
\hline \multicolumn{5}{c}{ Balance } \\
element & total & solids & solution & common comp. \\
$\mathrm{O} 2$ & $.277768 \mathrm{E}+02$ & $.190768 \mathrm{E}-02$ & $.277730 \mathrm{E}+02$ & $.277749 \mathrm{E}+02$ \\
$\mathrm{H} 2$ & $.555199 \mathrm{E}+02$ & $.000000 \mathrm{E}+00$ & $.555198 \mathrm{E}+02$ & $.555198 \mathrm{E}+02$ \\
$\mathrm{Cl} 2$ & $.996037 \mathrm{E}-03$ & $.000000 \mathrm{E}+00$ & $.996027 \mathrm{E}-03$ & $.996027 \mathrm{E}-03$ \\
$\mathrm{~S}$ & $.623719 \mathrm{E}-02$ & $.000000 \mathrm{E}+00$ & $.623723 \mathrm{E}-02$ & $.623723 \mathrm{E}-02$ \\
$\mathrm{C}$ & $.354851 \mathrm{E}-02$ & $.127178 \mathrm{E}-02$ & $.418288 \mathrm{E}-03$ & $.169007 \mathrm{E}-02$ \\
$\mathrm{Mg}$ & $.264304 \mathrm{E}-02$ & $.635892 \mathrm{E}-03$ & $.200722 \mathrm{E}-02$ & $.264311 \mathrm{E}-02$ \\
$\mathrm{Ca}$ & $.346094 \mathrm{E}-02$ & $.635892 \mathrm{E}-03$ & $.282507 \mathrm{E}-02$ & $.346096 \mathrm{E}-02$ \\
$\mathrm{Sr}$ & $.236868 \mathrm{E}-04$ & $.000000 \mathrm{E}+00$ & $.236864 \mathrm{E}-04$ & $.236864 \mathrm{E}-04$ \\
$\mathrm{Na}$ & $.526959 \mathrm{E}-02$ & $.000000 \mathrm{E}+00$ & $.526961 \mathrm{E}-02$ & $.526961 \mathrm{E}-02$ \\
$\mathrm{Cs}$ & $.136756 \mathrm{E}-05$ & $.000000 \mathrm{E}+00$ & $.136755 \mathrm{E}-05$ & $.136755 \mathrm{E}-05$ \\
& & & & \\
\hline
\end{tabular}


The carbon dioxide content in the aqueous solution is equal $1.0 \cdot 10^{-5}$. That corresponds to partial pressure of $\mathrm{CO} 2$ in the atmosphere. One can see that newly formed dolomite is present in the bottom sediments. This result is in good agreement with the results of mineralogical investigations of the bottom sediments of this reservoir. (Miass ). Newly formed carbonates were determined in reservoir \#11, and dissolution phenomena of the bottom dolomites of reservoir \#10 were fixed. Table 7.2 shows a distribution of strontium and cesium contents between different species. More then one half of strontium is contained in sulfate complexes. The share of sulfate strontium complexes in the aqueous solution of reservoir \#10 is much higher(about $70 \%$ ) due to a higher sulfate content in this reservoir. This should partly prevent strontium sorption on the bottom sediments. On the other hand most of the dissolved cesium of both reservoirs is presents as $\mathrm{Cs}^{+}$ion. It should be noted that the total cesium contents are not yet determined, they have to be taken into account to show the chemical behavior of cesium.

\subsubsection{Vertical diffusion of radionuclides in pore water of bottom soils, coupling sorption and desorption processes.}

The consideration of the data on radionuclide contamination of the reservoirs $R \# 10$ and $\mathrm{R} \# 11$ show, that the water-sediment interaction appears to be one of the main factors controlling the radionuclide behavior in these reservoirs (Section 6, Figure 6.1, 6.2). It may be concluded the ${ }^{90} \mathrm{Sr}$ and ${ }^{137} \mathrm{Cs}$ behavior in the bottom sediments is controlled by the following processes:

- ${ }^{90} \mathrm{Sr}$ and ${ }^{137} \mathrm{Cs}$ sorption on the sediments and soil particles,

- radionuclide diffusion in sediment pore water,

- radioactive decay of radionuclides in bottom sediments.

The effect of these processes on the radionuclide concentration in the reservoir water should be separately considered for different regions of the bottom sediments 
characterized by different mineral compositions and by different levels of radionuclide contamination (the channel and flood plain regions of the reservoirs had been contaminated by radioactivity discharge to the Techa river before the reservoirs were built).

Since the rates of the sediment accumulation in the sediments did not exceed 1-2 $\mathrm{mm} /$ year, we generally included only $1 \mathrm{~m}$ of sediments in the model.

We assumed, that the sediments can be considered as a uniform media which could be characterized by the distribution ratios for different radionuclides, the porosity, the sediment grain density, and the tortuosity. The distribution ratios quantify the partitioning between the solid phase and solution due to sorption.

The set of equations describing decay for ${ }^{90} \mathrm{Sr}$ (or ${ }^{137} \mathrm{Cs}$ ), sorption, and diffusion in the sediments is defined as:

$$
\begin{aligned}
& \frac{\partial c(x, t)}{\partial t}=D_{e f} \frac{\partial^{2} c}{\partial x^{2}}-\lambda t \\
& D_{e f}=f D /(k+b-k b) \\
& a(x, t)=(1 / k) c(x, t) \\
& c(x, 0)=c_{0}(x) \\
& a(0, t)=a_{0}(t)
\end{aligned}
$$

where

c the radionuclide concentration in solid phase,

a -the radionuclide concentration in pore water,

$c_{0} \quad$-initial concentration of the radionuclide in sediment,

a $\quad$-initial radionuclide concentration in the reservoir,

f -parameter of the media (in the first approximation it depends on porosity and tortuosity)

k -distribution coefficient,

b -porosity, 

$\lambda$ - decay constant,
D - radionuclide diffusion coefficient in pore water,
$\mathrm{D}_{\text {ef }}$ - effective radionuclide diffusion coefficient in sediment,
$x$ - spatial coordinate, $x=0$ corresponds to the surface of sediment
$\mathrm{t}$ - time.

The set of equation was solved by finite-differences. We have developed a computer program that allows us to calculate the temporal changes of the radionuclide concentration in the water of the reservoirs and the temporal changes of the vertical radionuclide distribution in the sediments for different radionuclides and different regions of the sediments.

The developed approach was applied to model the radionuclide behavior in the contaminated reservoirs during their history of 30 years. The results of this simulation are given in Section 8.

\subsection{Structure of the Computer Model}

The computer model is an integrated package of executive control program and program modules. The code is written in TURBO PASCAL. It organizes the data exchange between different modules, input and output, the text editor's to generate input data and the presentation of output data as tables and data-files for plotting. The main mathematical modules are the code "SLGSOL" for chemical equilibrium computation, and the code "DIFSORP" for solving the differential equations describing radionuclide diffusion in the pore solution of the sediments incorporating sorption and desorption. These codes were written in FORTRAN.

In this section the general structure of the program package and user interface facilities are described. The user interface allows one to view and to edit input data, to run 
and to exert control over the simulation programs, to receive results in tabulated and (or) in graphic forms, etc.

Information used by the program package is provided by the hierarchical data base, consisting of a sequential file of records and appropriate service programs. Monitoring data as well as simulation results are stored in fields of the record files.

The first field of each record contains the year, month and day to which all following information in the record relates. The following piece of information is broken down into several parts each being related to the corresponding reservoir.

The state of the water in the reservoir can be characterized by a vector. The first component of it is the volume of water stored in the reservoir, the second one is $\mathrm{pH}$, the third one is alkalinity. The following components are the species concentrations under consideration. The zeroth component takes one of two values: 0 and 1. It indicates the presence of appropriate monitoring data. Value 1 denotes that data are present. The structure of the forecast vector (result vector from calculation) is completely similar in structure to the corresponding vector of the monitoring data described above. The piece of information on flows can also be presented in vector form. We take account of the following flows:

1) external flow from reservoir $R \# 4$;

2) surface run-off;

3) atmospheric precipitations and evaporations;

4) flow from reservoir $\mathrm{R} \# 10$ to $\mathrm{R} \# 11$;

5) filtration from (into) a bank channel and

6) water discharge from reservoir R \#11. 
We suppose that reservoir $\mathrm{R} \# 10$ operates in the "maximal level" mode and reservoir $\mathrm{R} \# 11$ operates under condition of constant water discharge. The "maximal level" mode means that the water volume in the reservoir cannot exceed some given value.

The structure of the flow vectors are somewhat different. In the case of the flow from $\mathrm{R} \# 10$ to $\mathrm{R} \# 11$, the external flow from $\mathrm{R} \# 4$, and the discharge flow from $\mathrm{R} \# 11$, the flow rate is large enough for a complete description because the ion concentrations in these flows are equal to those in the corresponding reservoirs. In the case of precipitations and evaporations the flow rate would also suffice to give a full description inasmuch as ion concentrations in these flows are negligibly small. The structure of the other flow vectors is similar to the vectors describing the water state in the reservoirs. The first component is the flow rate, the second is $\mathrm{pH}$ and so on.

The sediments in the reservoirs can also be described by vectors. The first component is the total sediment mass of sediments. The following components are concentrations of minerals which constitute the basis for the thermodynamic calculations.

Description of the cleaning station has some peculiarities. In this case changes of concentrations are characterized. So substituted ions, substitution factors and substituting ions would be defined in the cleaning station description.

Thus our program package describes the reservoir in terms of:

1) the water state vectors;

2) the flow vectors;

3) the vectors characterizing the sediments.

These data enable to calculate the hydrochemical parameters of the reservoirs and concentrations in the sediments. To calculate concentration of radioactive elements, some added information on the state of the reservoir bottom and initial distribution of 
radioactive elements are needed. This information is stored in special files marked with the extension sto.

The data base described above provides a means for quick access to the necessary piece of information and allows one to transfer data to the simulation programs and to exert executive control. The principal block-scheme of the user interface is presented in Figure 7.2

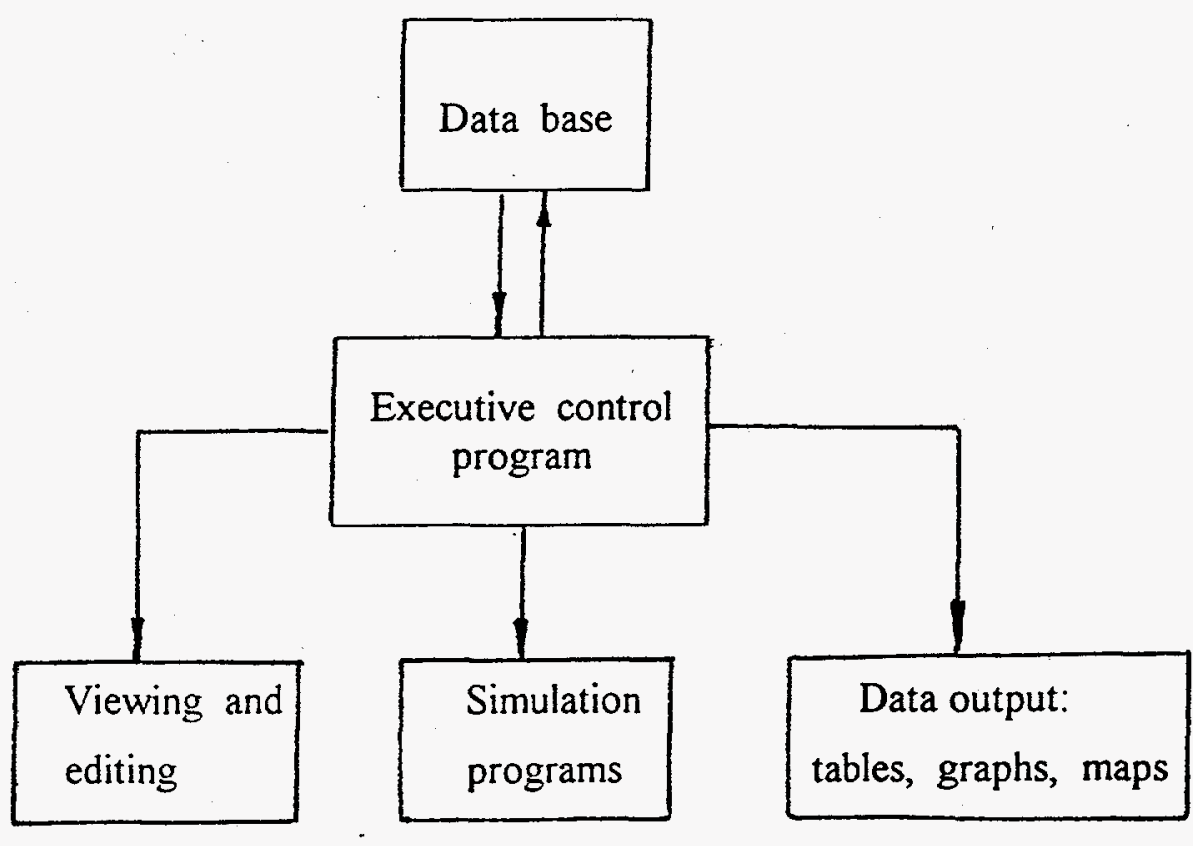

Figure 7.2. The principal block-scheme of the user interface.

The user interface includes a system of menus to control the data base and the executive program. Below we briefly describe the most important menus of the user interface. Selection of the appropriate option can be made by using arrow keys or by hitting a key which corresponds to the upper-case symbol. To execute selected options it is necessary to hit the "Enter" key. These rules are true for all menus and submenus.

The main menu consists of four options.

1. "Exit" allows to return to DOS. 
2. "Input data editing" By selecting this option, a transition to a sub menu is made. The sub menu appears in the bottom part of the screen. In the middle part of the screen, a brief information about the data base record loaded into RAM is displayed. This sub menu contains five options:

2.1. "Firsttime" provides entering a new record. This option is needed if there are no records in the data base. If at least one record is contained in data base, option "Editing" should be used.

2.2. "Search" conducts searching for a record. By picking this option, the horizontal sub menu with five options appears:

2.2.1. "Exit" allows to return to the previous menu.

2.2.2. "Viewing" scans the data base. During scaning a brief information about the current record is showed. Using vertical arrows it is possible to accelerate or to moderate the scan procedure. To stop scanning a space key has to be used.

2.2.3. "Date" asks for a date and searches for the records with this date and loads it from the hard disk into RAM.

2.2.4. "Previous" reads the record of the previous date (relative to the date which was previosly loaded into RAM) from the data base.

2.2.5. "Next" reads the records of the next data (relative to the date which was previosly loaded into RAM) from the data base.

2.3. "Editing" writes the records previously selected into a special file in which the user can correct it. The updated record is stored into data base. This option uses an external editor (in our version we use the "Norton editor", but in 
principle any other line editor may be used.) and has a sub menu consisting of three options:

2.3.1. "Exit" returns the previous menu.

2.3.2. "Radioactive elements" has its own sub menu every options of which relates to some radioactive element and some reservoir. For example, the option "Sr $r$ \#10" means editing data on ${ }^{90} \mathrm{Sr}$ in reservoir $\mathrm{R} \# 10$. If this option is selected, the user can see (and edit) two files which appear sequentially. The first one contains parameters of the reservoir, diffusivity and so on. The second files shows profiles of the radioactive elements in the sediments. In the first column of the former file the depth of the sediments is displayed. In the next columns the radioactivity $\left(\mathrm{Ci} / \mathrm{m}^{3}\right)$ of the elements under consideration is shown. When editing these two files, the user should abide by the requirement of FORTRAN as to position of record. We recommend to overtype new data in the positions of the old data using overtype mode for this purpose.

2.3.3. "General edition" shows on the screen the text file with the record previously selected. On this stage some external editor is used. The user can change any values in the data base including the date. By this way, new records can be entered to the data base. Limitations to data formats are minimal. The user should exclude reducing distances between string and numerical data in comparison with those already presented in the data base. To write changes in the data base one should save the text file on the hard disk before leaving this option.

2.4."Delete" deletes the selected record from data base. 
2.5. "Exit" returns to the main menu.

3. "Results". This option of the main menu has a vertical sub menu with three options:

3.1. "Exit" which returns to the main menu.

3.2. "Tables" allows viewing results in form of tables. There are two tables for each reservoir. One table for ions concentrations in the water and one table for mineral concentrations in the sediments.

3.3. "Graphics" attaches program package "Grapher". Further information can be received by using "Grapher".

4. "Viewing map". This option is described in a separate chapter (see Section 5).

Section 8

VERIFICATION OF THE MODEL AND ITS APPLICATION

TO THE SIMULATION OF RESERVOIRS CASCADE.

\subsection{Verification}

Adaptation and verification of these modules are currently conducted in parallel with further improvement of the program software and with a better understanding of the processes which influence the mobility and transformation of contaminants in the aqueous ecosystem. This first version of the model, generates results which are consistent with the observations of the reservoir states. As shown in figure 8.1, reservoir \#10 exibited of acid water ( $\mathrm{pH}$ was about 4.5) since 1982 as a result of a temporary increase of the volume of acid discharge into the Techa cascade of reservoirs. In 1991-1992, after decommission of the production reactors at PA "Mayak", the discharge of sulfuric acid with sewage was practically reduced to zero. 


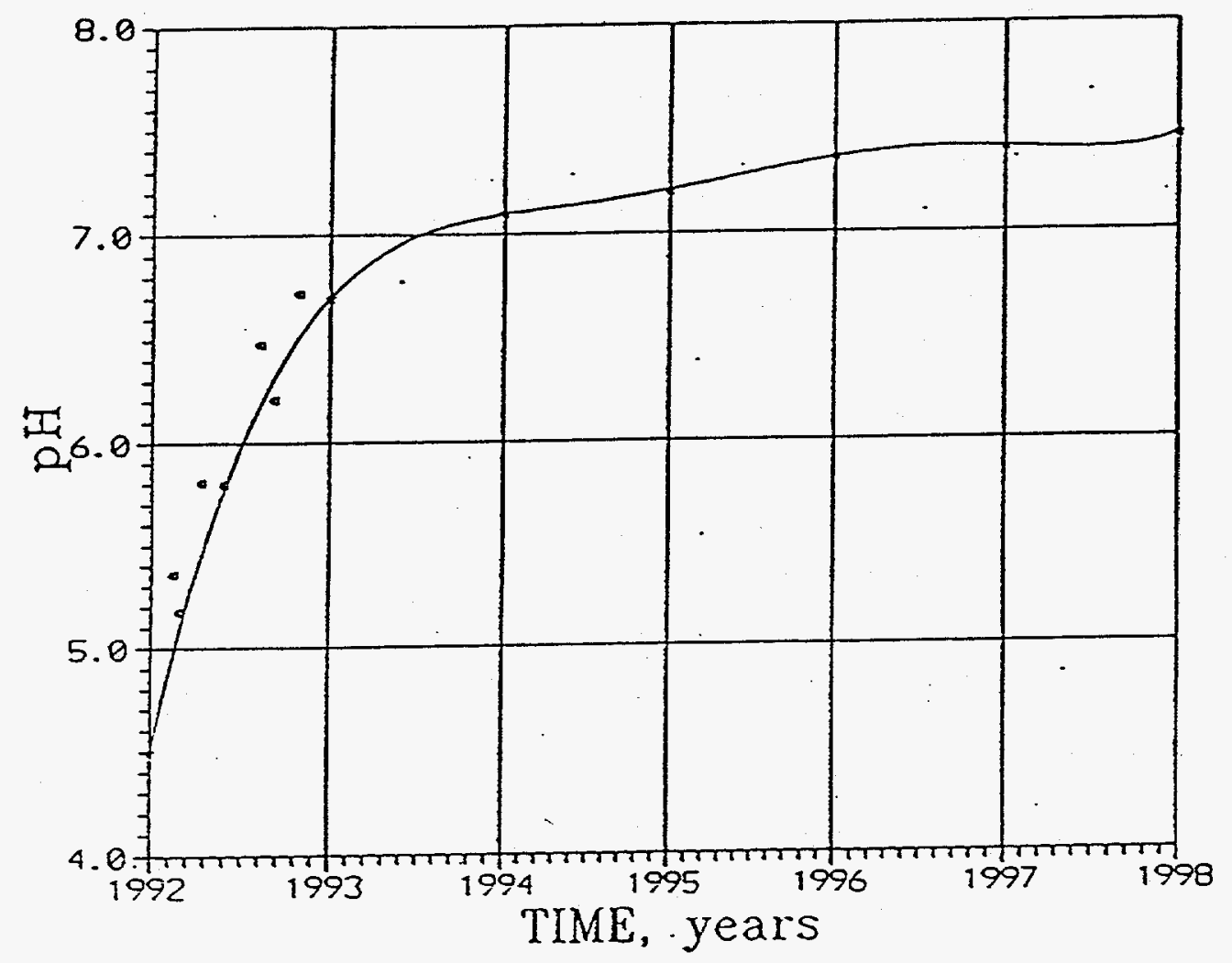

Figure 8.1. Comparison of measured and predicted $\mathrm{pH}$-values of reservoir $\# 10$ as a function of time 
In response to the stoppage of acid discharge, water $\mathrm{pH}$ in $\mathrm{R} \# 10$ slowly increased. The dynamic of increasing $\mathrm{pH}$ was predicted by Mironenko and Khodakovsky in the middle of 1991 using the balance-thermodynamic model (Figure 8.1) (Mironenko and Khodakovsky, 1991).

The approach presented in the Section 7.3.2. was applied to the simulation of the radionuclide behavior in contaminated reservoirs during the reservoir history (30 years).

The distribution ratios have been evaluated by the data on the radionuclide concentration in the water and in the sediments of flooded part of $R \# 10$ and $R \# 11$ by the following equation:

$k=c(x=0) / a$

where

$\mathbf{c}(\mathbf{x}=\mathbf{0})$ is the radionuclide concentration in the surface part of the sediment,

a - the radionuclide concentration in the water of the reservoir.

The effective radionuclide diffusion coefficient characterizing the behavior of the radionuclides in the sediments have been estimated by the following equation:

$$
D_{\text {ef }}=b \cdot D /(k+b-k \cdot b)
$$

The experimental data on D $(10 \mathrm{~m} / \mathrm{sec}$, Robinson R.A. Stokes R.H. Electrolyte Solutions, Butterworth, london 1959) and experimental values of $\mathbf{b}(6 \%)$ have been used.

The model was applied to study the radionuclide behavior in the sediments during the reservoir history (30 years). We suppose that the radionuclide concentration in the water of $\mathrm{R} \# 10$ and $\mathrm{R} \# 11$ are constant, and calculated the temporal changes of the radionuclide distributions in the sediments of the flooded part of the reservoirs. The estimated and used in the calculations $\mathbf{k}$ and $\mathbf{D}_{\mathbf{e f}}$ values are shown in the table 8.1. 
Table 8.1 The distribution ratios, and effective diffusion coefficients.

\begin{tabular}{lcccc}
\hline Reservoir & $\mathrm{KSr}_{\mathrm{S}-90}$ & $\mathrm{k}_{\mathrm{Cs}-137}$ & $\mathrm{D}_{\mathrm{ef}(\mathrm{Sr}-90)} \frac{\mathrm{CM}^{2}}{\mathrm{c}}$ & $\mathrm{D}_{\mathrm{ef}(\mathrm{Cr}-137) \frac{\mathrm{CM}^{2}}{\mathrm{c}}}$ \\
\hline $\mathrm{R} 10$ & 25 & 15000 & $2.5 \cdot 10^{-8}$ & $4.2 \cdot 10^{-11}$ \\
\hline $\mathrm{R} 11$ & 50 & 40000 & $1.3 \cdot 10^{-8}$ & $1.7 \cdot 10^{-10}$ \\
\hline
\end{tabular}

The results of the modeling show the difference in radioisotope mobility. the calculated vertical distributions of the ${ }^{90} \mathrm{Sr}$ and ${ }^{137} \mathrm{Cs}$ contaminations of the sediments are presented in figures 8.2 and 8.3. From the modeling, the thickness of the sediments layers, strongly contaminated by ${ }^{90} \mathrm{Sr}$ during the 30 year period, do not exceed $20 \mathrm{~cm}$. The thickness of the sediment layer which might be contaminated by ${ }^{137} \mathrm{Cs}$ owing to sorption coupled to diffusion and radioactive decay is less than $1 \mathrm{~cm}$.

The deceleration of the radionuclide penetration rate into the bottom sediment layers is the second important feature of this process. it is possible to show, that the radionuclide distribution approaches the curve which is described by the following equation (the stationary solution of the equation (1)):

$$
c(x)=K \cdot a_{0} \cdot \exp \left(-\sqrt{\lambda / D_{\text {ef }}} x\right)
$$

As shown in Tables 8.2 and 8.3 (see also Figures 8.2 and 8.3 ), as well as from Figure 8.4 actual distribution of ${ }^{90} \mathrm{Sr}$ and ${ }^{137} \mathrm{Cs}$ should be close to the limiting curve, and it is possible to affirm, that further penetration of radionuclides into the sediment will not occur. 


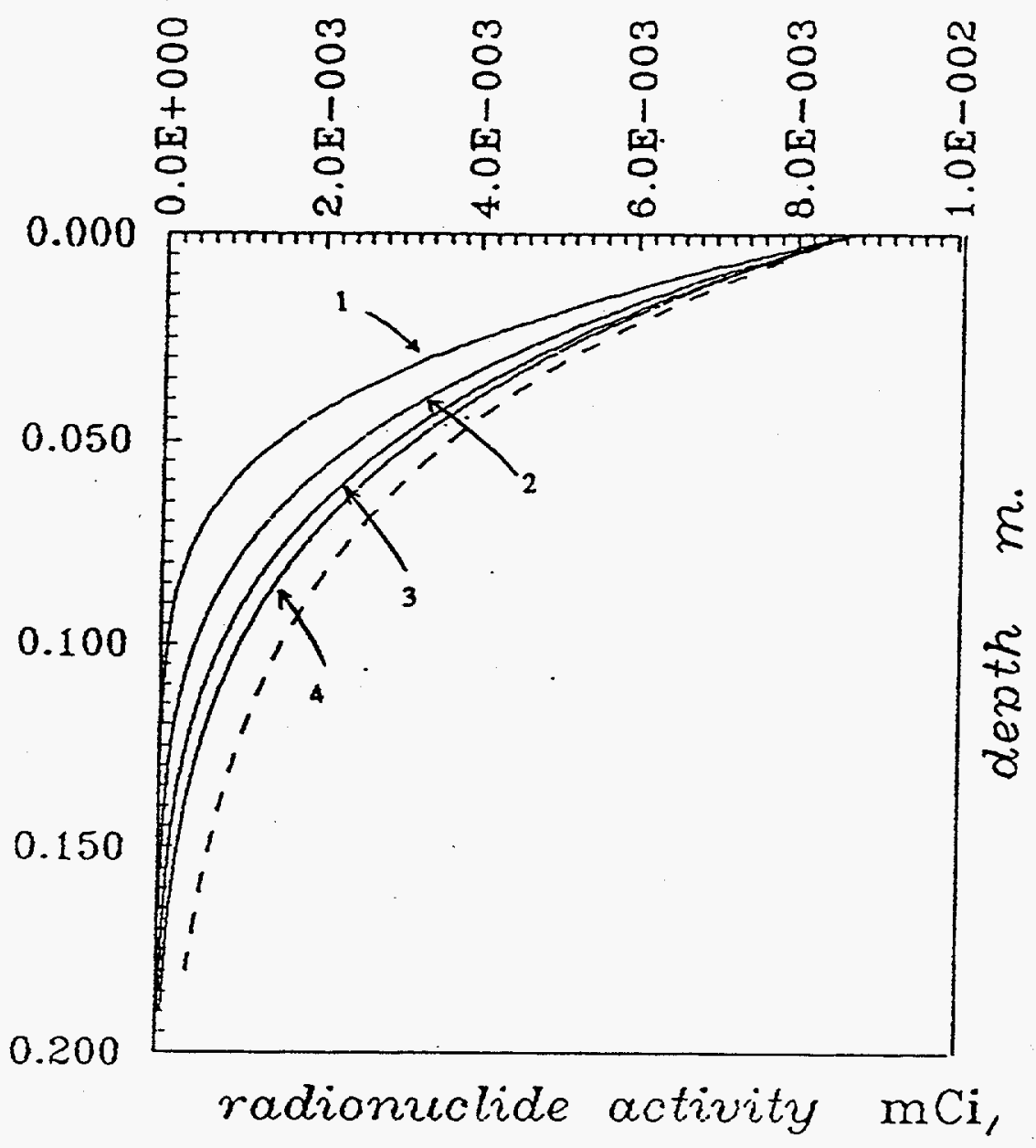

Figure 8.2. The calculated $90 \mathrm{Sr}$ distribution in the sediments in the inundated region of reservoir \#10 beyond the flood plain. The curves 1, 2, 3, 4 are the distribution formed during the periods $10,20,30,40$ years after inundation. The dashed curve corresponds to infinite time 


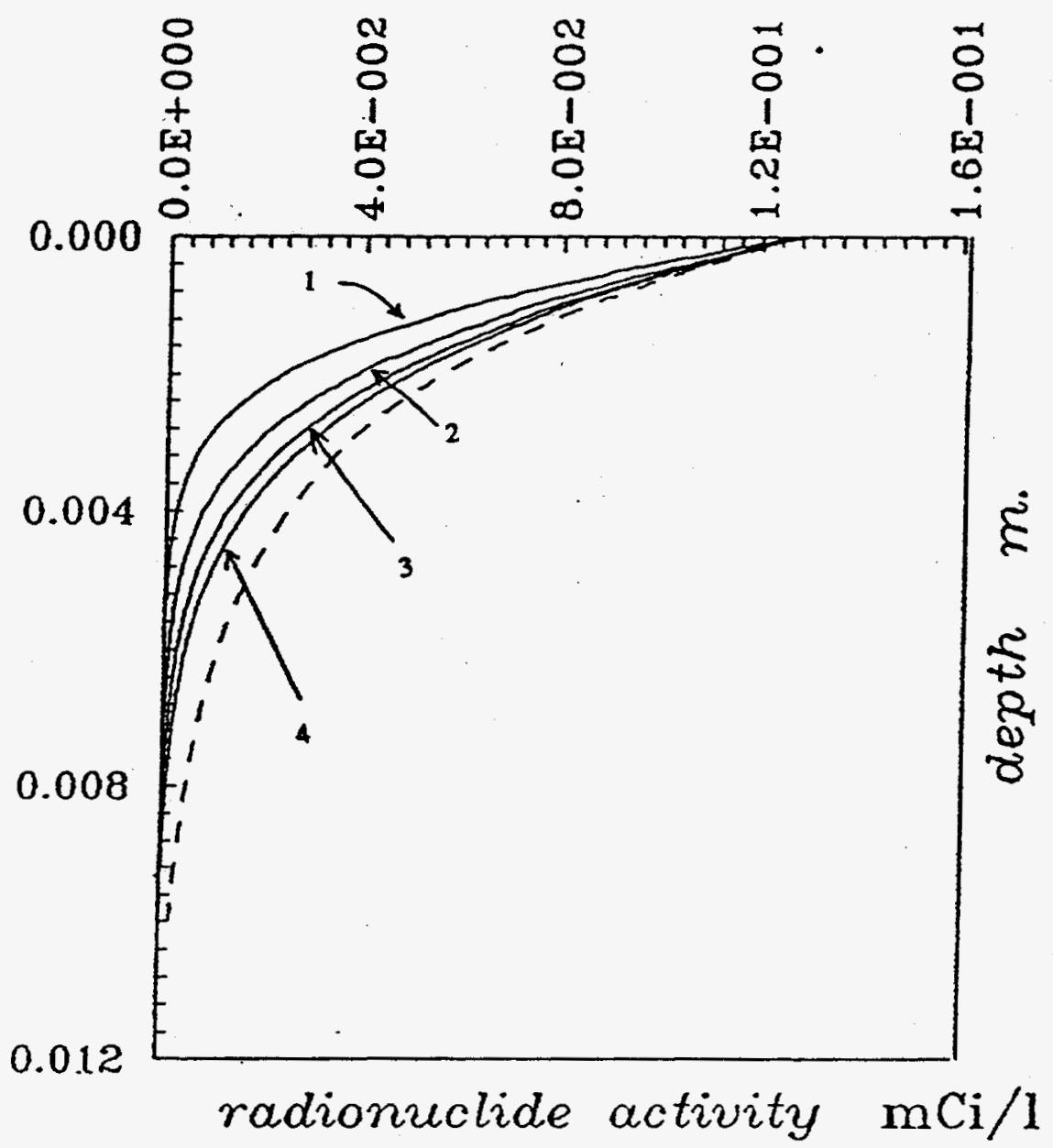

Figure 8.3. The calculated ${ }^{137} \mathrm{Cs}$ distribution in the sediments in the inundated region of reservoir \#10 beyond the flood plain. The curves 1, 2, 3, 4 are the distribution formed during the periods $10,20,30,40$ years after inundation. The dashed curve corresponds to infinite time 


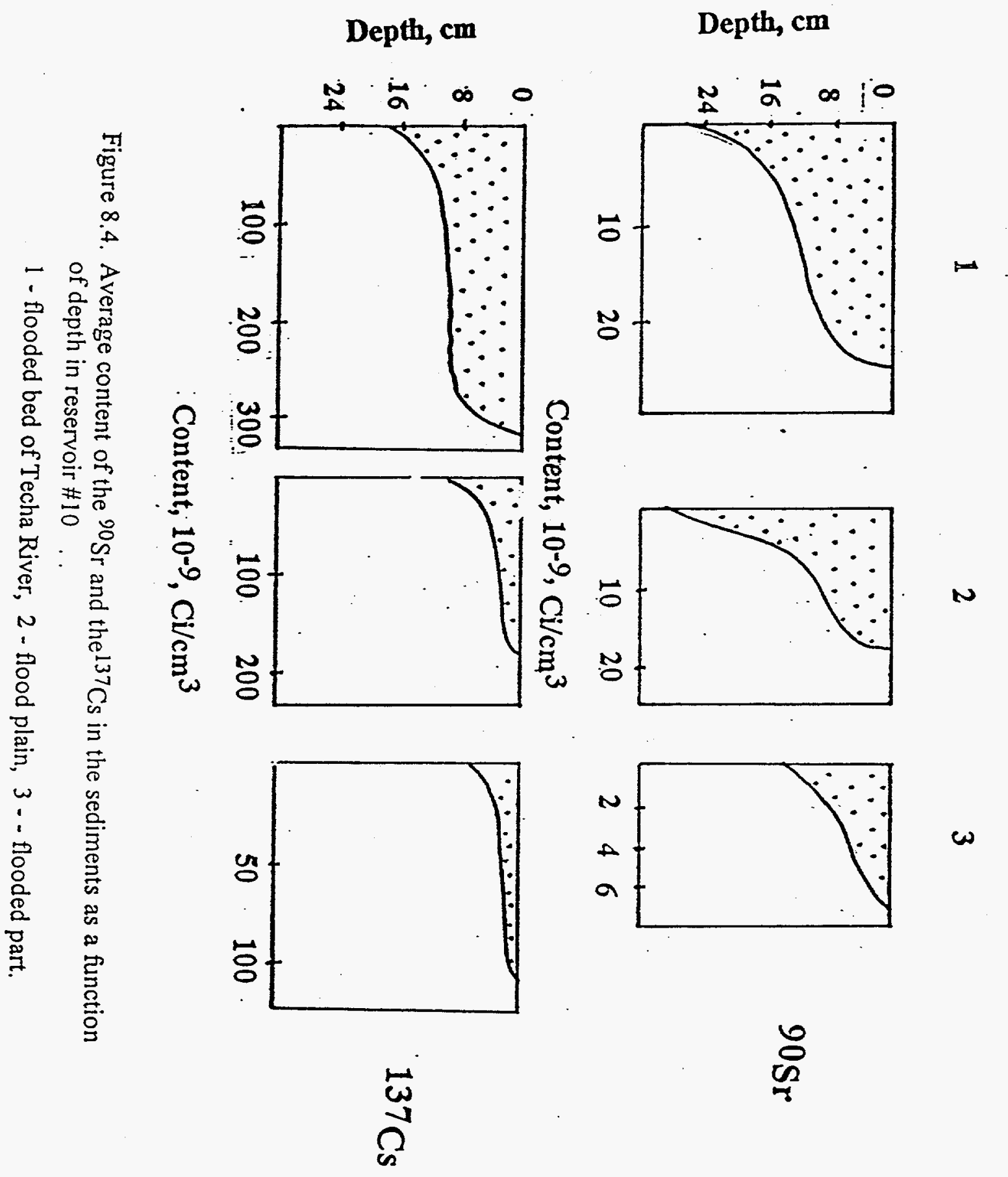


Table 8.2 Calculated ${ }^{90} \mathrm{Sr}$ distribution in the sediments of flooded part of $R \# 10$

\begin{tabular}{|c|c|c|c|c|c|}
\hline \multirow[t]{2}{*}{ Depth, m } & \multicolumn{4}{|c|}{${ }^{90} \mathrm{Sr}$ activity, $\mathrm{mCi} / \mathrm{dm}^{3}$} & \multirow[b]{2}{*}{ endless } \\
\hline & 10 years & 20 years & 30 years & 40 years & \\
\hline $.00000 E-01$ & $.87500 \mathrm{E}-02$ & $.87500 \mathrm{E}-02$ & $.87500 \mathrm{E}-02$ & $.87500 \mathrm{E}-02$ & $.87500 \mathrm{E}-02$ \\
\hline $.10000 \mathrm{E}-01$ & .66060 E-02 & $.69936 \mathrm{E}-02$ & $.71294 \mathrm{E}-02$ & $.71897 \mathrm{E}-02$ & $.73400 \mathrm{E}-02$ \\
\hline $.20000 \mathrm{E}-01$ & $.48298 \mathrm{E}-02$ & $.55449 \mathrm{E}-02$ & $.58035 \mathrm{E}-02$ & $.59209 E-02$ & $.61600 \mathrm{E}-02$ \\
\hline $.30000 \mathrm{E}-01$ & $.33855 \mathrm{E}-02$ & $.43241 \mathrm{E}-02$ & $.46835 \mathrm{E}-02$ & $.48514 \mathrm{E}-02$ & $.51600 \mathrm{E}-02$ \\
\hline $.40000 \mathrm{E}-01$ & $.22702 \mathrm{E}-02$ & $.33112 \mathrm{E}-02$ & $.37430 \mathrm{E}-02$ & $.39523 E-02$ & $.43400 \mathrm{E}-02$ \\
\hline $.50000 E-01$ & $.14546 \mathrm{E}-02$ & $.24861 E-02$ & $.29593 \mathrm{E}-02$ & $.31989 \mathrm{E}-02$ & $.36500 \mathrm{E}-02$ \\
\hline $.60000 E-01$ & $.89047 E-03$ & $.18279 E-02$ & $.23124 \mathrm{E}-02$ & $.25705 \mathrm{E}-02$ & $.30600 \mathrm{E}-02$ \\
\hline $.70000 \mathrm{E}-01$ & $.52109 \mathrm{E}-03$ & $.13150 \mathrm{E}-02$ & $.17844 \mathrm{E}-02$ & $.20494 \mathrm{E}-02$ & $.25700 \mathrm{E}-02$ \\
\hline $.80000 \mathrm{E}-01$ & $.29180 \mathrm{E}-03$ & $.92480 \mathrm{E}-03$ & $.13587 \mathrm{E}-02$ & $.16201 \mathrm{E}-02$ & $.21520 \mathrm{E}-02$ \\
\hline $.90000 \mathrm{E}-01$ & $.15658 \mathrm{E}-03$ & $.63554 \mathrm{E}-03$ & $.10203 \mathrm{E}-02$ & $.12692 \mathrm{E}-02$ & $.18100 \mathrm{E}-02$ \\
\hline $.10000 \mathrm{E}+00$ & $.80649 \mathrm{E}-04$ & $.42663 \mathrm{E}-03$ & $.75505 \mathrm{E}-03$ & $.98483 E-03$ & $.15100 E-02$ \\
\hline $.11000 E+00$ & .39940 E-04 & .27970 E-03 & $.55048 \mathrm{E}-03$ & $.75651 E-03$ & \\
\hline $.12000 \mathrm{E}+00$ & $.19052 \mathrm{E}-04$ & $.17908 \mathrm{E}-03$ & $.39522 \mathrm{E}-03$ & $.57505 \mathrm{E}-03$ & $.10700 E-02$ \\
\hline $.13000 E+00$ & $.87696 \mathrm{E}-05$ & $.11199 \mathrm{E}-03$ & $.27934 \mathrm{E}-03$ & $.43241 \mathrm{E}-03$ & \\
\hline $.14000 \mathrm{E}+00$ & $.39019 \mathrm{E}-05$ & $.68410 \mathrm{E}-04$ & $.19433 \mathrm{E}-03$ & $.32153 \mathrm{E}-03$ & $.75000 \mathrm{E}-03$ \\
\hline $.15000 \mathrm{E}+00$ & $.16810 \mathrm{E}-05$ & $.40831 \mathrm{E}-04$ & $.13304 \mathrm{E}-03$ & $.23636 \mathrm{E}-03$ & \\
\hline $.16000 \mathrm{E}+00$ & $.70236 \mathrm{E}-06$ & $.23820 \mathrm{E}-04$ & $.89620 \mathrm{E}-04$ & $.17173 \mathrm{E}-03$ & .53000 E-03 \\
\hline $.17000 \mathrm{E}+00$ & $.28505 E-06$ & $.13587 E-04$ & $.59403 E-04$ & $.12330 \mathrm{E}-03$ & \\
\hline $.18000 \mathrm{E}+00$ & $.11253 \mathrm{E}-06$ & $.75808 \mathrm{E}-05$ & $.38742 \mathrm{E}-04$ & $.87466 \mathrm{E}-04$ & $.37000 \mathrm{E}-03$ \\
\hline $.19000 E+00$ & $.3271 \mathrm{E}-07$ & 41390E-05 & $.4862 \mathrm{E}-04$ & $.1298 \mathrm{E}-04$ & \\
\hline $20000 \mathrm{e}+00$ & & & & & \\
\hline
\end{tabular}


Table 8.3 Calculated ${ }^{137} \mathrm{Cs}$ distribution in the sediments of flooded part of $R \# 10$

\begin{tabular}{|c|c|c|c|c|c|}
\hline \multirow[t]{2}{*}{ Depth, m } & \multicolumn{4}{|c|}{${ }^{137} \mathrm{Cs}$ activity, $\mathrm{mCi} / \mathrm{dm}^{3}$} & \multirow[b]{2}{*}{ endless } \\
\hline & 10 years & 20 years & 30 years & 40 years & \\
\hline $.00000 \mathrm{E}-02$ & $.12900 \mathrm{E}+00$ & $.12900 \mathrm{E}+00$ & $.12900 \mathrm{E}+00$ & $.12900 \mathrm{E}+00$ & $.12900 \mathrm{e}+00$ \\
\hline $.10000 \mathrm{E}-02$ & $.61426 \mathrm{E}-01$ & $.74018 \mathrm{E}-01$ & $.78767 \mathrm{E}-01$ & $.80990 \mathrm{E}-01$ & $.85140 \mathrm{e}-01$ \\
\hline $.20000 \mathrm{E}-02$ & $.23599 \mathrm{E}-01$ & $.38631 \mathrm{E}-01$ & $.45782 \mathrm{E}-01$ & $.49479 \mathrm{E}-01$ & $.56000 \mathrm{e}-01$ \\
\hline $.30000 \mathrm{E}-02$ & $.74175 \mathrm{E}-02$ & $.18028 E-01$ & $.24886 \mathrm{E}-01$ & $.28968 \mathrm{E}-01$ & $.37000 \mathrm{e}-01$ \\
\hline $.40000 \mathrm{E}-02$ & $.19606 \mathrm{E}-02$ & $.75096 \mathrm{E}-02$ & $.12559 E-01$ & $.16133 E-01$ & $.25000 \mathrm{e}-01$ \\
\hline $.50000 \mathrm{E}-02$ & $.44689 \mathrm{E}-03$ & $.28033 \mathrm{E}-02$ & $.58654 \mathrm{E}-02$ & $.85027 \mathrm{E}-02$ & $.16500 \mathrm{e}-01$ \\
\hline $.60000 \mathrm{E}-02$ & $.89697 \mathrm{E}-04$ & $.94391 \mathrm{E}-03$ & $.25340 \mathrm{E}-02$ & $.42278 \mathrm{E}-02$ & $.10900 \mathrm{e}-01$ \\
\hline $.70000 \mathrm{E}-02$ & $.16126 \mathrm{E}-04$ & $.28882 \mathrm{E}-03$ & $.10143 \mathrm{E}-02$ & $.19806 \mathrm{E}-02$ & $.73100 \mathrm{e}-02$ \\
\hline $.80000 \mathrm{E}-02$ & $.26328 \mathrm{E}-05$ & $.80904 \mathrm{E}-04$ & $.37715 \mathrm{E}-03$ & $.87404 \mathrm{E}-03$ & $.48500 \mathrm{e}-02$ \\
\hline $.90000 \mathrm{E}-02$ & $.39482 E-06$ & $.20893 \mathrm{E}-04$ & $.13072 E-03$ & $.36367 E-03$ & $.32000 \mathrm{e}-02$ \\
\hline $.10000 \mathrm{E}-01$ & $.54891 \mathrm{E}-07$ & $.50056 \mathrm{E}-05$ & $.42378 \mathrm{E}-04$ & $.14287 \mathrm{E}-03$ & $.20600 \mathrm{e}-02$ \\
\hline $.11000 \mathrm{E}-01$ & $.71308 \mathrm{E}-08$ & $.11191 \mathrm{E}-05$ & $.12897 E-04$ & $.53090 \mathrm{E}-04$ & \\
\hline $.12000 \mathrm{E}-01$ & $.87129 \mathrm{E}-09$ & $.23468 \mathrm{E}-06$ & $.36974 \mathrm{E}-05$ & $.18698 \mathrm{E}-04$ & \\
\hline $.13000 \mathrm{E}-01$ & .10070 E-09 & $.46374 \mathrm{E}-07$ & $.10018 \mathrm{E}-05$ & $.62546 \mathrm{E}-05$ & \\
\hline $.14000 \mathrm{E}-01$ & $.11062 \mathrm{E}-10$ & $.86708 \mathrm{E}-08$ & $.25735 E-06$ & $.19914 \mathrm{E}-05$ & \\
\hline
\end{tabular}

The distribution ratios have been evaluated using data from the radionuclide concentration in the water and in the sediments of the flooded part of $\mathrm{R} \# 10$ and $\mathrm{R} \# 11$. It is within the limits of the values reported in the literature.

In addition, it was found that the sorption of radionuclides is irreversible in most parts of the former river-bed area of the Techa river. 


\subsection{Application}

As an illustration of the application of this model, the results of a long-time computer simulation, are presented in this report. The simulation assumes that the recovering plant using ion-exchange technology will be in operation by 1997 . The plant takes water from reservoir \#11, exchanges $\mathrm{Ca}^{2+}, \mathrm{Mg}^{2+}, \mathrm{Sr}^{2+}$ (including ${ }^{90} \mathrm{Sr}$ ) with $\mathrm{Na}^{+}$with $90 \%$ efficiency, and discharges clean water to $\mathrm{R} \# 10$. The mass and chemical composition of waste discharge from $\mathrm{R} \# 4$ also change with time. It is difficult to estimate the uncertainties of this scenario, but it is possible to use it for comparison of simulate results obtained using different models. The input data for this scenario are in Appendix 2.

Output data of the simulation are stored in the computer database and can be presented in tables or graphs. The changes of concentration of $\mathrm{SO}_{4}{ }^{2-}$ in the aqueous phase of reservoirs \#10 and \#11 as a function of time are shown in figures 8.5. 


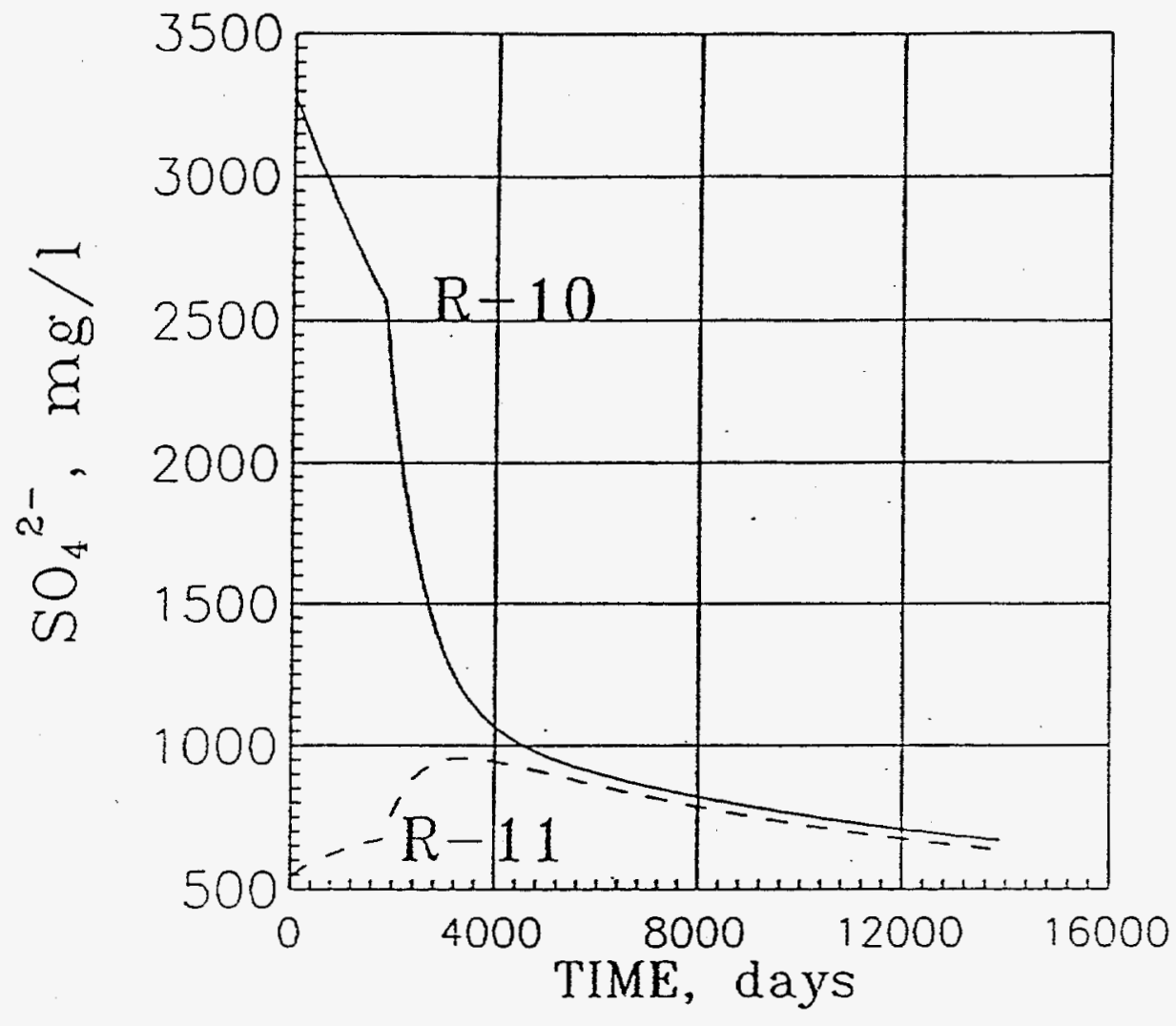

Figure 8.5. Concentration of $\mathrm{SO}_{4}{ }^{2-}$ in aqueous phase of reservoirs $\# 10$ and $\# 11$ as a functions of time (results of the computer simulation) 
Section 9

\section{CONCLUSIONS AND THE DIRECTIONS FOR FURTHER MODEL DEVELOPMENT AND NECESSARY EXPERIMENTAL DATA.}

The most important conclusions based on the results of the simulation are the following:

1. The present aqueous phase of the $R \# 11$ is supersaturated with respect to magnesium and calcium carbonates, the carbonate rocks underlying sediments of the $R$ \#10 will to be dissolved during the short time period of fast increasing $\mathrm{pH}$.

2. Due to the more intensive water exchange between the reservoirs after cleanup starts, the secondary contamination of the reservoir \# 11 will take place.

3. Despite the fact of removing calcium and magnesium from the aqueous phase due to cleanup operation the dissolution of carbonates from the sediments will not take place because the $\mathrm{pH}$ increases.

4. Because of the strong sorption ability and inert behavior to jon exchange cleaning, the decreasing of ${ }^{137} \mathrm{Cs}$ contents in the sediments should be due mainly to radioactive decay.

The most important directions for further development of the model are the following:

1. Including mathematical description of the filtration together with sorption and desorption of the radionuclides through the most permeable parts of the reservoirs bottom. It will improve the simulation of waste water sorption and migration into underground formations. Since the content of the radionuclides in aqueous phase of the reservoirs is not very high and the sorption constants are high, expected radionuclide migration paths are 
not expected to be long. The main challenge is the development of the better interface between the simulation modules and the database, and graphical presentation of input data and output results. For this aim a computer map of the cascade of the reservoirs is being developed currently at the Vernadsky Institute, using Geographic Information System (GIS).

2. Taking into account the chemical interactions of radionuclides and other components with organic matter of the reservoirs (complex forming in aqueous solutions, sorption by suspended organic matter, incorporation of radionuclides by hydrobiota and their behavior during metabolic processes). For this goal we need stability constants of metal-organic complexes, the distribution coefficients of the radionuclides between the aqueous solution and hydrobiota, and new analytical determinations of the main dissolved organic substances. We also need to couple this model with the biochemical model of the cascade, developed by the Institute of Water Problems, of the Russian Academy of Sciences (Moscow) (Leonov, 1993).

3. Simulating coprecipitation of ${ }^{90} \mathrm{Sr}$ with carbonates and sulfates, using solid solutions approach in the framework of Gibbs free energy minimization method. For this purpose, analytical determination of the total strontium content in the waters should be carried out. ${ }^{90} \mathrm{Sr}$ alone cannot be taken into account as a chemical component in the thermodynamic calculations due to its low chemical concentration. Its distribution among various species and phases should be similar to the distribution of total strontium.

4. Incorporating a more correct description of the chemical reaction rates within the framework of Gibbs free energy minimization method.

5. Developing the database to take into account seasonal fluctuations of rainfall, flows and temperature. 
6. Improving the simulation of sorption and desorption processes. We need constants. It is possible to obtain the necessary radionuclide soprtion constants for any mineral or organic substance and then calculate the sorption ability of the bottom sediment as a function of its substance composition. However this approach needs a lot of experimental work. A more efficient approach is to carry out model experiments with real sediments to obtain effective sorption parameters for these reservoirs. It is not a simple task because it requires studying sorption and desorption as a function of time,

$\mathrm{pH}$, and chemical composition of the aqueous phase to evaluate the influence of complex forming in simulating the sorption processes. As described in this report, we evaluated those effective constants, suggested that the radionuclides sorption constants may be estimated on the basis of data on present radionuclides contents in the upper part of the sediments and their concentrations in the aqueous phase.

\section{ACKNOWLEDGMENTS}

This work was prepared under the auspices of Russian-American Center for Contaminant Transport Studies at the Lawrence Berkeley Laboratory. We appreciate the funding from the Department of Energy's Office of Environmental Management, Office of Technology Development (DOE/EM-OTD) and the Office of Energy Research, Office of Basic Energy Sciences (DOE/ER-BES) through Contract Number DC-AC0376SF0098. We would like to thank Chin-Fu Tsang, Lawrence Berkeley Laboratory for supporting the study and giving methodological assistance. The authors are also grateful to John A. Apps, Stefan Finsterle and Joe Wang for their review, and to William Lay for his assistance for the publication of this report. 


\section{REFERENCES}

Avramenko, M.I., E.G. Drozhko, Yu.V. Glagolenko, A.V. Glagolev, Yu.G.Mokrov, L.M. Samsonova, V.I. Sharalopov, V.A. Simonenko, A.P. Vasilykova, G.A. Zinina, On Current State of Ground Waters Radioactive Contamination in Lake Karachay Region. Moscow, Preprint, 1993.

Bol'shakov, V.N., R.M. Aleksakhin, L.A.Bol'shov, V.N.Chukanov, L.A. Kochetkov, V.I. Petukhov, and A.F. Tsyb. 1991. "Conclusion of the Commission for Evaluating the Ecological Situation in the Sphere of Influence of the Industrial Plant (IP) "Mayak" of the USSR Ministry of Atomic Energy", (Organized by the Presidium of the USSR Academy of Sciences No. 1140-501, on June 12, 1990), Moscow, 1991.

Bradley, D.J. 1991. Radioactive Waste Management in the USSR: A Review of Unclassified Sources. Volume II. PNL-7645, Pacific Northwest Laboratory, Richland, Washington, March 1991.

Bradley, D.J. 1992. Radioactive Waste Management in the Former USSR: Volume III. PNL-8074, Pacific Northwest Laboratory, Richland, Washington, June 1992.

Bradley, D.J., and K.J. Schneider. 1990. Radioactive Waste Management in the USSR: A Review of Unclassified Sources, 1963-1990 PNL-7182, Pacific Northwest Laboratory, Richland, Washington, March 1990.

Chukanov, V.N., E.G.Drozhko, A.P. Kulignin, G.A. Mesyats, A.N. Penyagin, A.V. Trapeznikov, and P.N.Volobuev. April 10-14, 1991. Ecological Consequences of the Creation of Nuclear Weapons on the Example of the Atomic Industrial Complex Near the City of Kyshtym. Distributed at the Conference on Environmental Consequences of Nuclear Development, University of California, Irvine, and translated for Lawrence Livermore Laboratory by the Ralph McElroy Translation Co.

Cochran T.B. Norris, R.S., Suokko, K.L. Radioactive Contamination at Chelyabinsk-65, Russia, Annual Review of Energy and the Environment, Vol.18, 507-528, 1993.

Comans, R.N., M. Haller, and P. De Preter, Sorption of cesium on illite: Non-equilibrium behavior and reversibility, Geochim. Cosmochim. Acta, Vol. 55, 1991, pp. 433-440.

Davis, J.A. and Kent D.B., Surface complexation modeling in aqueous geochemistry, Reviews in Mineralogy, Volume 23, 1990, pp. 177-248.

Drozhko, E.G., Sharalapov, V.I. at al. History, Contamination and Monitoring of Water Bodies at P/A "Mayak"; Proceedings of the International Conference on Nuclear Waste Management and Environmental Remediation, Prague, Czechoslovakia, 1993.

Drozhko, E.G., Suslov, A.P. at al; Basic Direction and Problems of Radioactive Waste Management Program in the "Mayak" Production Association, Chelyabinsk, Russia; Proceedings of the International Conference on Nuclear Waste Management and Environmental Remediation, Prague, Czechoslovakia, 1993.

Emelyanenkov, A.F., Popov V., Compiles. Atom Without Stamp "Classified": Points of View; Moscow-Berlin, p. 144, 1992. 
Glynn, P.D., MBSSAS: a code for the computation of Margules parameters and equilibrium relations in binary solid-solution agueous- solution systems. Computers \& Geosciences Vol. 17, pp.907-966, 1991.

Hauge F. and Nilsen, K.E. Mayak the Most Radioactive Polluted Place on Earth; Bellona Working Papers, N 1, p.29, The Bellona Foundation, Oslo, Norway, 1992.

Izrael, Yu.A., Nazarov, I.M., Fridman, Sh.D., Avdjushin, S.I., Kvasnikova, E.V., Kontarovich, P.C., Imshennik E.B., Shusharina, N.M., Radiological Situation in the Territory of the European Part of SNG and Ural in 1991. Meteorology and Hydrology, 1992, N.11, p.p. 4-27.

Khodakovsky, I.L., M.V. Mironenko, Yu.V. Semenov et al., "Dianik"-thermodynamic database a scientific tools for simulations of migration behavior of the actinide and fission products in the geosphere. Abstracts of the 4th Intern. Conf. Migration-93, Charleston, SC, USA., 1993.

Kossenko, M.M., M.O. Degteva, and N.A. Petrushova. 1990. Chelyabinsk Branch Office of the Institute of Biophysics of the USSR Ministry of Health, Chelybinsk. "Leukemia Risk Estimate on the Base of Nuclear Incidents in the Southern Urals". Presented at the Japan/USSR Seminar on Radiation Effects Research, June 25-29, 1990, Tokyo, Japan.

Kossenko, M.M., Kostyuchenko, Shvedov, V.L., V.A., Buldakov, L.A., 1991. Consequences of irradiating the population in the main part of the Eastern Urals radioactive footprint. Atomnaya Energiya, 71(5): 444-48. Translated into English by Plenum.

Laverov, N.P., I.L. Khodakovsky Radiation Safety of the Biosphere, Priroda, 1994 (in preparation)

Mironenko M.V., Zolotov M.Yu., Frenkel M.Ya. The algorithm, program code and database for computation of chemical equilibrium in multicomponent systems, containing non ideal aqueous, gas and solid solutions. Abstracts of the Second Intern. Symposium "Thermodynamics of Natural Processes". 13-20 Sept. 1992. Novosibirsk, Russia. Siberian Branch of RAS, Novosibirsk, p.112.

Mokrov Yu.G., Drozhko Eu.G., Glagolenko Yu.V., Smirnov A.B. The prospects of usage of information data base at the P/A "Mayak" as for modeling of the Ural region ecosystems. 1993 INTERNATIONAL CONFERENCE ON NUCLEAR WASTE MANAGEMENT AND ENVIRONMENTAL REMEDIATION. Advance Program.

Monroe, S.D. Chelyabinsc: The Evolution of Disaster; Post-Soviet Geography, N 8, p.533-545, 1992.

Murphy, W.M., Calculations of geochemical mass transfer as a function of temperature and time. Proceedings of the Workshop on Geochemical Modeling, Fallen Leaf Lake, California, 1986, pp. 27-33.

Nazarov, A.G., Ye.B. Burlakova, D.P.Osanov, G.S. Sakulin, L.N. Shadrin, V.A.Shevchenko, Ye.A.Yakovlev, I.A.Seleznev, N.I.Mironova, K.V. Kuranov, and 
I.I.Pavlinova. February 21, 1991. "Resonance: The Yuzhno-Uralskaya Nuclear Generating Station: To Be or Not To Be ?," Chelyabinsk Yuzhno-Ural'skoye knizhnoye izdatel'stvo.

Nikipelov, B.V., Drozhko, Ye.G. 1990. An explosion in the Southern Urals. Priroda, May: pp 48-49.

Nikolsky M.A., Fedorov A.L., Drozhkin A.I. Numerical modeling of the neutral contaminants transport in shallow sea water. Meteorologia and Hydrologia, 1990, N1, p.57-63. (In Russian)

Novikov, A.P., Mysoedov, B.F. Report " Experimental modeling of migration conditions of secondary contamination. Analysis of contents and chemical forms as function of different geochemical and hydrodynamical conditions. Contract "Construction of models of radionuclide migration during secondary contamination of R10 and R11". Vernadsky Inst., $21 \mathrm{p}$.

Petukhov V.I. February 1991. Execution of the Ecological Expertise in the South Urals Region (Mayak Industrial Amalgamation). Presented at the US. National Academy of Sciences, USSR National Academy of Sciences, and Nuclear Regulatory Commission Meeting on Public Information. Wisconsin, USA.

Polukhin, G.A., First steps; History of the Production Association "Mayak", 1993.

Proceedings of the International Conference of "Chemistry and migration behavior of actinides and fission products in the geocphere" 1989, Radiochim.Acta Vol. 52/53 1991.

Robinson R. A., Stokes R.H. Electrolyte Solutions, Butterworth ,London 1959

Romanov, G.N., Buldakov, L.A., Shvedov, V.L., 1990. Irradiation of the population and the medical consequences of the explosion. Priroda, May: p???.

Romanov, G.N., Vorovov, A.S.1990. The radiation situation after the explosion. Priroda, May: p???

Samsonova L.M., Vasil'kova N.A., Zinina G.A. et al. Report on contract OH-92-06: Development of mathematical description and computer codes on construction of filtration model and waster migration from R 10 and R11. Part 1: Basis of hydrogeologic filtration model of cascade of the artificial reservoirs 4,10 , and 11 area.

Shapkin, A.I., I.L. Khodakovsky, A.V. Garanin, V.A. Dorofeeva, Yu.V. Semenov, Dialoged scientific-information complex for solution of tasks of chemical thermodynamics. In: Direct and inverse tasks of the chemical thermodynamics. Novosibisk, Nauka, 1987, p.80-88.

Smagin, A.I. Ph.D, Aqueous ecosystems in the conditions antropogenic influence on case technological reservoirs of nuclear industry plant of the Production Association "Mayak", Chelyabinsk-65, 1994.

Smirnov, A.B., Ph.D.,Chelyabinsk-65, 1994. 
Smirnov, A.B., Mironenko, M.V., Drozhko E.G., Khodakovsky I.L. The Effect of the Sulfuric Acid Bearing Wastes on Hydrochemical Conditions and on the Radionuclides Behavior in Technological Reservoir of the Radiochemical Plant "Mayak". Abstracts of the Second Intern. Symp. "Thermodynamics of Natural Processes". Novosibirsk., 1992 , p.57

Spirin, D.A., Smirnov, E.G., Suvornova, L.I., Tikhomirov, F.A. 1990 Radioactive impact on living nature. Priroda, May: p???.

Sposito, G., The Chemistry of Soils, Oxford University Press, New York, 1989.

Trabalka, J.R., Eymen, L.D. Auerbach, S.I. Analysis of the 1957-1958 Soviet Nuclear Accident; Science, V.209, N 4454, 1980.

Viani, B.E. and C.J. Bruton, Modeling ion exchange in clinoptilolite using the EQ3/6 geochemical modeling code. Water-Rock interaction, Kharaka \& Maest (eds), Balkema, 1992, p.73-77.

Zachara, J.M., C.E. Cowan, and C.T. Resch, Sorption of divalent metals on calcite, Geoch. Cosmoch. Acta, Vol. 55, 1991, pp.1549-1562. 


\section{APPENDIXES}

\section{APPENDIX 1 Help for program "Computer map of the reservoir \#11"}

1. When the lake is describes in isolines, in order to continue the work you should press any key (except ESC), for example, ENTER. In order to quit the program you should press ESC.

2. After you pressed any key, the blue lake is painted on the green background, the menu is placed on the right side. In the lower part of the menu there are 5 switches, which mean the following:

2.1 START - You start the program from the beginning.

2.2 TO YEAR - You choose the year, by the end of which the reservoir \# 11 will keep growing.

2.3 SCALING - You choose the region with the help of mouse.

2.4 VOLUME - The calculation of volumes and resources.

2.5 END - The end.

To choose something from the menu you should press the key "Arrow down", marking the option, and then press ENTER.

If you have chosen 2.1 , the program begins working, draving the lake's isolines.

If you have chosen 2.2 , the new menu appears, and you should choose the year, using the key "Arrow down" and then pressing ENTER.

If you have chosen 2.3, the cursor of the MOUSE appears in the center of the screen. Pressing the left button of mouse, you mark at first the upper left corner of the rectangle, then the lower right corner of the rectangle. Then you should press the right button of the 
mouse, and it will appear the contour of the chosen region. Pressing ENTER, you increase the rectangle up to the size of the screen.

If you have chosen 2.4 you are starting the program calculation of Volumes and resources. When in the upper menu you see the list of dissolved particles, you are to choose the particle, for which it is necessary to calculate the resources.

(If you want to mark all particles, choose the lower word ALL.)

Footnote: The result is recorded into the file "DOC" of the current directory.

\section{APPENDIX 2 AN EXAMPLE OF A RECORD IN THE INPUT DATA BASE}

The main record

111992

Reservoirs:

$\# 10$

Presence of water data:

Volume of water, mln cub. meters:
\#11

$+1$

220.0

Water characteristics of reservoir:

$\mathrm{pH}$

Alkal., mg-eq

0.070

3.76

$\mathrm{CO}_{2}, \mathrm{mg} / \mathrm{l}$

$\mathrm{Ca}^{2+}, \mathrm{mg} / \mathrm{l}$

0.44

0.44

$\mathrm{Mg}^{2+}, \mathrm{mg} / \mathrm{l}$

272.0

100.9

139.4

$\mathrm{Na}^{+}, \mathrm{mg} / 1$

1142.0

$\mathrm{Cl}^{-}, \mathrm{mg} / \mathrm{l}$

119.64

$\mathrm{SO}_{4}{ }^{2-}, \mathrm{mg} / \mathrm{l}$

$\mathrm{NH}_{4}{ }^{+}, \mathrm{mg} / \mathrm{l}$

3282.3

$\mathrm{NO}_{3}^{-}, \mathrm{mg} / \mathrm{l}$

$\mathrm{PO}_{4}{ }^{3-}$, $\mathrm{mg} / \mathrm{l}$

${ }^{90} \mathrm{Sr}, \mu \mathrm{Ci} / \mathrm{l}$

${ }^{137} \mathrm{Cs}, \mu \mathrm{Ci} / \mathrm{l}$

$\mathrm{Sr}(\mathrm{Tot}), \mathrm{mg} / \mathrm{l}$

$\mathrm{Cs}(\mathrm{Tot}), \mathrm{mcg} / \mathrm{l}$

Presence of calculated water data

$\begin{array}{ll}0.0 & 0.00000 \\ 0.0 & 0.15 \\ 0.0 & 0.0 \\ 0.35 & 0.051 \\ 0.0086 & 0.00002 \\ 6.5 & 2.4 \\ 500.0 & 200.00000\end{array}$

0.00000

0.0

0.051

0.00002

200.00000

100.0

70.2

548.0

$-1$ 
Presence of flow data:

$+1+1$

Flows to the pump station, min.cub.meters/month:

$\begin{array}{ll}0.0 & 0.0\end{array}$

Flows FROM the pump station mln.cub.meter/month

$0.0 \quad 0.0$

The water Flow (mln.cub. $m$ /month from reservoir $\mathrm{R} \# 4$ to reservoir: $\mathrm{R} \# 10$

0.348

0.0

\section{Characteristics of the flow from reservoir, $\# 4$}

pH:

5.3

Alkali., mg-eq : $\quad 0.0$

$\mathrm{CO}_{2}$, mg/l:

0.0

$\mathrm{Ca}^{2+}, \mathrm{mg} /$ :

74.0

$\mathrm{Mg}^{2+}, \mathrm{mg} / \mathrm{l}$ :

35.7

$\mathrm{Na}^{+}, \mathrm{mg} /$ :

193.8

$\mathrm{Cl}^{-}, \mathrm{mg} / \mathrm{l}$ :

65.0

$\mathrm{SO}_{4}{ }^{2-}, \mathrm{mg} / \mathrm{l}$ :

560.0

$\mathrm{NH}_{4}{ }^{+}, \mathrm{mg} / \mathrm{l}$ :

0.0

$\mathrm{NO}_{3}^{-}, \mathrm{mg} / \mathrm{l}$ :

20.5

$\mathrm{PO}_{4}^{3-}, \mathrm{mg} / \mathrm{l}$ :

0.0

${ }^{90} \mathrm{Sr}, \mu \mathrm{Ci} / \mathrm{l}$ :

0.212

${ }^{137} \mathrm{Cs}, \mu \mathrm{Ci} / \mathrm{l}$ :

0.0673

$\mathrm{Sr}$ (Tot) $\mathrm{mg} / \mathrm{l}$ :

0.50

$\mathrm{Cs}$ (Tot) $\mathrm{mcg} / \mathrm{l}$ :

0.0

Reservoir:

$\# 10$

\#11

Atmospheric precipitations, mln.cub. $\mathrm{m} /$ month:

0.728

2.03

The evaporation flow, mln.cub. $\mathrm{m} / \mathrm{month}$ :

0.904

2.29

The surface runoff, $\mathrm{mln}$.cub.m/month:

$1.080000 \mathrm{E}-0001$

$1.680000 \mathrm{E}-0001$

Characteristics of the surface runoff:

pH:

Alkali. mg-eq:

$\mathrm{CO}_{2}, \mathrm{mg} / \mathrm{l}$ :

$\mathrm{Ca}^{2+}, \mathrm{mg} / \mathrm{l}$ :

$\mathrm{Mg}^{2+}, \mathrm{mg} / \mathrm{l}$ :

$\mathrm{Na}^{+}, \mathrm{mg} /$ :

$\mathrm{Cl}^{-}, \mathrm{mg} / \mathrm{l}$ :

$\mathrm{SO}_{4}{ }^{2-}, \mathrm{mg} / \mathrm{l}$ :
7.0

3.0

0.44

40.0

18.61

23.92

32.0

36.02
7.0

3.0

0.44

40.0

18.61

23.92

32.0

36.02 
$\mathrm{NH}_{4}{ }^{+}, \mathrm{mg} / \mathrm{l}:$

0.0

0.0

$\mathrm{NO}_{3}{ }^{-}, \mathrm{mg} / \mathrm{l}$ :

0.0

0.0

${ }^{137} \mathrm{Cs}, \mu \mathrm{Ci} / \mathrm{l}$ :

$\mathrm{Sr}$ (Tot) mg/:

0.0

0.0

$\mathrm{Cs}$ (Tot) $\mathrm{mcg} / \mathrm{l}$ :

0.0

0.0

0.0

0.0

Other flows (Losses), mln.cub.m/month (point with sign -):

$$
0.083
$$

The ground water flow, mln.cub.m/month:

$$
0.033
$$

Characteristics of ground water flow:

$\mathrm{pH}$ :

Alkali. mg-eq :

3.0

3.0

$\mathrm{CO}_{2}, \mathrm{mg} / \mathrm{l}$ :

0.446

0.44

$\mathrm{Ca}^{2+}, \mathrm{mg} /$ :

58.8

58.8

$\mathrm{Mg}^{2+}, \mathrm{mg} / \mathrm{l}$ :

23.79

23.79

$\mathrm{Na}^{+}$, mg/:

40.02

40.02

$\mathrm{Cl}^{-}$, mg/:

21.01

$\mathrm{SO}_{4}{ }^{2-}, \mathrm{mg} / \mathrm{l}$ :

21.01

$\mathrm{NH}_{4}{ }^{+}, \mathrm{mg} /$ :

0.0

64.07

$\mathrm{NO}_{3}{ }^{-}, \mathrm{mg} /$ :

0.0

0.0

0.0

0.0

0.0

$\mathrm{PO}_{4}{ }^{3-}, \mathrm{mg} / \mathrm{l}$

0.0

0.0

${ }^{137} \mathrm{Cs}, \mu \mathrm{Ci} / \mathrm{l}$ :

0.0

0.0

$\mathrm{Sr}$ (Tot) $\mathrm{mg} / \mathrm{l}$ :

0.0

0.0

Cs(Tot) $\mathrm{mcg} / \mathrm{l}$ :

0.0

0.0

\section{Sediments :}

Presence of sediments data:

Total amount of sediments, $\mathrm{kg}$

$$
+1
$$$$
+1
$$

80000000 .

220000000.00

Sediments composition, \%:

Calcite

0.0

Dolomite

10.0

0.0

Magnesite

0.0

0.0

Gypsum

0.0

0.0

Anhydrite

0.0

0.0

Leonhardit

0.0

0.0

Epsomite

0.0

0.0

Illite

30.0

40.0 
Sr90 sorb.

Cs137sorb.

Sr tot.

Cs tot.

Org. matt.

Kaolinite

Presence of sediment calculation data
0.0

0.0

0.0

0.0

40.0

40.0

$-1$

\section{CLEANING STATION}

Flows TO the cleaning station from reservoirs, mln.cub.m/month:

$$
\mathrm{R} 10
$$

R11

$$
0.0
$$

Flows FROM the cleaning station to reservoirs, mln.cub.m/month:

$$
\begin{array}{cr}
\mathrm{R} 10 & \mathrm{R} 11 \\
0.0 & 0.0
\end{array}
$$

Number of substituted ions: 4

\begin{tabular}{llrrr}
\multicolumn{2}{l}{ Old ion Number } & New ion Number & Subst.coefficient, $\%$ \\
$\mathrm{Ca}^{2+}$ & 2 & $\mathrm{Na}^{+}$ & 4 & 90.0 \\
$\mathrm{Mg}^{2+}$ & 3 & $\mathrm{Na}^{+}$ & 4 & 90.0 \\
$90 \mathrm{Sr}$, & 10 & $\mathrm{Na}^{+}$ & 4 & 90.0 \\
$\mathrm{Sr}$ (Tot) & 12 & $\mathrm{Na}^{+}$ & 4 & 90.0
\end{tabular}

THE LIST OF SUBSTITUTED COMPONENTS AND THEIR NUMBERS

Number Component

$\begin{array}{rl}1 & \mathrm{CO}_{2} \\ 2 & \mathrm{Ca}^{2+} \\ 3 & \mathrm{Mg}^{2+} \\ 4 & \mathrm{Na}^{+} \\ 5 & \mathrm{Cl}^{-} \\ 6 & \mathrm{SO}_{4}^{2-} \\ 7 & \mathrm{NH}_{4}^{+} \\ 8 & \mathrm{NO}_{3}^{-} \\ 9 & \mathrm{PO}_{4}^{3-} \\ 10 & 90 \mathrm{Sr}^{-} \\ 11 & { }^{137} \mathrm{Cs} \\ 12 & \mathrm{Sr} \text { (Tot) } \\ 13 & \mathrm{Cs} \text { (Tot) } \\ 14 & \text { Deleting without substitution }\end{array}$


To delete a component without substitution it is needed to write number 14 in the column "number" after the column "new ion". In the total number of substituted ions deleted ion should be included.

\section{APPENDIX 3. THE INPUT DATA USED FOR PROGNOSES COMPUTATION OF CONDITIONS OF THE RESERVOIRS DURING 1992 - 2000.}

The simulation supposed the operation of the recovering plant using ion-exchange technology beginning in 1997. (The case, where the plant takes water from Reservoir $\mathbf{R}$ \#11, exchanges $\mathrm{Ca}^{2+}, \mathrm{Mg}^{2+}, \mathrm{Sr}^{2+}$ (including ${ }^{90} \mathrm{Sr}$ ) with $\mathrm{Na}^{+}$, and discharges clean water to the $\mathrm{R} \# 10$ ).

It is difficulty to estimate a reality of given conditions, but it is possible to use this scenario for comparing of different models.

01/01/92.

RESERVOIRS:

\#10

\#11

Volumes, M. $\mathrm{m}^{3}$ :

80.0

220.0

Chemical composition and the radionucledes contents in solutions on 1.01.1992

$\mathrm{pH}$

5.26

7.30

Alkalin

0.07

3.76

$\mathrm{CO}_{2} \quad \mathrm{mg} / \mathrm{l}$

0.44

0.44

$\mathrm{Ca}^{2+}$

$\mathrm{mg} / \mathrm{l}$

272.0

139.4

$\mathrm{Mg}^{2+} \mathrm{mg} / \mathrm{l}$

100.9

65.7

$\mathrm{Na}^{+}$

$\mathrm{mg} / \mathrm{l}$

1142.0

100.0

$\mathrm{Cl}^{-} \mathrm{mg} / \mathrm{l}$

119.64

70.2

$\mathrm{SO}_{4}{ }^{2-}$

$\mathrm{mg} / \mathrm{l}$

3282.29

548.0

${ }^{90} \mathrm{Sr}$

$\mu \mathrm{Ci} / 1$

0.35

0.05

${ }^{137} \mathrm{Cs}$

$\mu \mathrm{Ci} / 1$

0.0086

$2.0 \cdot 10^{-4}$

$\mathrm{Sr}$ (tot)

$\mathrm{mg} /$

$\mathrm{Cs}$ (tot)

$\mathrm{mg} / 1$ (apriori)

6.5

2.4

0.5

0.2

DATA CONCERNING BOTTOM SEDMMENTS (mineral composition):

Total mass, kg

Contents, \%

calcite

dolomite

illite
400000000 .

10.0

10.0

30.0
2800000000.
0.0
0.0
40.0 
${ }^{90} \mathrm{Sr}$ sorb, $\mathrm{Ci} / \mathrm{kg}$

${ }^{137} \mathrm{Cs}$ sorb(deposited), $\mathrm{Ci}$

organic matter

Kaolinite
$3.5 \cdot 10^{-6}$

$1.5 \cdot 10^{-4}$

20.0

30.0
$1.3 \cdot 10^{-6}$

$1.3 \cdot 10^{-7}$

40.0

40.0

FLOW FROM RES. \#4 INTO RES. \#10:

Period of time: from

to

Volume, M. $\mathrm{m}^{3} /$ month

Parameters

$\mathrm{pH}$

$\mathrm{CO}_{2} \mathrm{mg} / \mathrm{l}$

$\mathrm{Ca}^{2+} \mathrm{mg} / \mathrm{l}$

$\mathrm{Mg}^{2+} \mathrm{mg} / \mathrm{l}$

$\mathrm{Na}^{+} \mathrm{mg} / \mathrm{l}$

$\mathrm{Cl}^{-} \quad \mathrm{mg} / \mathrm{l}$

$\mathrm{SO}_{4}{ }^{2-} \mathrm{mg} / \mathrm{l}$

${ }^{90} \mathrm{Sr} \quad \mu \mathrm{Ci} / 1$

${ }^{137} \mathrm{Cs} \mu \mathrm{Ci} / \mathrm{l}$

$\mathrm{Sr}$ (tot) $\mathrm{mg} / 1$
$01 / 01 / 92$

$12 / 01 / 96$

0.3480

5.30

0.0

74.0

35.7

193.8

65.0

560.00000

0.21

0.0673

0.50
$01 / 01 / 1997$

$12 / 01 / 2004$

0.177

2.80

0.44

108.6

45.3

295.0

102.0

1026.0

0.21

0.0

0.50

$\# 11$

2.03

2.29

1.68E-0001

Parameters of surface runoff:

$\begin{array}{lllc}\text { Alkalinity } & \text { mg-eq./ } & 0.003 & 0.003 \\ \mathrm{CO}_{2} & \mathrm{mg} / \mathrm{l} & 0.44 & 0.44 \\ \mathrm{Ca}^{2+} & \mathrm{mg} / \mathrm{l} & 40.0 & 40.0 \\ \mathrm{Mg}^{2+} & \mathrm{mg} / \mathrm{l} & 18.61 & 18.61 \\ \mathrm{Na}^{+} & \mathrm{mg} / \mathrm{l} & 23.92 & 23.92 \\ \mathrm{Cl}^{-} & \mathrm{mg} / 1 & 31.99 & 31.99 \\ \mathrm{SO}_{4}{ }^{2-} & \mathrm{mg} / 1 & 36.02 & 36.02\end{array}$

Filtration from the North side canal, M.m³/month 0.083

0.0 
Parameters:

Alkalinity

$$
\text { mg-eqv./l: }
$$

0.003

0.003

$\mathrm{CO}_{2}$ $\mathrm{mg} / \mathrm{l}$

0.44

0.44

$\mathrm{Ca}^{2+}$

$\mathrm{mg} / \mathrm{l}$

40.0

40.0

$\mathrm{Mg}^{2+}$

$\mathrm{mg} / \mathrm{l}$

18.61

18.61

$\mathrm{Na}^{+} \mathrm{mg} / \mathrm{l}$

40.02

40.02

$\mathrm{Cl}^{-}$

$\mathrm{mg} / \mathrm{l}$

50.06

50.06

$\mathrm{SO}_{4}{ }^{2-}$

$\mathrm{mg} / \mathrm{l}$

50.05

50.05

Underground inflow, M.m $3 /$ month:

Parameters:

0.033

0.833

Alkaline

mg-eq/1

0.003

0.003

$\mathrm{CO}_{2} \mathrm{mg} / \mathrm{l}$

$\mathrm{CO}_{2} \mathrm{mg} / \mathrm{l}$

0.446

$\mathrm{Mg}^{2+}$

$\mathrm{mg} / \mathrm{l}$

58.8

0.440

$\mathrm{Na}^{+}$

$\mathrm{mg} / \mathrm{l}$

23.79

58.8

$\mathrm{Cl}^{-}$

$\mathrm{mg} / \mathrm{l}$

40.02

23.79

21.01

40.02

$\mathrm{SO}_{4}{ }^{2-}$

$\mathrm{mg} / \mathrm{l}$

64.07

21.01

64.07

\section{CLEANING INSTALLATION (BEGINNING FROM 01/01/1997)}

FLOW OUT OF R \#11 TO THE CLEANING INSTALLATION: $2.5 \mathrm{M} . \mathrm{m}^{3} / \mathrm{month}^{2}$ FLOW INTO R \#10 OUT OF CLEANING INSTALLATION TO THE R \#10:

$2.5 \mathrm{M} . \mathrm{m}^{3} . / \mathrm{month}$

Parameters of work of station:

Number of exchanged ions: 4

initial cation

$\mathrm{Ca}^{2+}$

$\mathrm{Mg}^{2+}$

${ }^{90} \mathrm{Sr}$

Sr(tot) exchanging cation

$\mathrm{Na}^{+}$

$\mathrm{Na}^{+}$

$\mathrm{Na}^{+}$

$\mathrm{Na}^{+}$ exchange factor $(\%)$

90.0

90.0

90.0

90.0 